\title{
Role of alternative splicing in the biological properties of the voltage-gated potassium channel $K_{V} 10.1$
}

\author{
Dissertation \\ for the award of the degree \\ "Doctor rerum naturalium" \\ Division of Mathematics and Natural Sciences \\ of the Georg-August-Universität Göttingen \\ within the doctoral program CMPB \\ of the Georg-August University School of Science (GAUSS)
}

submitted by

Vincenzo Romaniello

from Aversa, Italy.

Göttingen, April 2014 

Thesis committee members

Prof. Dr. Walter Stühmer (Referee), dept. of Molecular Biology of Neuronal Signals, Max Planck Institute of Experimental Medicine, Göttingen.

Prof. Dr. Michael Hörner $\left(2^{\text {nd }}\right.$ Referee $)$, dept. of Cellular Neurobiology, JohannFriedrich-Blumenbach-Institute for Zoology and Anthropology, Göttingen.

Prof. Dr. Tobias Moser, dept. of Otolaryngology, University Medical School, Göttingen.

Prof. Dr. Luis A. Pardo, dept. of Molecular Biology of Neuronal Signals, Max-Planck Institute of Experimental Medicine, Göttingen.

Extended committee members

Prof. Dr. Blanche Schwappach, dept. of Molecular Biology, University Medical School, Göttingen.

Dr. Manuela Schmidt, Somatosensory Signaling Group, Max-Planck Institute of Experimental Medicine, Göttingen.

Date of oral examination $\mathbf{2 0}^{\text {th }}$ May 2014 


\section{Declaration}

I hereby declare that this thesis has been written independently and with no other aids or sources than quoted.

Vincenzo Romaniello

Göttingen, $8^{\text {th }}$ April 2014. 


\section{Table of Contents}

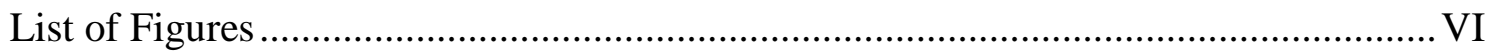

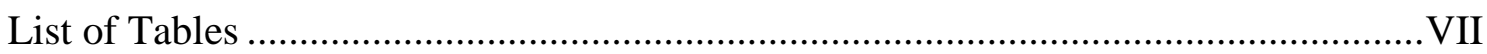

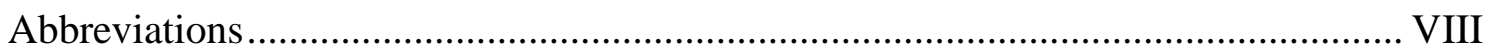

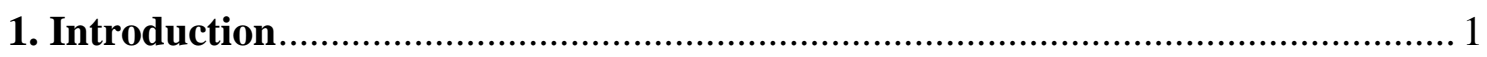

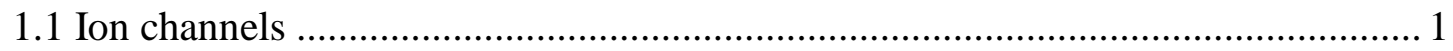

1.1.1 The superfamily of voltage-gated channels ................................................... 4

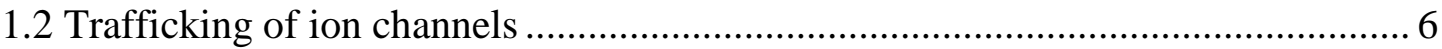

1.3 Physiological and pathophysiological roles of ion channels.................................. 7

1.3.1 Role of ion channels in cell proliferation and cancer ...................................... 8

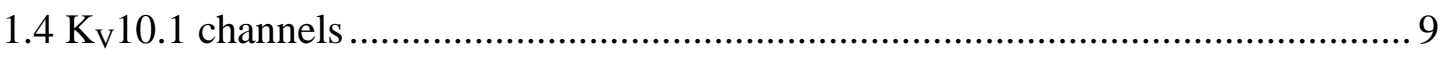

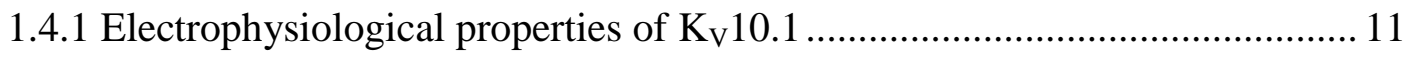

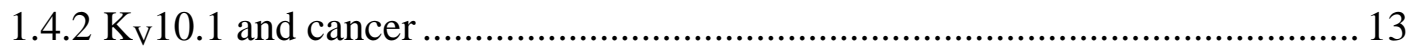

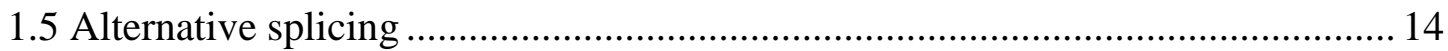

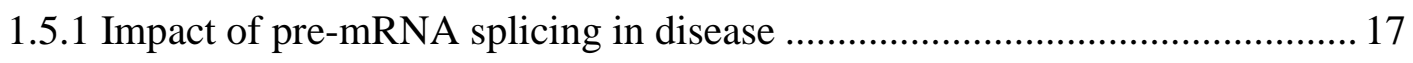

1.5.2 Impact of AS on ion channels physiology and pathophysiology ………....... 18

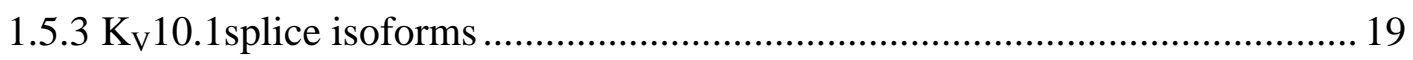

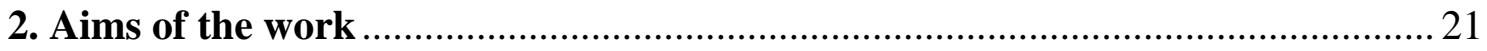

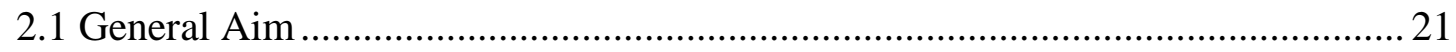

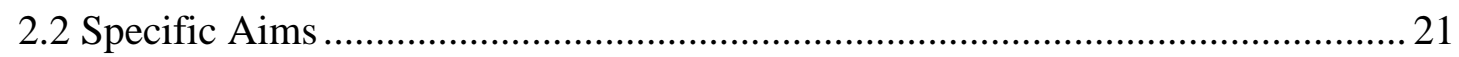

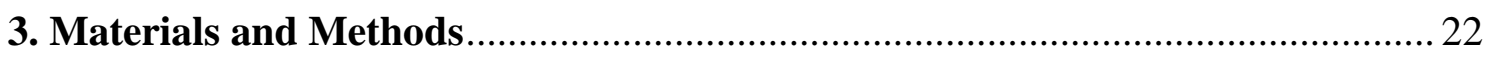

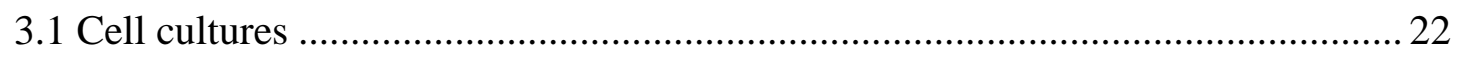

3.1.1 Mammalian cell lines and media composition …………………………….... 22

3.1.2 Cell cultures: routine handling ................................................................ 22

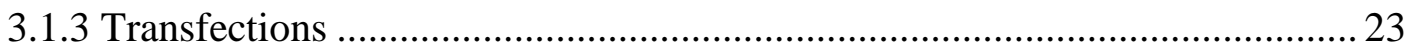

3.1.4 Xenopus laevis oocyte preparations........................................................... 24

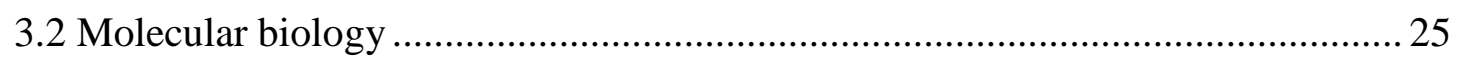

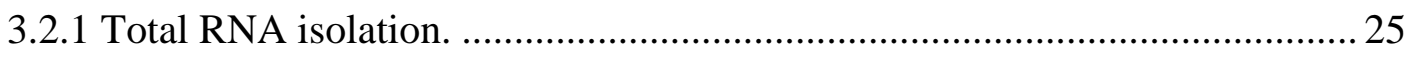

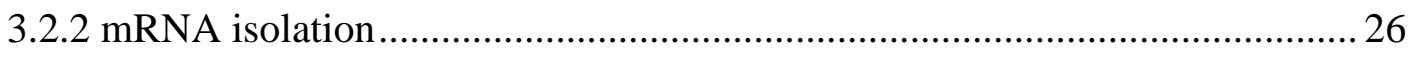

3.2.3 Capped RNA (cRNA) synthesis ................................................................... 27 


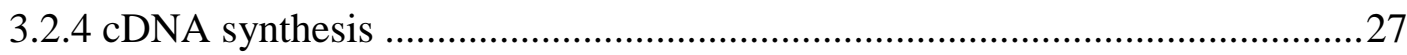

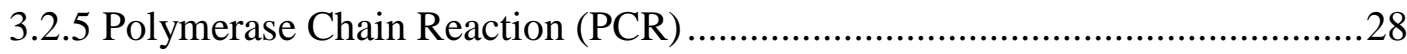

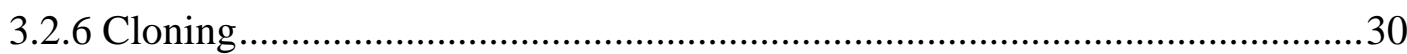

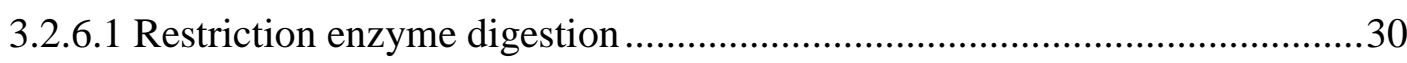

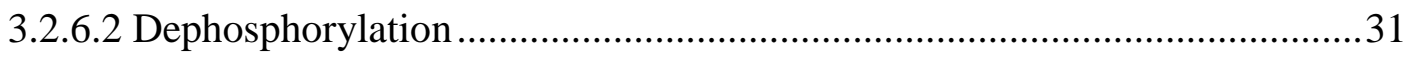

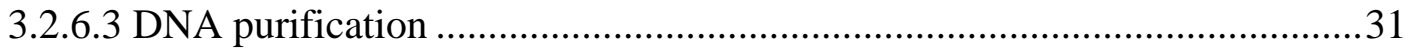

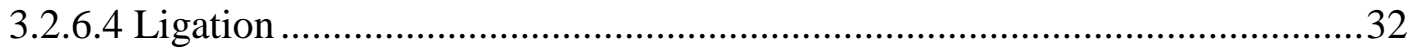

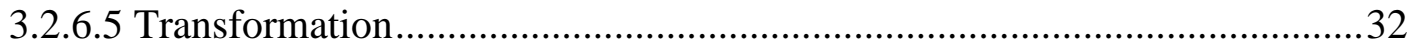

3.2.7 Small scale plasmid DNA preparation (Mini-prep) ......................................32

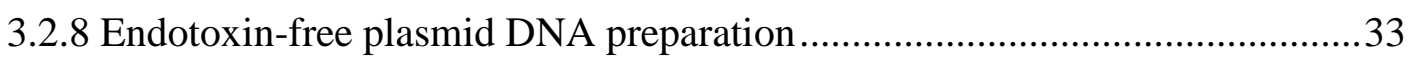

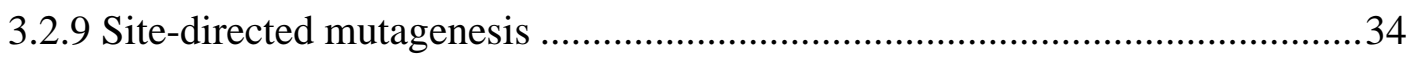

3.2.10 Probe preparation for RNase protection assays and in vitro transcription....35

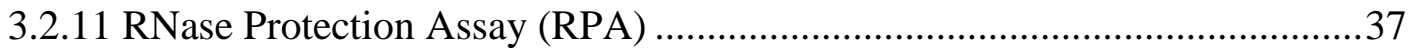

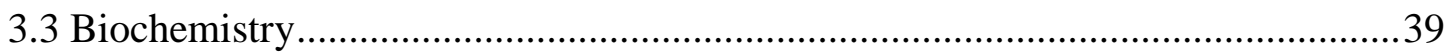

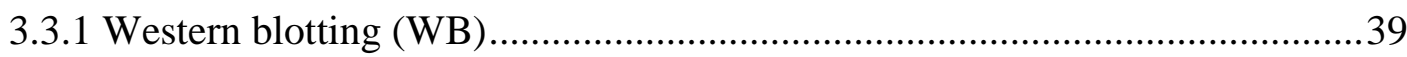

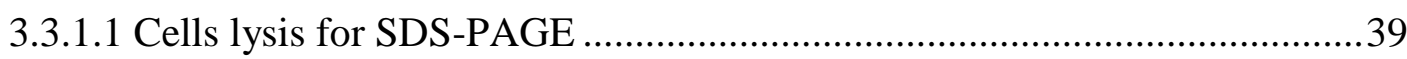

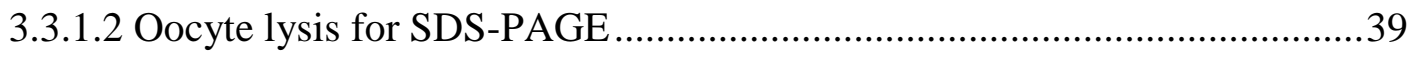

3.3.1.3 Cells lysis for protein analysis under native conditions.............................39

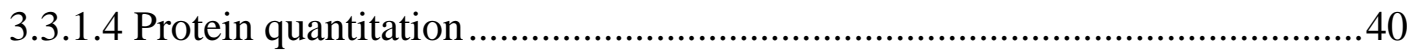

3.3.1.5 SDS-PAGE and protein blotting on nitrocellulose membrane ...................41

3.3.1.6 Blue Native PAGE (BN-PAGE) and protein blotting on PVDF membrane42

3.3.1.7 Two-dimensional Blue Native PAGE (2D BN-PAGE) .............................43

3.3.1.8 Membrane blocking and protein signal detection ..................................43

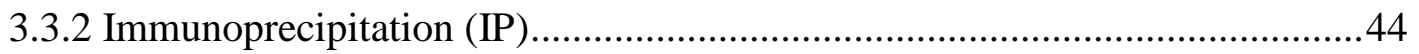

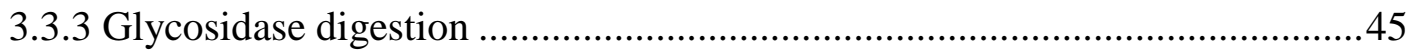

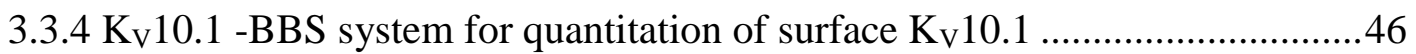

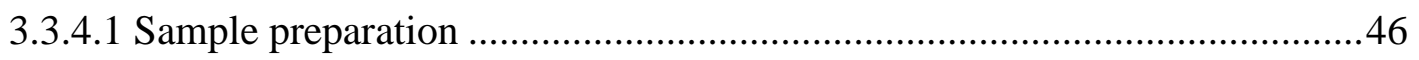

3.3.4.2 Enzyme-Linked ImmunoSorbent Assay (ELISA) …...............................47

3.3.5 Cell fixation for fluorescent proteins imaging ..........................................4

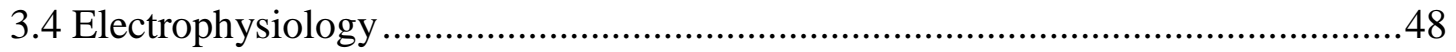

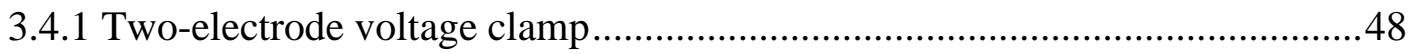

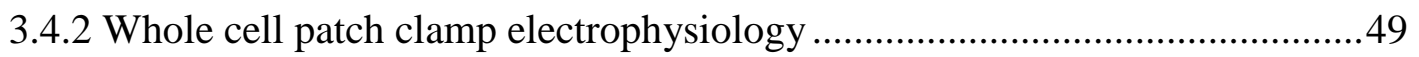

3.4.3 Outside-out patch clamp recordings for noise analysis ................................50 


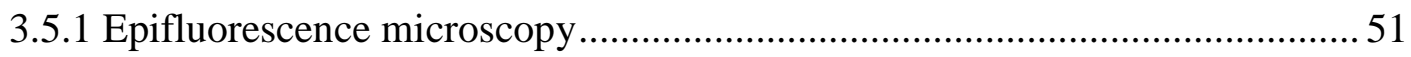

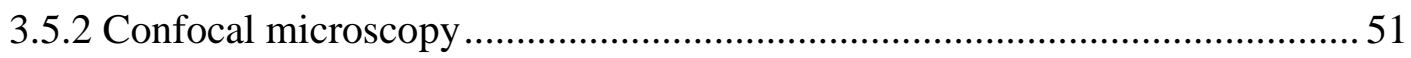

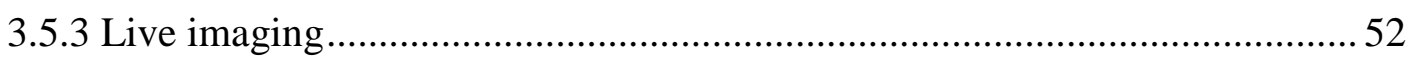

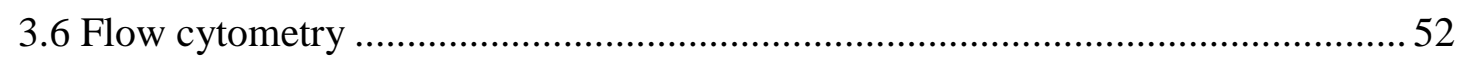

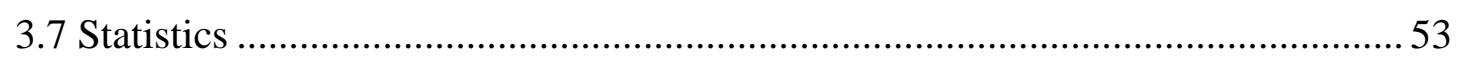

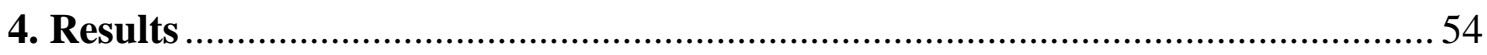

$4.1 \mathrm{~K}_{\mathrm{V}} 10.1^{\Delta 4-9}$ and $\mathrm{K}_{\mathrm{V}} 10.1^{\Delta 4-7}$ splice isoforms expression in diverse cell lines ........ 54

$4.2 \mathrm{~K}_{\mathrm{V}} 10.1^{\Delta 4-9}$ and $\mathrm{K}_{\mathrm{V}} 10.1^{\Delta 4-7}$ interaction with full-length $\mathrm{K}_{\mathrm{V}} 10.1$ channel ..............58

4.3 Impact of $K_{V} 10.1^{\Delta 4-9}$ and $K_{V} 10.1^{\Delta 4-7}$ on $K_{V} 10.1$ electrophysiological properties in

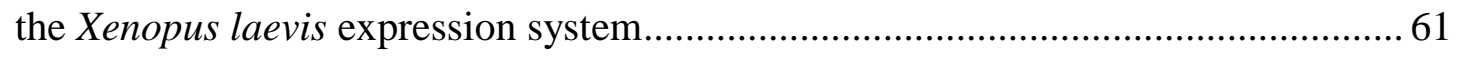

$4.4 \mathrm{~K}_{\mathrm{V}} 10.1^{\Delta 4-9}$ and $\mathrm{K}_{\mathrm{V}} 10.1^{\Delta 4-7}$ impact on $\mathrm{K}_{\mathrm{V}} 1.4$-elicited currents ..............................6 65

$4.5 \mathrm{~K}_{\mathrm{V}} 10.1^{\Delta 4-9}$ and $\mathrm{K}_{\mathrm{V}} 10.1^{\Delta 4-7}$ effects on $\mathrm{K}_{\mathrm{V}} 10.1$ currents in a heterologous

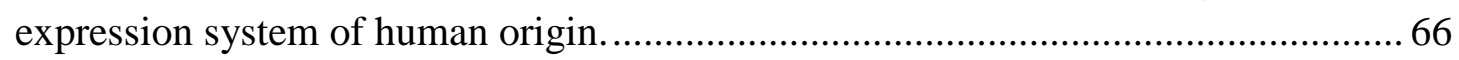

4.5.1 Investigations on the voltage dependence of the $\mathrm{K}_{\mathrm{V}} 10.1$ conductance under

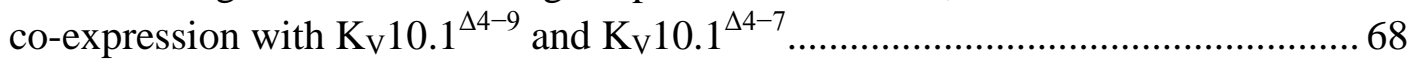

4.6 Mechanism of current amplitude reduction of $\mathrm{K}_{\mathrm{V}} 10.1$ channels induced by

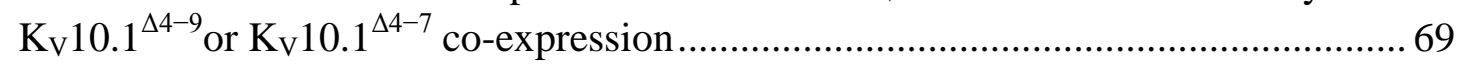

$4.7 \mathrm{~K}_{\mathrm{V}} 10.1$ Surface amount modification in presence of $\mathrm{K}_{\mathrm{V}} 10.1^{\Delta 4-9}$ and $\mathrm{K}_{\mathrm{V}} 10.1^{\Delta 4-7} 71$

$4.8 \mathrm{~K}_{\mathrm{V}} 10.1, \mathrm{~K}_{\mathrm{V}} 10.1^{\Delta 4-9}$ and $\mathrm{K}_{\mathrm{V}} 10.1^{\Delta 4-7}$ organization in native conditions................. 73

4.9 Structural determinants of the interaction between $K_{V} 10.1^{\Delta 4-9}$ and $K_{V} 10.1^{\Delta 4-7}$ and

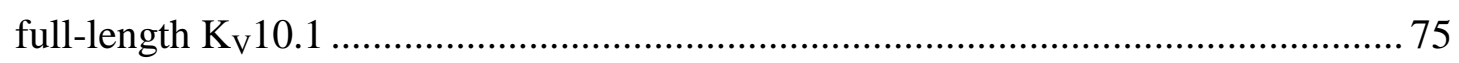

4.9.1 Impact of TCC inactivation on the $\mathrm{K}_{\mathrm{V}} 10.1$ current modulation exerted by

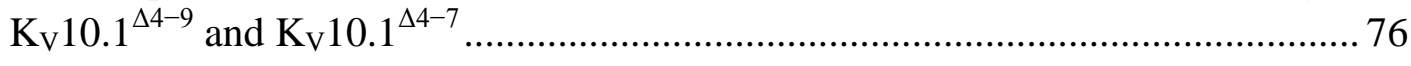

4.9.2 Effects on $K_{V} 10.1$ glycosylation pattern mediated by $K_{V} 10.1^{\Delta 4-7}$ interaction

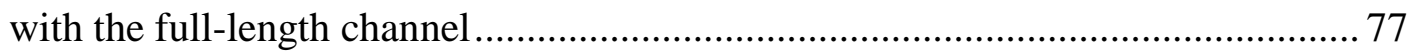

4.10 Analyses of the impact of $\mathrm{K}_{\mathrm{V}} 10.1^{\Delta 4-9}$ and $\mathrm{K}_{\mathrm{V}} 10.1^{\Delta 4-7}$ on the proliferation and cell

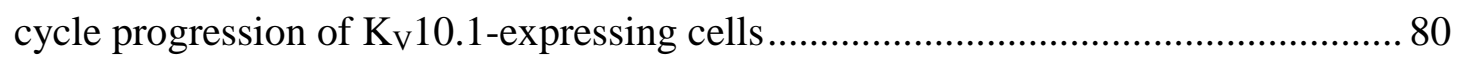

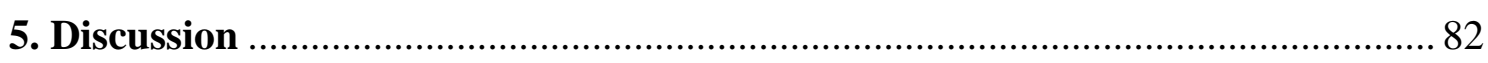

$5.1 \mathrm{~K}_{\mathrm{V}} 10.1$ short isoforms are expressed in normal brain and cell lines from diverse origins. 82

5.2 E65 and E70 interact with $\mathrm{K}_{\mathrm{V}} 10.1$ channel and modulate its function .85

5.3 Involvement of the TCC domain in the modulation of $\mathrm{K}_{\mathrm{V}} 10.1$ channels by E65. 89

5.4 Altered $\mathrm{K}_{\mathrm{V}} 10.1$ glycosylation could explain the modulation of $\mathrm{K}_{\mathrm{V}} 10.1$ channels by E70.. 


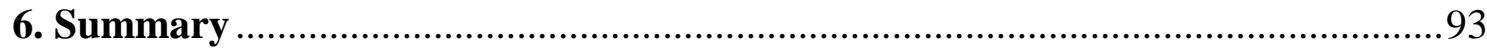

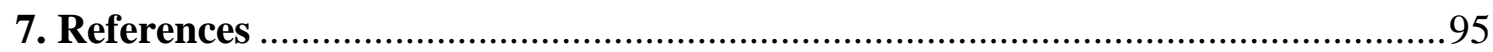

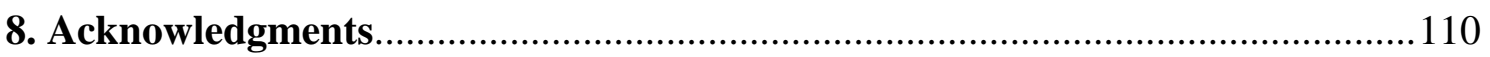

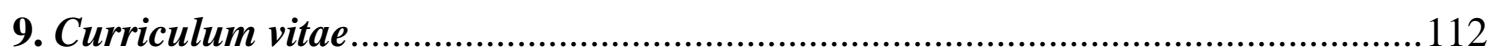

\section{List of Figures}

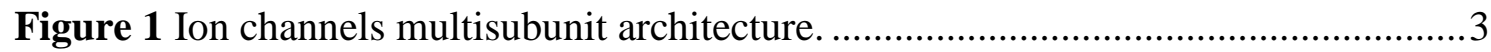

Figure 2 General architecture of a voltage-gated channel...........................................5

Figure 3 Putative structure of a subunit of the voltage-gated potassium channel

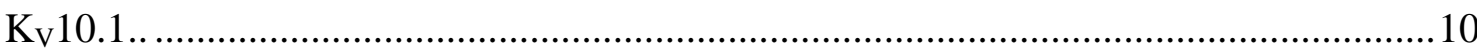

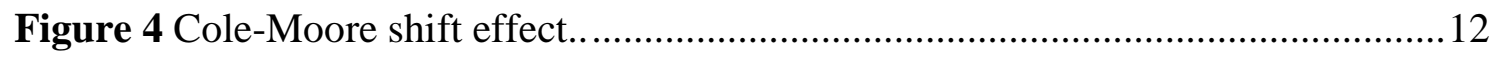

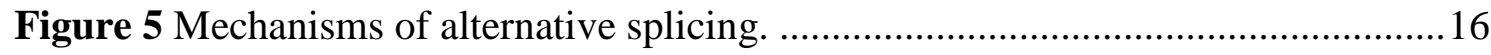

Figure 6 Exon organization of the full-length channel transcripts $K_{V} 10.1 a, K_{V} 10.1 b$, and of the truncated isoforms E65 and E70.

Figure 7 Nucleotide sequence of the RNA antisense probe targeting E70 transcripts...36

Figure $8 \mathrm{Gel}$ purification of RNA probes for RNase protection assay.. .37

Figure $9 K_{V} 10.1$-expressing cells exhibit $K_{V} 10.1^{\Delta 4-9}$ - and $K_{V} 10.1^{\Delta 4-7}$ - compatible

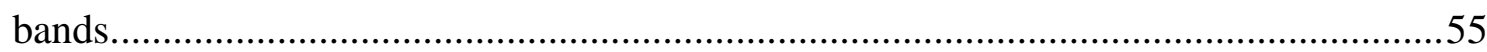

Figure $10 \mathrm{~K}_{\mathrm{V}} 10.1^{\Delta 4-9}$ and $\mathrm{K}_{\mathrm{V}} 10.1^{\Delta 4-7}$ TaqMan probes amplification efficiency..........57

Figure $11 K_{V} 10.1^{\Delta 4-9}$ and $K_{V} 10.1^{\Delta 4-7}$ transcripts detected with RNase protection assay. .58

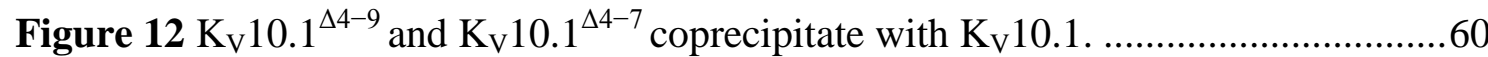

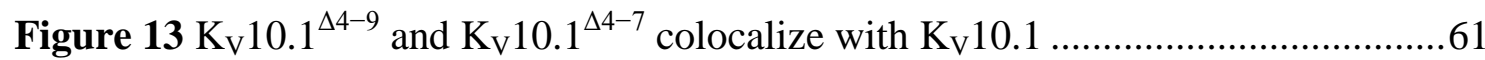

Figure $14 \mathrm{~K}_{\mathrm{V}} 10.1$ current is down-regulated under co-expression with $\mathrm{K}_{\mathrm{V}} 10.1^{\Delta 4-9}$ and $\mathrm{K}_{\mathrm{V}} 10.1^{\Delta 4-7}$ in a dose-dependent manner.

Figure $15 \mathrm{~K}_{\mathrm{V}} 10.1$ activation kinetics result decelerated under co-expression (in 1:10 ratio) with $\mathrm{K}_{\mathrm{V}} 10.1^{\Delta 4-9}$ and $\mathrm{K}_{\mathrm{V}} 10.1^{\Delta 4-7}$. 64

Figure $16 K_{V} 1.4$ current is not altered by co-expression with $K_{V} 10.1^{\Delta 4-9}$ and $K_{V} 10.1^{\Delta 4-7}$ (except for $\mathrm{K}_{\mathrm{V}} 1.4 / \mathrm{K}_{\mathrm{V}} 10.1^{\Delta 4-9}$ samples in $1 / 10$ ratio). .66 
Figure $17 \mathrm{~K}_{\mathrm{V}} 10.1$ current is down-regulated under co-expression with $\mathrm{K}_{\mathrm{V}} 10.1^{\Delta 4-9}$ and $\mathrm{K}_{\mathrm{V}} 10.1^{\Delta 4-7}$ in a human-derived heterologous expression system.

Figure 18 Voltage dependence of the $\mathrm{K}_{\mathrm{V}} 10.1$ conductance is not affected by coexpression with $\mathrm{K}_{\mathrm{V}} 10.1^{\Delta 4-9}$ and $\mathrm{K}_{\mathrm{V}} 10.1^{\Delta 4-7}$

Figure 19 Impact of $K_{V} 10.1^{\Delta 4-9}$ and $K_{V} 10.1^{\Delta 4-7}$ co-expression on $K_{V} 10.1$ single channel current and open probability. .71

Figure $20 \mathrm{~K}_{\mathrm{V}} 10.1$ surface amount increases in presence of $\mathrm{K}_{\mathrm{V}} 10.1^{\Delta 4-9}$ but not with $\mathrm{K}_{\mathrm{V}} 10.1^{\Delta 4-7}$ 72

Figure $21 K_{V} 10.1^{\Delta 4-9}$ and $K_{V} 10.1^{\Delta 4-7}$ interact with $K_{V} 10.1$ in native conditions. .74

Figure $22 \mathrm{~K}_{\mathrm{V}} 10.1$ short isoforms expressing a defective TCC domain coprecipitate with the full-length channel. .75

Figure $23 K_{V} 10.1$ current amplitude is unaffected by co-expression with $K_{V} 10.1^{\Delta 4-9}$ -

L20Y, whereas diminished with $\mathrm{K}_{\mathrm{V}} 10.1^{\Delta 4-7}$-L20Y. .77

Figure 24 Analyses of $K_{V} 10.1$ glycosylation under co-expression with $K_{V} 10.1^{\Delta 4-7}$ and $\mathrm{K}_{\mathrm{V}} 10.1^{\Delta 4-9}$ 79

Figure $25 \mathrm{~K}_{\mathrm{V}} 10.1^{\Delta 4-9}$ and $\mathrm{K}_{\mathrm{V}} 10.1^{\Delta 4-7}$ overexpression does not significantly affect the growth rate of SH-SY5Y cells.

Figure 26 Expression of $K_{V} 10.1^{\Delta 4-9}$ and $K_{V} 10.1^{\Delta 4-7}$ does not alter the cell cycle profile of $\mathrm{CHO}-\mathrm{K}_{\mathrm{V}} 10.1$ and $\mathrm{SH}-\mathrm{SY} 5 \mathrm{Y}$ cells. .81

\section{List of Tables}

Table 1 List of the primers used for PCR and nested PCR amplification.....................29

Table 2 List of the TaqMan probes and primers used for real-time PCR ..................... 30

Table 3 BSA dilution pattern used for protein quantization experiments..................... 40

Table 4 List of primary antibodies used in IP, ELISA and WB. 45

Table 5 Endo H and PNGase F digestions: list, and used amount of the components for each sample. .46

Table 6 Summary of results from nested PCR experiments followed by sequencing analysis. 


\title{
Abbreviations
}

\author{
Units \\ $\sigma^{2}$ \\ Variance \\ A \\ Absorbance \\ $\mathrm{bp}, \mathrm{kb}$ \\ Base pair, kilobase \\ $\mathrm{C}_{\text {fast }}, \mathrm{C}_{\text {slow }}$ \\ Fast capacitance, slow capacitance \\ $\mathrm{Ci}, \mu \mathrm{Ci}$ \\ Curie, Microcurie \\ $\mathrm{Cp}$ \\ Crossing point \\ cpm \\ Counts per minute \\ $\mathrm{kDa}$ \\ Kilodalton \\ $\mathrm{G}, G_{\max }$ \\ Conductance, maximal conductance \\ $g$ \\ Acceleration (relative centrifugal force) \\ i \\ Single channel current \\ I \\ Macroscopic (total) current \\ $k$ \\ Slope factor \\ $\min$ \\ Minute \\ mOsm \\ Milliosmole \\ MW \\ Molecular weight \\ $\mathrm{ON}$ \\ Overnight \\ $\mathrm{N}$ \\ Total number of channels \\ nt \\ Nucleotide \\ $\mathrm{P}_{\mathrm{o}}$ \\ Open probability \\ R \\ Resistance \\ rpm \\ Rotations per minute \\ $\mathrm{R}_{\mathrm{S}}$ \\ Series resistance
}




$\begin{array}{ll}\text { RT } & \text { Room temperature } \\ \mathrm{U} & \text { Unit } \\ \mathrm{V}_{\text {Half }} & \text { Voltage for half-maximal activation } \\ \text { vol } & \text { Volume } \\ \text { w/v } & \text { Weight for volume }\end{array}$

Cell lines, Organisms, Genes and Proteins

AChR

Acetylcholine receptor

AS

Alternative splicing

BBS

Bungarotoxin-binding site

cNBD

Cyclic nucleotide binding domain

$\mathrm{CHO}$

Chinese hamster ovary

DNA，cDNA

Deoxyribonucleic acid, complementary DNA

HEK

Human embryonic kidney

E. coli

Escherichia coli

ER

Endoplasmic reticulum

ESEs/ISEs

Exonic splicing enhancers/intronic splicing enhancers

ESSs/ISSs

Exonic splicing silencers/intronic splicing silencers

hnRNPs

Heterogeneous nuclear ribonucleoproteins

$\mathrm{IgG}$

Immunoglobulin G

NLS

Nuclear localization signal

$\mathrm{PAS} / \mathrm{PAC}$

Per-Arnt-Sim/PAS associated C-terminal

PTB

Polypyrimidine tract binding protein

RNA, cRNA, mRNA

Ribonucleic acid, capped RNA, messenger RNA

SR

Serine-rich

TCC

Tetramerizing coiled coil 
Wild-type

\section{Methods and Chemicals}

ABTS

Ar

ATP,CTP,GTP,UTP

BN-PAGE

BP

BSA

BTX

$\mathrm{CaM}$

$\mathrm{CO}_{2}$

DAPI

$\mathrm{dH}_{2} \mathrm{O}$

DDM

DEPC

DMEM

DMSO

DNase

dNTP

DTT

ECL

EDTA

EGTA

ELISA

Endo H 2,2'-azino-bis(3-ethylbenzothiazoline-6-sulphonic acid)

Argon

Adenosine-, Cytidine-, Guanosine-, Uridine- triphosphate

Blue native-Polyacrylamide gel electrophoresis

Band pass

Bovine serum albumin

$\alpha$-Bungarotoxin

Calmodulin

Carbon dioxide

4',6-diamidino-2-phenylindole

Distilled water

$n$-Dodecyl $\beta$-D-Maltopyranoside

Diethyl pyrocarbonate

Dulbecco's modified eagle medium

Dimethyl sulfoxyde

Deoxyribonuclease

Deoxyribonucleoside triphosphate

1,4-Dithio-DL-threitol

Enhanced chemiluminescence

Ethylenediamine tetraacetic acid

Ethylene glycol tetraacetic acid

Enzyme-linked immunosorbent assay

Endoglycosidase $\mathrm{H}$ 


\begin{tabular}{|c|c|}
\hline FCS & Fetal calf serum \\
\hline Fiji & Fiji is just ImageJ \\
\hline GFP & Green fluorescent protein \\
\hline HEPES & (4-(2-hydroxyethyl)-1-piperazineethanesulfonic acid) \\
\hline HRP & Horseradish peroxidase \\
\hline IP & Immunoprecipitation \\
\hline IPTG & Isopropyl $\beta$-D-1-thiogalactopyranoside \\
\hline JACoP & Just another colocalization plugin \\
\hline LB & Luria Bertani broth \\
\hline LP & Long pass \\
\hline MEM & Minimum essential medium \\
\hline NFR & Normal frog ringer \\
\hline NMDG & $\mathrm{N}$-methyl- $D$-glucamine \\
\hline PBS & Phosphate buffered saline \\
\hline PCR & Polymerase chain reaction \\
\hline $\mathrm{Pi}$ & Propidium iodide \\
\hline PI & Protease inhibitor \\
\hline PKA & Protein kinase A \\
\hline $\mathrm{PKC}$ & Protein kinase $\mathrm{C}$ \\
\hline PNGase F & Peptide N-Glycosidase F \\
\hline PVDF & Polyvinylidene difluoride \\
\hline RNAi, siRNA & RNA interference; small interfering RNA \\
\hline RNase & Ribonuclease \\
\hline RPA & Ribonuclease protection assay \\
\hline RPMI & Roswell Park Memorial Institute \\
\hline SDS & Sodium dodecyl sulphate \\
\hline
\end{tabular}


SDS-PAGE

SEM

TBE

TBS

TEA

TEMED

TEVC

X-Gal
SDS Polyacrylamide gel electrophoresis

Standard deviation of the mean

Tris-Borate-EDTA

Tris-buffered saline

Tetraethylammonium acetate

N`N`N`N Tetramethylethyldiamine

Two-electrode voltage clamp

5-bromo-4-chloro-3-indolyl- $\beta$-D-galactopyranoside 


\section{Introduction}

\subsection{Ion channels}

The flow of ions across the cell membrane is a crucial process for life: it provides nutrients, generates electrical signals, regulates cell volume, secretes electrolytes across epithelial layers (Hille, 2001). Ion channels, together with transporters and pumps are the main players to accomplish these physiological functions. Ion channels are proteins equipped with a hydrophilic pore traversing the entire lipid bilayer of the membrane of all prokaryotic and eukaryotic cells. They allow the transit through the membrane of different inorganic ions, like $\mathrm{Na}^{+}, \mathrm{K}^{+}, \mathrm{Ca}^{2+}$ and $\mathrm{Cl}^{-}$, with a very high flow rate: up to 100 million ions/s can flow through a single channel (Kandel, 2000). Two main factors distinguish ion channels from simple aqueous pores. The first is the ion selectivity, meaning that ion channels allow the passage exclusively (or with very high selectivity) of one ion rather than another. This is thought to be mediated by the selectivity filter region of the channel that preferentially interacts with and mediates the passage of the proper ion. The second important distinction is that the former are not always in open state. Events of opening and closure (or "gating") are continuously occurring and, depending on a specific stimulus, strictly regulated.

The first insights into the structure and function of ion channels had been derived from molecular and structural biology studies as well as pioneering electrophysiological investigations. The first milestone in the latter field was achieved by Hodgkin and Huxley who in 1952, based on evidence provided by voltage clamp experiments, elaborated a series of mathematical models describing how ionic current generated by ion channels give rise to action potential in neurons (Hodgkin and Huxley, 1952). Later on, towards end of the 1970s, the field of electrophysiology was revolutionized by the invention of the patch-clamp technique, a powerful method that allows real time analysis of current flowing at the level of single channel molecule (Neher et al., 1978). About thirty years ago the first ion channel was cloned (Noda et al., 1983), and to date genes for most of the major classes of ion channels have been cloned and sequenced. 
Moreover, after the first structure of a bacterial potassium channel obtained by X-ray crystallography (Doyle et al., 1998), several different channel structures are now available. Ion channels subunit sequences have also been extensively engineered through manipulation of their DNA sequence, providing hints about the function associated with the mutated DNA region.

Based on data from various fields, we know that ion channels are generally macromolecular (oligomeric) complexes formed by assembly of several subunits. The majority of channels have three, four, or five homologous or identical $\alpha$ subunits arranged in circular symmetry, forming a single aqueous pore at their axial intersection (Fig. 1 A). In certain types of channels, additional accessory subunits are coupled to the ion conducting $(\alpha)$ subunits (Fig. 1 B). Ion channels possess many features typical of membrane proteins: they are synthesized and inserted into the membrane of the endoplasmic reticulum (ER), glycosylated in the Golgi, and transported and inserted into target membranes by membrane fusion processes (see section 1.2).

The wide variety of ion channel structures is correlated with a large diversity regarding the main type of stimulus causing their opening: change in the voltage across the membrane (voltage-gated channels), mechanical stress (mechanically gated channels), or the binding of a ligand (ligand-gated channels). The ligand can be either an extracellular mediator, a neurotransmitter (transmitter-gated channels) or an intracellular mediator, such as an ion (ion-gated channels), or a nucleotide (nucleotidegated channels) (Alberts et al., 2002). The activity of many ion channels can be moreover modulated by post-translational modification like phosphorylation, dephosphorylation, ubiquitinylation, SUMOylation, palmitoylation and N-linkedglycosilation. Mechanisms of alternative splicing (as will be described in section 1.5.2) as well as interaction of the $\alpha$ subunits of the channels with auxiliary ( $\beta$ or $\gamma$ ) subunits play a critical role expanding ion channel diversity and in the modulation of their function (Fig. 1 B) (Li and Um; 2006). 

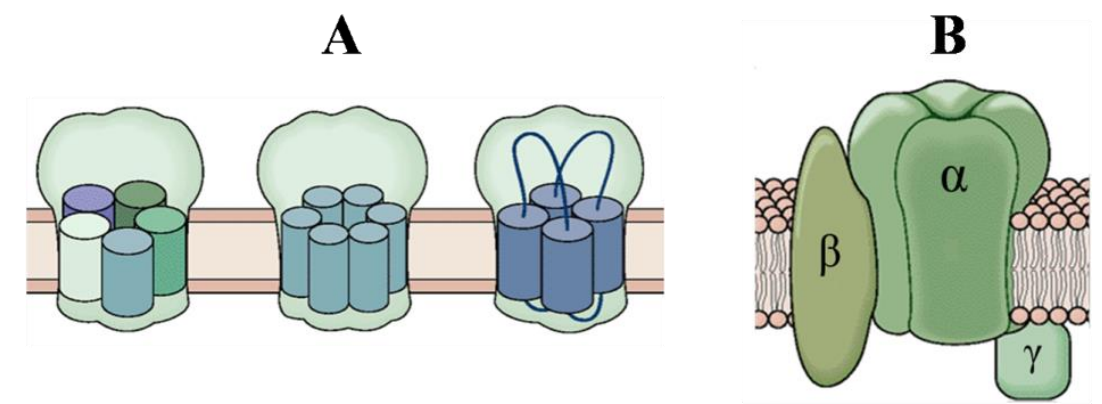

Figure 1 Ion channels multisubunit architecture. (A) Ion channels can be formed by heterooligomers from distinct subunits (left), as homooligomers from a single type of subunit (middle), or from a single polypeptide chain organized into repeating motifs, where each motif behaves like one subunit (right). (B) Some channels contain auxiliary subunits $(\beta$ or $\gamma)$, which modulate the gating characteristics of the central core (figure modified from Kandel, 2001).

To date, more than one hundred genes coding for several hundreds of different ion channels have been identified (Gabashvili et al., 2007). The need for classification of this plethora of molecules led to the elaboration of a numbering system for mammalian voltage-gated potassium channel (Chandy, 1991), then for voltage-gated calcium channels (Ertel et al., 2000) and for voltage-gated sodium channels (Goldin, 2002). However, a classification system widely accepted nowadays is based on the IUPHAR (International Union of basic and clinical Pharmacology) classification (http://www.iuphar-db.org), in which the products of gene families and superfamilies are named based on the chemical symbol of the main permeating ion $(\mathrm{Na}, \mathrm{K}$, or $\mathrm{Ca})$ and with the principal physiological regulator depicted subscript (for example, a voltage activated potassium channel will be depicted with $K_{v}$ ) followed by a number indicating the gene subfamily and a decimal that separates the number assigned to specific channel isoforms. This classification system will be used wherever appropriate in this thesis.

Overall, in recent years improved electrophysiological methods coupled with advanced molecular and structural biology techniques have provided a much more comprehensive knowledge about the once 'black box' of ion channels. 


\subsubsection{The superfamily of voltage-gated channels}

As the name already suggests, voltage-gated channels are opened by changes in membrane potential. They all consist of four homologous motifs, each of them formed by six transmembrane segments ( $\mathrm{S} 1$ to S6) containing a voltage sensor domain and a pore-forming domain (Fig. 2). The four pore-forming $\alpha$ domains converge to form the single central pore, whereas the four voltage sensors are placed laterally within the membrane lipid bilayer. The opening and establishment of ionic conductance requires that voltage-gated channels are provided with charges that would respond to voltage changes, as already postulated by Hodgkin and Huxley in 1952. Subsequently, the existence of the voltage sensor was demonstrated: it consists of a region within the S4 transmembrane segment of each domain composed of repeated motifs of one positively charged residue followed by two hydrophobic residues, potentially creating a helical arrangement of positive charges through the membrane (Noda et al., 1984). Neutralization of the four positively charged residues in the S4 segment of domain I of the sodium channel by site-directed mutagenesis has major effects on the voltage dependence of activation (Stühmer et al., 1989). The movement of the voltage-sensor charged by changes of electric field across the membrane therefore alters the equilibrium between the closed and open states of the channel, thus controlling the ion flow. The passage of ions occurs through the pore region, situated between S5 and S6 transmembrane segment of each domain. Voltage-gated channels show different ion selectivities for monovalent cations and are therefore classified as $\mathrm{Na}_{V}, \mathrm{~K}_{\mathrm{V}}$, and $\mathrm{Ca}_{\mathrm{V}}$ channels.

Apart from the similar backbone structure previously mentioned, the final structure of the voltage-gated channels show relevant differences between different families: in $\mathrm{Na}_{\mathrm{v}}$ channels, the four homologous $\alpha$ domains, (each of them formed by six transmembrane segments) are derived by a single, linear sequence connected by intracellular loops and associated with one or more auxiliary $\beta$-subunits, the latter required for normal kinetics and voltage dependence of gating (Catterall, 2000a). In the case of $\mathrm{Ca}_{v}$, the poreforming $\alpha 1$ linear sequence is assembled together with a transmembrane, disulfidelinked complex of $\alpha 2$ and $\delta$ subunits and an intracellular $\beta$ subunit. In some cases, a transmembrane $\gamma$ subunit is also found. Mutations in these subunits have a tremendous impact on expression level, voltage dependence and gating properties of the channels 
(Catterall, 2000b). With forty known genes, voltage-gated potassium channels represent the largest superfamily of ion channels. Unlike voltage-gated calcium and sodium channels, the voltage-gated potassium channels encode in their primary sequence only a single $\alpha$ domain. The assembly of four $\alpha$ domains is primarily mediated by a region located within the intracellular hydrophilic amino-terminus $\left(\mathrm{K}_{\mathrm{V}} 1\right)$ or carboxy-terminus, (as the case of $K_{V} 7, K_{V} 10, K_{V} 11$ and $K_{V} 12$ channels)(Jenke et al., 2003). This region is known as the tetramerization domain ( $\mathrm{Li}$ et al., 1992). Homo- or heterotetramers (formed by different subunits within the same family) of $\alpha$ subunits form the functional voltage-gated potassium channel. $\beta$ subunits can also interact with these types of channels, modulating their function (Catterall, 1995). In this regard, the tetramerization domain may also serve as a scaffold to bind accessory $\beta$ subunits (Tombola et al., 2006).

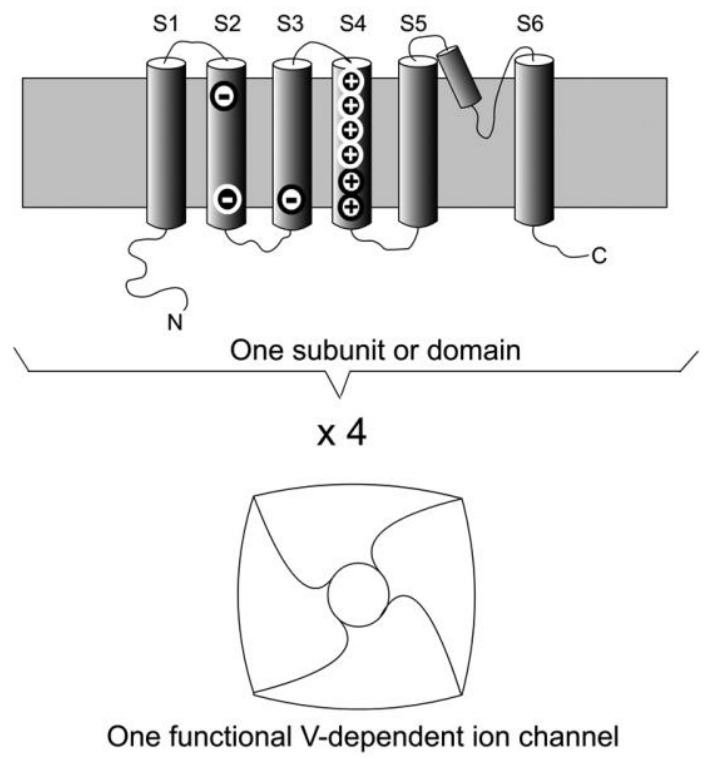

Figure 2 General architecture of a voltage-gated channel. Top shows the basic subunit (or domain in the case of $\mathrm{Na}^{+}$and $\mathrm{Ca}^{2+}$ channels). The gray background represents the lipid bilayer. The cylinders represent transmembrane segments. The region between S5 and S6 forms the pore. The voltage sensor part of the channel consists of the segments from S1 to S4. The + or - signs indicate charges involved in voltage sensing. In the bottom part, a schematic view of the channel from the outside showing the assembled four subunits or domains is seen. Figure from (Bezanilla, 2005). 


\subsection{Trafficking of ion channels}

The intracellular trafficking of membrane proteins such as ion channels is a complex and highly regulated process. It involves both forward (towards the plasma membrane) and backward (internalization from the plasma membrane) transport. The journey starts when the nascent protein chain moves from the ER membrane bound ribosome into the ER lumen. Here the processes of folding and assembly occur, in a co-translational manner (Kosolapov and Deutsch, 2003). In most of the voltage-gated potassium channels (including $\mathrm{K}_{\mathrm{V}} 10.1$ channels) the 'newborn' protein may additionally undergo core-glycosylation at this phase (Napp et al., 2005, Steele et al., 2007). A presynthesized oligosaccharide (Glc3MangGlcNAc2) is transferred to an asparagine (Asn) residue in the nascent peptide chain by the enzyme oligosaccharyltransferase (Kaplan et al., 1987). Core glycosylation generally occurs at the Asn residues in the sequon Asn-XSer/Thr, ( $\mathrm{X}$ is any amino acid except proline) (Kaplan et al., 1987). N-Linked glycosylation represents a common form of membrane protein processing that can profoundly affect protein expression, structure, and function. Defects in glycosylation may result in the generation of misfolded, aggregated proteins failing to reach a functional state.

Quality control mechanisms at the ER, such as heat shock protein (Hsp) 70 and 90, and calnexin (Zerangue et al., 1999; Ficker et al., 2003; Steele et al., 2007; Staudacher et al., 2010) ensure that only correctly folded, assembled channel proteins are exported from the ER to Golgi (Ellgaard and Helenius, 2001) whereas misfolded proteins are retained in the ER (aggregating with other misfolded proteins) and eventually targeted for degradation (Zerangue et al., 1999). In the Golgi, further processing of the channel protein like complex glycosylation occurs; the oligosaccharides gain complexity as proteins progress through the Golgi apparatus, resulting in complex, high-mannose, or hybrid oligosaccharides. From the Golgi network the complex glycosylated proteins are directed to the plasma membrane to be finally inserted within the lipid bilayer. Remarkably, ion channels do not simply traffic to any random area in the plasma membrane, but rather localize to specific cell surface domains (Steele et al., 2007). Membrane insertion process occurs by means of SNARE-mediated fusion of vesicles containing the ion channel protein with the plasmalemma. SNAREs are thought to 
deform membranes, affecting the hydrophobic-hydrophilic boundary and directly inducing fusion (Jahn and Scheller, 2006). In order to ensure adequate cellular plasticity and homeostasis, ion channels expression at level of the cell surface is finely regulated. Channels undergo internalization and can either be recycled or degraded in proteasomes or lysosomes (Steele et al., 2007).

\subsection{Physiological and pathophysiological roles of ion channels}

Ion channels play important roles in diverse processes such as nerve and muscle excitation, hormone secretion, cell proliferation, sensory transduction, learning and memory, regulation of blood pressure, salt and water balance, fertilization and cell death (Ashcroft, 2006). In particular, voltage-gated potassium channels control cell excitability and set the resting potential, contributing to the origin and propagation of the action potential in neurons and other excitable cells.

Ion channel dysfunctions can result in a large variety of diseases; to date, mutations in over 60 ion channel genes have been associated with human pathologies. The dysregulation of certain types of voltage-gated channels causing hyperexcitability may result in different pathologic phenotypes: epilepsy, occurring in central neurons; myotonia (prolonged muscle contraction) in skeletal muscle, arrhythmia when in the heart. Other example of pathologic phenotypes associated with ion channels are cystic fibrosis, hypertension, diabetes, and gastrointestinal disorders (Ashcroft, 2006). Increasing evidences suggest an involvement of ion channels in cell proliferation and cancer (see section 1.3.1). Given the important role of ion channels in many pathophysiological events, together with their structural heterogeneity and convenient transmembrane localization, these molecules represent an attractive target for pharmacologic therapies. Indeed, it is not surprising that currently more than $13 \%$ of all available pharmacologic therapies utilizes drugs having ion channels as their primary therapeutic target (Overington et al., 2006). 


\subsubsection{Role of ion channels in cell proliferation and cancer}

An emerging physiological and pathophysiological role of ion channels expression is their implication with cell proliferation (Wonderlin and Strobl, 1996; Pardo, 2004; Kunzelmann, 2005). Oscillation of membrane potential exerted by ion channels is required for progression of the cell cycle: the membrane potential in early G1 phase is depolarized and the transition from G1 to S phase during mitosis is accompanied by hyperpolarization of the membrane potential (Wonderlin et al., 1995). In this context, potassium channels expression, while inducing a shift of the membrane potential towards negative values, would provide the driving force required for calcium to enter the cell. Calcium is an important mediator of intracellular signals, implicated in the control of proliferation among other crucial processes in cell physiology (Lee et al., 1993). Beside the calcium-mediated effect, another hypothesis about ion channel impact on proliferation relies on the regulation in cell volume mediated by chloride channels: changes in cell size would either favor the progression along the cell cycle, or commit the cell to undergo apoptosis (Lang et al., 2000). Moreover, inhibition of $\mathrm{K}^{+}$channels may affect regulation of cytosolic $\mathrm{pH}$ and reduce proliferation by causing cellular acidification (Kunzelmann, 2005). The proliferative stimulus related to expression of potassium channels $\left(\mathrm{K}_{\mathrm{Ca}} 3.1\right.$ and $\left.\mathrm{K}_{\mathrm{V}} 1.3\right)$ is also crucial for lymphocyte $\mathrm{B}$ and $\mathrm{T}$ maturation and proliferation. These channels have been proposed as novel therapeutic targets for autoimmune disorders (Beeton et al., 2005). More interestingly, dysregulation of $\mathrm{Ca}^{2+}$-channels (in particular transient receptor potential - TRP channels), $\mathrm{K}^{+}$channels (like $\mathrm{K}_{\mathrm{Ca}} 1.1, \mathrm{~K}_{\mathrm{Ca}} 3.1, \mathrm{~K}_{\mathrm{V}} 1.3, \mathrm{~K}_{\mathrm{V}} 10.1$ and $\mathrm{K}_{\mathrm{V}} 11.1$ ) and $\mathrm{Na}^{+}$ channels (like $\mathrm{Na}_{\mathrm{V}} 1.5$ and $\mathrm{Na}_{\mathrm{V}} 1.7$ ) all contribute to cancer progression, acting through a series of mechanisms, ranging from cell cycle and cell metabolism regulation, influencing the cell motility and capacity of invasion of tumor cells (Pedersen and Stock, 2013; Pardo and Stühmer, 2014; Urrego et al., 2014). 


\section{$1.4 K_{V} 10.1$ channels}

$\mathrm{K}_{\mathrm{V}} 10.1$ (also named Eag1) is a member of the ether-à-go-go (eag) family of voltage activated potassium channels. The name eag was assigned to a mutant showing legshaking in response to ether anesthesia in the fruit fly Drosophila melanogaster (Kaplan and Trout, 1969). Subsequent cloning of the gene revealed that $K_{V} 10.1$ encodes a voltage-gated potassium channel (Brüggemann et al., 1993). The human ortholog of Drosophila eag gene $\left(\mathrm{K}_{\mathrm{V}} 10.1\right)$ was cloned in 1998: the gene is located at position 32.132.3 of the long arm of human chromosome 1; it encodes eleven exons (Occhiodoro et al., 1998; Pardo et al., 1999) and it is translated into a protein of apparent molecular weight of $\sim 130 \mathrm{kDa}$ (Napp et al., 2005). To date, the eag family includes eight members: beside $K_{V} 10.1$, the closely related $K_{V} 10.2$ (eag2), the $K_{V} 12$ (elk) subfamily (elk1, elk2, elk3) and the $\mathrm{K}_{\mathrm{V}} 11$ (erg) proteins (erg1, erg2, erg3) have been identified. Similarly to the other $\mathrm{K}_{\mathrm{V}}$ superfamily members, $\mathrm{K}_{\mathrm{V}} 10.1$ shows the characteristic six transmembrane domains with long intracellular amino- and carboxyl- terminal regions, bearing several recognizable motifs. In the N-terminal domain, a Per-Arnt-Sim (PAS)/PAS associated C-terminal (PAC) domain and a binding site for calmodulin. Two binding sites for calmodulin, a cyclic nucleotide binding domain (cNBD), a nuclear localization signal (NLS) and a tetramerizing coiled-coil (TCC) domain in the carboxyl-terminus (Fig. 3). The binding sites for calmodulin modulate channel function (see below). The TCC domain is crucial for assembly in the tetrameric conformation typical of functional channels (Jenke et al., 2003; Ludwig et al., 1997). The functional roles of $\mathrm{K}_{\mathrm{V}} 10.1 \mathrm{PAS} / \mathrm{PAC}$ (frequently named eag domain) and $\mathrm{cNBD}$ domains are still undisclosed. However, recent crystal structure analyses show that PAS/PAC and cNBD domains extensively interact; disruption of this interaction induced by mutations alters the gating properties of $\mathrm{K}_{\mathrm{V}} 10.1$ channels (Haitin et al., 2013). $\mathrm{K}_{\mathrm{V}} 10.1$ channels also undergo post-translational modifications: glycosylation sites are present on asparagine residues at positions 388 and 406 of the extracellular loop between S5 and S6 transmembrane domains. Asn-388 seems to undergo only core glycosylation; additionally complex sugars are bound to Asn-406. Correct glycosylation is critical for the proper trafficking of the channel to the membrane, as well as for its correct function once the channel reached already the membrane (Napp et al., 2005). Regarding the channel trafficking, $\mathrm{K}_{\mathrm{V}} 10.1$ undergoes very rapid surface turnover (a given set of 
membrane channels is getting internalized once during 100 min), which controls the subcellular distribution and life cycle of the channel (Kohl et al., 2011). $\mathrm{K}_{\mathrm{V}} 10.1$ channels are partitioned in different subdomains along the plasma membrane, and their activity varies depending on their distribution (Jiménez-Garduño et al., 2013). This could provide a functional correlate to the finding that endogenous $K_{\mathrm{V}} 10.1$ channels diffuse within the plasmatic membrane of hippocampal neurons (Gómez-Varela et al., 2010).

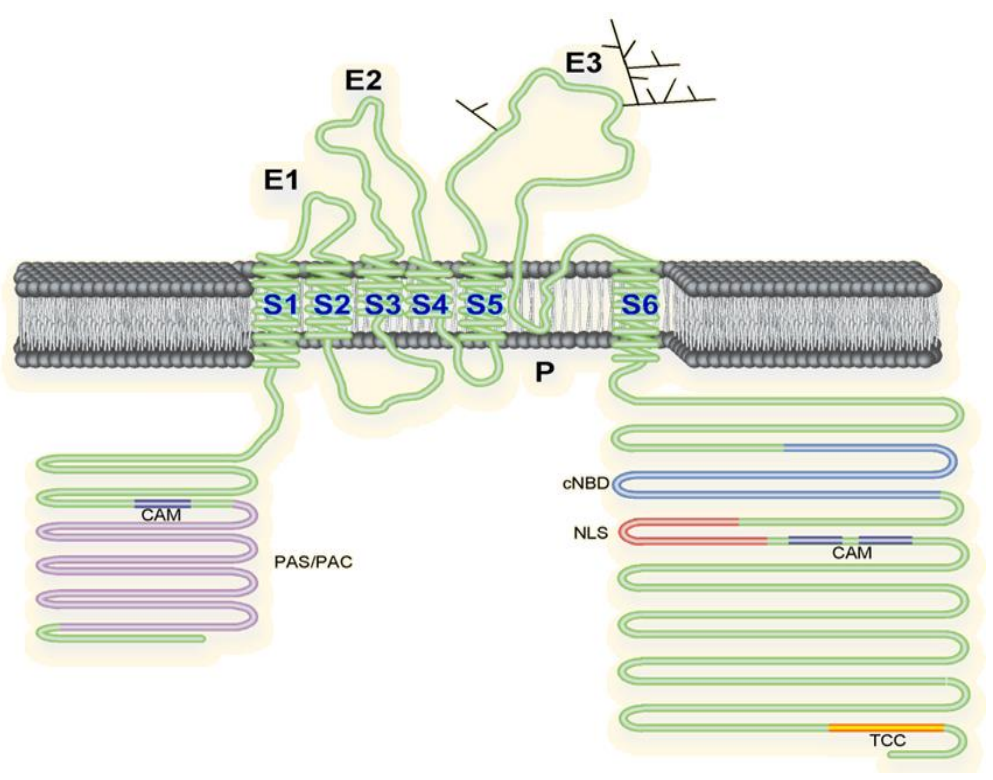

Figure 3 Putative structure of a subunit of the voltage-gated potassium channel $K_{V} 10.1$. Each subunit is formed by six transmembrane domains; the voltage sensor is located between S1 and S4, and the pore between S5 and S6. The branches along the third extracellular loop (E3) represent glycosylation sites. Two long intracytoplasmic regions containing several binding motifs are also highlighted.

A second $K_{V} 10.1$ transcript (called $K_{V} 10.1 b$, to distinguish it from the originally cloned, $\left.\mathrm{K}_{\mathrm{V}} 10.1 \mathrm{a}\right)$ has been cloned from mouse and human brain, and bovine retina. $\mathrm{K}_{\mathrm{V}} 10.1 \mathrm{~b}$ has an insertion of 27 amino acids in the extracellular linker between transmembrane segments S3 and S4 (Warmke and Ganetzky, 1994; Frings et al., 1998; Pardo et al., 1999). As far as determined, $K_{V} 10.1 \mathrm{a}$ and $K_{V} 10.1 b$ share expression pattern and electrophysiological properties. Additional $\mathrm{K}_{\mathrm{V}} 10.1$ transcripts derived from events of alternative splicing have been recently detected in human brain and cancer cell lines (see section 1.5.3). 
In a physiological context, $\mathrm{K}_{\mathrm{V}} 10.1$ expression pattern is limited to adult brain and myoblasts, and virtually absent in peripheral tissues (Occhiodoro et al., 1998). In myoblasts, $\mathrm{K}_{\mathrm{V}} 10.1$ contributes to the hyperpolarization required for the differentiation of these cells in post-mitotic, fusion-competent myotubes (Bijlenga et al., 1998). In brain, $\mathrm{K}_{\mathrm{V}} 10.1$ channels have preferential presynaptic localization, and contribute to short-term synaptic plasticity. Parallel fiber/Purkinje cell synapses of $K_{V} 10.1$ knockout mice show increased short-term facilitation (Mortensen PhD thesis, 2012). $\mathrm{K}_{\mathrm{V}} 10.1$ deficient mice show no detectable alterations during embryogenesis and develop normally to adulthood. No major behavioral effects were detected, apart from a mild hyperactivity and longer lasting haloperidol-induced catalepsy (Ufartes et al., 2013).

However, despite the only partially characterized role of $\mathrm{K}_{\mathrm{V}} 10.1$ in physiology, this channel subfamily has been extensively studied because of their involvement in oncogenesis (see section 1.4.2).

\subsubsection{Electrophysiological properties of $K_{V} 10.1$}

$\mathrm{K}_{\mathrm{V}} 10.1$ is a voltage-gated potassium channel producing slow activating, outward rectifying currents, which do not inactivate. A slight inward rectification is observed with strong depolarizations, compatible with block by intracellular sodium (Pardo et al., 1998). The best known $K_{V} 10.1$ blockers are astemizole, imipramine (García-Ferreiro et al., 2004) and dofetilide (Ficker et al., 2001). However, none of these compounds is specific for $\mathrm{K}_{\mathrm{V}} 10.1$, since they also block $\mathrm{K}_{\mathrm{V}} 11$ channels. Additionally, $\mathrm{K}_{\mathrm{V}} 10.1$ is relatively insensitive to the commonly used potassium channel blockers tetraethylammonium acetate (TEA) and 4-aminopyridine (Brüggemann et al., 1993).

$\mathrm{K}_{\mathrm{V}} 10$-elicited currents have a defining electrophysiological feature, making them easily distinguishable from other ion channels. This consists in a marked dependence of the activation kinetics on the potential prior to the stimulus: $\mathrm{K}_{\mathrm{V}} 10.1$ activates faster the more depolarized the potential was before the stimulus (see Fig. 4). This phenomenon is reminiscent of the shift described by Cole and Moore (Cole, 1978), although orders of magnitude more pronounced. The Cole-Moore shift is augmented by extracellular magnesium and protons in a dose-dependent manner (Terlau et al., 1996). $\mathrm{K}_{\mathrm{V}} 10.1$ 
channels function is inhibited by intracellular $\mathrm{Ca}^{2+} /$ calmodulin $(\mathrm{CaM})$, through the $\mathrm{Ca}^{2+} / \mathrm{CaM}$ binding domains on both $\mathrm{N}$ - and C- termini (Schönherr et al., 2000; Ziechner et al., 2006; Gonçalves and Stühmer, 2010).

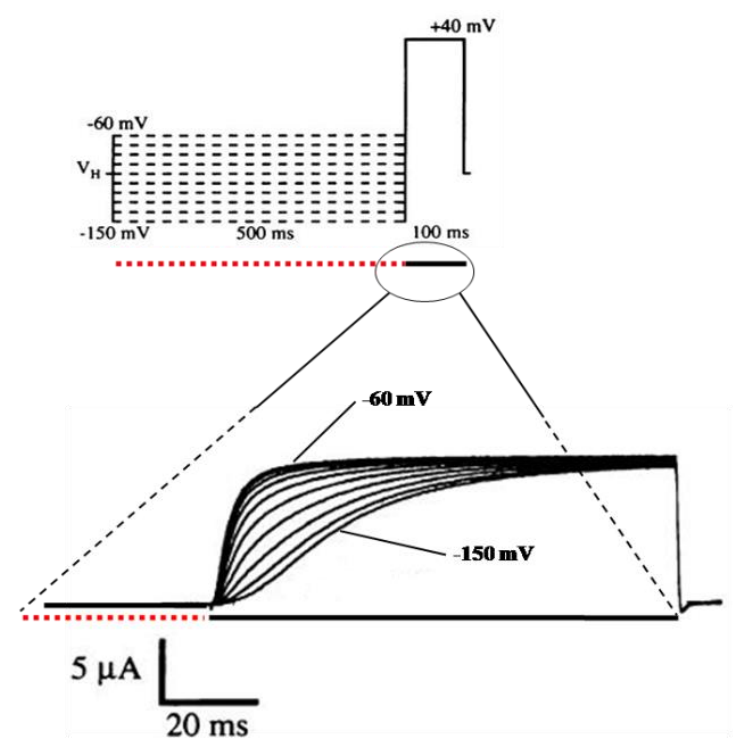

Figure 4 Cole-Moore shift effect. $K_{\mathrm{V}} 10.1$ activation kinetics are strongly influenced by the pre-pulse potentials. Pre-pulse conditioning time interval is highlighted with a red dotted line. The black line is associated with the depolarization time. Figure modified from (Ludwig et al., 1994).

Interestingly, another factor modulating $\mathrm{K}_{\mathrm{V}} 10.1$ channels current is the phase of the cell cycle: macroscopic current derived from injection of rat $\mathrm{K}_{\mathrm{V}} 10.1$ channels into Xenopus laevis oocytes was regulated during cell cycle, since maturation in oocytes triggered by mitosis-promoting factor altered the current properties. Current amplitude was reduced, and this effect was accompanied by a strong inward rectification (Brüggemann et al., 1997). Currents compatible with $K_{V} 10.1$ profile have been detected in several cancer cell lines. In this context, $\mathrm{K}_{\mathrm{V}} 10.1$ current is also dependent on the cell cycle, as human neuroblastoma cells synchronized in G0/G1 phase show reduced amount of Eag1 current (Meyer and Heinemann, 1998). Using a heterologous expression system, Camacho and co-workers report that $\mathrm{K}_{\mathrm{V}} 10.1$ current amplitude is consistently downregulated at the M-phase of the cell cycle. The observed electrophysiological changes could be due to reorganization of the cytoskeleton occurring during the G2/M transition (Camacho et al., 2000). 


\subsection{2 $\mathrm{K}_{\mathrm{V}} 10.1$ and cancer}

The discovery of a relation between cell cycle and $\mathrm{K}_{\mathrm{V}} 10.1$ function made this potassium channel attractive for cancer research. Soon it was shown that $\mathrm{K}_{\mathrm{V}} 10.1$ channels possess oncogenic properties. Cell lines transfected with $\mathrm{K}_{\mathrm{V}} 10.1$ acquire features typical of cancerous cells, showing faster growth rate, losing cell contact inhibition, being able to keep growing in very low serum concentrations and inducing formation of aggressive tumors when injected into immune-depressed mice (Pardo et al., 1999). Expression of currents compatible with $\mathrm{K}_{\mathrm{V}} 10.1$ was initially described in neuroblastoma (Meyer and Heinemann, 1998), and breast cancer cell lines (Ouadid-Ahidouch et al., 2001). Subsequently, a larger screening of $\mathrm{K}_{\mathrm{V}} 10.1$ expression levels (in terms of mRNA transcript and protein) was performed. Here it was confirmed that $\mathrm{K}_{\mathrm{V}} 10.1$ was not (or only scantly) expressed in healthy non-neural tissue while it was aberrantly expressed in numerous cancer cell lines, and in over $70 \%$ of the tested human cancer tissues from diverse origin (Hemmerlein et al., 2006; Mello de Queiroz et al., 2006). Based on their restricted expression pattern in normal tissue, combined with their high expression in cancer, $\mathrm{K}_{\mathrm{V}} 10.1$ channels have been proposed as potential candidate as early cancer biomarker (Farias et al., 2004; Pardo and Stühmer, 2008; Rodríguez-Rasgado et al., 2012).

$\mathrm{K}_{\mathrm{V}} 10.1$ pharmacological blockade with astemizole and imipramine decreases tumor cell proliferation in vitro (Ouadid-Ahidouch et al., 2001; Gavrilova-Ruch et al., 2002) and, in the case of astemizole, also in vivo: in mouse models, oral doses of astemizole (far below the toxicity range of the compound) reduce the progression of subcutaneous tumors (melanoma, pancreas and mammary carcinomas) and the frequency of metastasis in lung carcinoma models, with a potency comparable to the maximal tolerable dose of cyclophosphamide, an established chemotherapeutic compound (Downie et al., 2008). Additional strategies, more specific than the available pharmacological tools, for the inhibition of the expression and/or function of $\mathrm{K}_{\mathrm{V}} 10.1$ have also been successfully developed. Interfering-RNA against $\mathrm{K}_{\mathrm{V}} 10.1$ transcript leads to a reduction in proliferation in cell lines expressing this channel (Weber et al., 2006). Moreover, a monoclonal antibody specifically targeting the pore region of the channel and blocking its function, inhibits tumor cell growth both in vitro and in vivo (Gómez- 
Varela et al., 2007). Another promising approach aiming treatment of $\mathrm{K}_{\mathrm{V}} 10.1$-positive tumors combines the specificity of a single chain antibody targeting $\mathrm{K}_{\mathrm{V}} 10.1$ with the potency of TRAIL (tumor necrosis factor-related apoptosis-inducing ligand), an apoptosis-inducing molecule. This fusion protein successfully induced apoptosis selectively to tumor cells, leaving alive the surrounding non-cancer cells (Hartung et al., 2011).

The contribution of $\mathrm{K}_{\mathrm{V}} 10.1$ channels to tumorigenesis is not completely dependent on its function as ion channel. Engineered $K_{V} 10.1$ channels bearing a mutation in the pore region that cancels ion permeation are still capable of increasing cell proliferation and tumor growth in immune-deficient mice, emphasizing a non-canonical function for these channels. Recent reports provide additional evidence for $\mathrm{K}_{\mathrm{V}} 10.1$ non-canonical function in cancer. Conformational changes of the voltage sensor of the channel may activate of p38 MAPK kinases signaling, a critical pathway modulating cell proliferation (Hegle et al., 2006). $\mathrm{K}_{\mathrm{V}} 10.1$ expression in mammalian cells results in increased secretion of VEGF (vascular endothelial growth factor), providing an increased vascularization to the $\mathrm{K}_{\mathrm{V}} 10.1$-positive tumor miroenvironment. Moreover, an increased HIF-1 (hypoxia-inducible factor 1) transcription factor activity, activating many genes promoting cell survival under hypoxic conditions has been detected in $\mathrm{K}_{\mathrm{V}} 10.1$ expressing cells (Downie et al., 2008). $\mathrm{K}_{\mathrm{V}} 10.1$ channels are also expressed at the inner nuclear membrane, where their amino- and carboxyl- terminal region exposed to the nucleoplasm could interact with heterochromatin, modulating accordingly gene expression (Chen et al., 2011).

\subsection{Alternative splicing}

pre-mRNA splicing represents a crucial step in mRNA maturation: introns are removed and exons are joined together, leading to a single gene product for each transcriptional unit in a process called constitutive splicing. Proteomes are however much more complex than genomes. The human genome contains 20,000-25,000 protein-coding genes, only four times those found in the yeast Saccharomyces cerevisiae. The genome 
of Drosophila melanogaster contains fewer protein-coding genes $(\sim 14,000)$ than the apparently simpler organism Caenorhabditis elegans $(\sim 19,000)$ (International Human Genome Sequencing Consortium, 2005). A way to expand proteomic complexity without increasing the number of genes consists of generating two or more different proteins from a single gene by alternative splicing (AS) (Hui, 2009). The multiple mRNAs originated by AS from a single gene often encode structurally and functionally different proteins with specific enzymatic activity, ligand binding properties, cellular localization, protein stability and/or post-translational modifications. AS is a very common biological event, with up to $95 \%$ human multiexon genes exhibiting it (Barash et al., 2010).

The splicing reaction is catalyzed by a set of multicomponent ribonucleoprotein complexes that form the spliceosome, which recognizes the intron-exon boundaries along the pre-mRNA and catalyzes the reactions that removes introns and joins exons. Exon recognition by the spliceosome machinery is achieved through the identification of conserved intronic dinucleotides: GU at the 5' (donor) and AG at the 3' (acceptor) ends. Constitutive splicing occurs at strong splice sites, which are always recognized by the spliceosome. The exact sequence around the splicing site determines the affinities of cognate splicing factors, eventually affecting their recognition by the splicing machinery (Kornblihtt et al., 2013). Weaker sites, where the pre-mRNA sequence diverges from the consensus can promote the occurrence of alternative splicing.

The use of weak sites is regulated by RNA binding, trans-acting proteins (repressors and activators) and cis-acting regulatory sites (silencers and enhancers) on the premRNA. Exonic and intronic splicing enhancers (ESEs/ISEs) promote exon recognition, while exonic and intronic splicing silencers (ESSs/ISSs) reduce the probability that a neighbouring site is used as a splice junction (Matlin et al., 2005). The majority of splicing repressors are heterogeneous nuclear ribonucleoproteins (hnRNPs) and polypyrimidine tract binding protein (PTB). Most of the activator proteins that bind to ESEs are members of the SR protein family. Such proteins contain RNA recognition motifs and arginine and serine-rich (SR) domains. Although commonly considered as repressors, individual hnRNPs can also promote the usage of alternative splice sites, mainly through ISEs (Matlin et al., 2005). Moreover, additional RNA binding proteins can function as splicing regulators by binding ISSs or ISEs (Lewin et al., 2011). The 
coordinated expression and/or activity of splicing trans-acting proteins determines the composition of the pool of protein isoforms in a given cell type, developmental stage etc. Adding further complexity to this system, the effects of regulatory factors are sometimes position-dependent. For example, a splicing factor can be an activator when bound to an intronic enhancer element, and a repressor when bound to an exon (Lim et al., 2011). Alternative exon usage is also modulated by secondary structure of the premRNA (Warf and Berglund, 2010), transcriptional rates of RNA polymerase II, chromatin structure and modifications (Kornblihtt et al., 2013).

The relative positions of weak and strong sites may give rise to different modes of alternative splicing, as summarized in Fig. 5. One or more exons can be either included or excluded from the final transcript (exon skipping); an alternative 3' and 5' splice sites can favor the lengthening or shortening of a particular exon; a portion of an intron can be included in the final transcript (intron retention). Exon skipping is the most common mechanism of AS, accounting for $\sim 40 \%$ of the entire alternative splicing events (Keren et al., 2010).

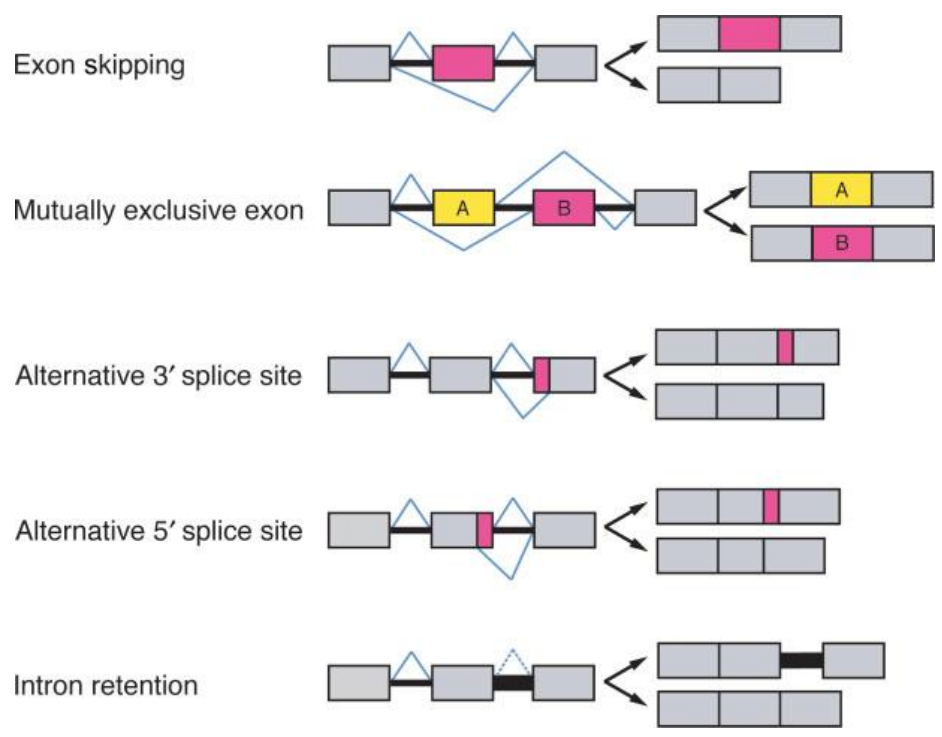

Figure 5 Mechanisms of alternative splicing. Schematic representation of different strategies of AS. Grey boxes represent exons; the black lines joining them are introns. The blue lines indicate the splicing sites. Figure from Liu and Cheng, 2013. 


\subsubsection{Impact of pre-mRNA splicing in disease}

Due to the complexity of the alternative splicing mechanism, mutation may occur at different levels along the splicing reaction and modify the splicing pattern. Mutations involving cis-acting regulatory sites along the pre-mRNA sequence can disrupt the normal splicing patterns or activate alternative splice patterns in an inappropriate tissue or developmental stage, as is the case of familial isolated growth hormone deficiency type II, where an increased alternative splicing of the growth hormone gene results in short stature (Binder et al., 1996). Mutations in components of the spliceosome or in their auxiliary factors cause retinitis pigmentosa (loss of rod photoreceptors)(Faustino and Cooper, 2003), or spinal muscular atrophy (loss of spinal cord motorneurons resulting in skeletal muscle denervation) (Kolb et al., 2007). Changes in alternative splicing patterns are also associated with neoplasia and metastasis (Philips and Cooper, 2000), as is the case of CD44 in pancreatic ductal carcinoma (Günthert et al., 1991), NF1 in neurofibromatosis (Ars et al., 2000), BRCA1 and BRCA2 in ovary and breast cancer (Claes et al., 2003), or the oncogene MDM2 (Bartel et al., 2002).

Manipulation of alternative splicing may open new therapeutic avenues. Isoformspecific antisense oligonucleotides and interference RNAs have been developed and tested for the treatment of several diseases, ranging from certain types of thalassemia and dystrophies, to cystic fibrosis, cancer, and pain (Forte et al., 2005; Sazani and Kole, 2003). Bifunctional oligonucleotides that bind specific regions of pre-mRNAs and then modify splicing mechanism via an antisense-targeting domain can enhance the inclusion of exon 7 in the SMN2 transcript and reduce the severity of spinal muscular atrophy (Owen et al., 2011). Additional approaches use compounds that affect phosphorylation of splicing factors (Pilch et al., 2001), stabilize putative pre-mRNA secondary structures (Varani et al., 2000), or directly interact with spliceosome components. Two natural compounds interfering with the spliceosome (Spliceostatin A and Pladienolide) display antitumor activity in vitro and in vivo (Kaida et al., 2007; Kotake et al., 2007). 


\subsubsection{Impact of AS on ion channels physiology and pathophysiology}

Alternative splicing modulates features of several ion channels, affecting their physiology and pathophysiology. AS modulation may result in changes in electrophysiological properties, surface expression, intracellular localization and pharmacological profile of ion channels. For example, Cav1.2 have a cardiac-specific splice isoform showing less sensitivity to diltiazem, a potent vasodilator (Zhang et al., 2010). It is also known that alternative splicing in this particular channel is regulated by the PTB protein (a trans-acting splicing regulator protein), mediating a switch between two mutually exclusive exons. Mutations in either of these two exons underly the Timothy syndrome (a systemic disorder, resulting in a severe pleiotropic disease phenotype) (Tang et al., 2011). Alternative splicing in the C-terminus of Cav1.3 modulates its electrophysiological properties, and $\mathrm{Ca}_{\mathrm{V}} 1.4$ channels express 19 splice isoforms, some of them with characteristic electrophysiological behavior (Tan et al., 2011).

A naturally occurring variant of $\mathrm{Na}_{\mathrm{V}} 1.1$ recovers more rapidly from inactivation. This is thought to modify the seizure likelihood and response to anti-epileptic drugs (Fletcher, et al., 2011). The cardiac $\mathrm{Na}_{\mathrm{v}} 1.5$ channels have at least nine splice variants, which can have either unchanged electrophysiological properties, altered kinetics or produce nonfunctional channels. The distribution of the variants involves species-dependent, tissuespecific, and developmental factors (Schroeter et al., 2010).

$\mathrm{K}_{\mathrm{Ca}} 1.1$ channels represent a typical example of extensive $\mathrm{AS}$ in potassium channels. These are encoded by a large gene consisting of 35 exons; here AS leads to the production of channels with distinct properties, including differences in calcium/voltage sensitivity (Chen et al., 2005), subcellular targeting (Zarei et al., 2004) and regulation by cellular signaling pathways (Erxleben et al., 2002; McCartney et al., 2005; Tian et al., 2001). Remarkably, one of the short isoforms is not functionally expressed at the cell surface and acts as a dominant negative of cell surface expression by trapping other $\mathrm{K}_{\mathrm{Ca}} 1.1$ channel $\alpha$-subunits in the endoplasmic reticulum and perinuclear compartments (Chen et al., 2005). Similarly, in a breast cancer cell line a functionally inactive variant of $\mathrm{K}_{\mathrm{ir}} 3.1$ exerts a dominant negative effect on the full-length channel (Wagner, Stadelmayer et al., 2010). The same applies in a physiological context for $\mathrm{K}_{2 \mathrm{P}} 2.1$ 
channels in the brain (Veale et al., 2010) or to $\mathrm{K}_{\mathrm{Ca}} 3.1$ in human lymphoid tissues (Ohya et al., 2011). Two spliced isoforms of $\mathrm{K}_{\mathrm{V}} 11.1$ expressed almost exclusively in tumors form heterotetramers with the full length channels, down-regulating the current and blocking cell differentiation and inducing escape from apoptotic death (Guasti, Crociani et al., 2008).

\subsubsection{K 10.1 splice isoforms}

The human $\mathrm{K}_{\mathrm{V}} 10.1$ channel gene has eleven exons: the long $\mathrm{N}$-terminal cytoplasmic region is encoded by exons one to five; exons six and seven encode the transmembrane domains, and exons eight to eleven generate the long $\mathrm{C}$-terminal cytoplasmic region of the channel. As mentioned previously, a second $K_{V} 10.1$ splice variant $\left(K_{V} 10.1 b\right)$ was cloned in 1994, where exon 6 is spliced 81 base pairs downstream the site for the short variant (via alternative 5' splicing site), forming exon $6 \mathrm{~b} . \mathrm{K}_{\mathrm{V}} 10.1 \mathrm{a}$ and $\mathrm{K}_{\mathrm{V}} 10.1 \mathrm{~b}$ show the same expression pattern and similar electrophysiological features.

Sun and colleagues (2009) reported the expression of a Drosophila $\mathrm{K}_{\mathrm{V}} 10.1$ splice variant, in COS cells transfected with a full length $\mathrm{D}-\mathrm{K}_{\mathrm{V}} 10.1 \mathrm{cDNA}$. Such protein (that they called Eag80) contains both $\mathrm{N}$ - and C-terminal sequences of the full-length channel but lacks all channel-forming transmembrane domains. Eag80 production is stimulated by either PKA or PKC, and by calcium influx. Eag80 can activate a MAPK kinase signaling pathway affecting the cell morphology (Sun et al., 2009).

More recently two short isoforms derived from exon skipping events have been described in the human $K_{V} 10.1$ channel. They were named E65 and E70 after the predicted molecular weight of 65 and $70 \mathrm{kDa}$, respectively. E65 lacks exons from 4 to 9, while E70 is missing exon 4 to 7 (see Fig. 6). Both E65 and E70 mRNA are devoid of transmembrane domains. Therefore, they do not form a functional ion channel. E65 was cloned from tumor cell lines (Ramos Gomes $\mathrm{PhD}$ thesis) and E70 from human brain (Pardo LA, unpublished data). 


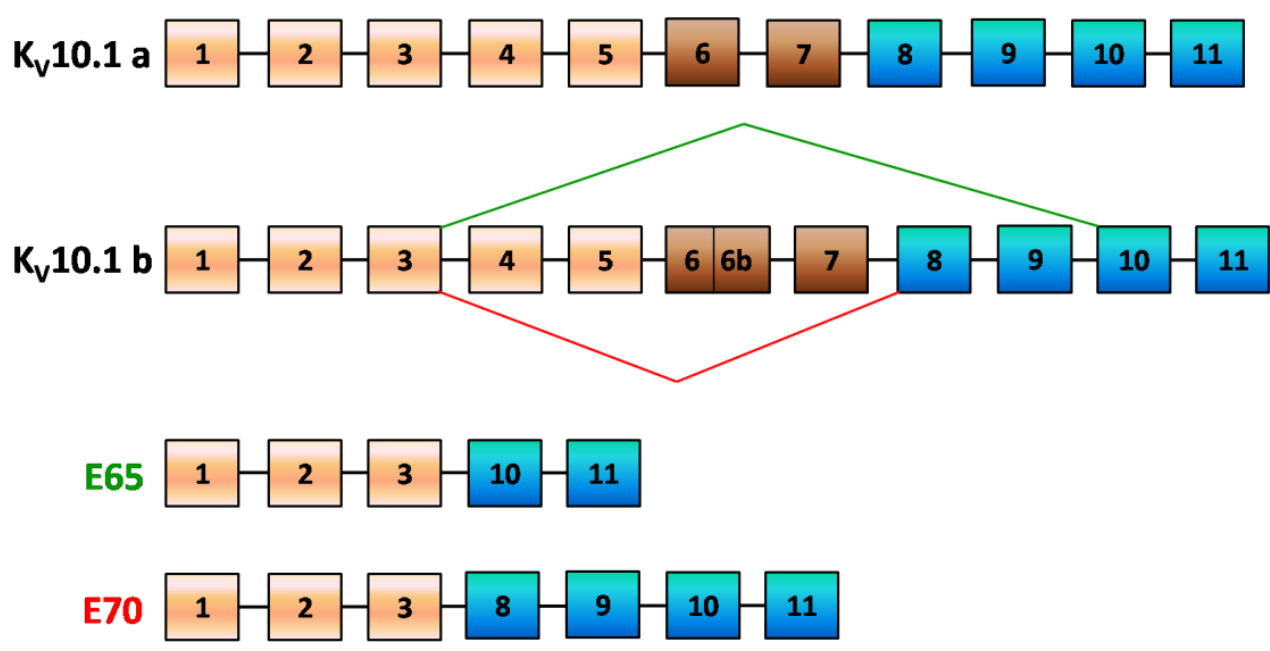

Figure 6 Exon organization of the full-length channel transcripts $K_{v} 10.1 a, K_{v} 10.1 b$, and of the truncated isoforms E65 and E70. Boxes represent exon sequences, the black line connecting them are intron sequences. More in details, orange boxes represent exons coding $\mathrm{N}$-terminal region of the channel protein; brown exons encode the transmembrane domain, blue exons the $\mathrm{C}$-terminal region. The green and red lines depicted on the $\mathrm{K}_{\mathrm{V}} 10.1 \mathrm{~b}$ sequence represent the splicing sites determining E65 and E70 expression.

Finally, it has been found that E65 modifies the electrophysiological properties of the full-length channel when both are co-expressed in Xenopus laevis oocytes. The modified current resembles the one recorded from mature oocytes. This is due to a direct activation of the maturation of the oocyte by E65, suggesting a role in cell cycle regulation for this splicing isoform (Ramos Gomes Ph.D. thesis, 2010). 


\section{Aims of the work}

\subsection{General Aim}

To study the impact of alternative splicing on $\mathrm{K}_{\mathrm{V}} 10.1$ biological properties

\subsection{Specific Aims}

To confirm the expression of $\mathrm{K}_{\mathrm{V}} 10.1$ short isoforms in native system

To check for interaction between $\mathrm{K}_{\mathrm{V}} 10.1$ and its short isoforms

To investigate the impact of E65 and E70 expression on the electrophysiological properties of $\mathrm{K}_{\mathrm{V}} 10.1$

To study the mechanisms by which E65 and E70 modulate $\mathrm{K}_{\mathrm{V}} 10.1$ electrophysiological properties 


\section{Materials and Methods}

\subsection{Cell cultures}

\subsubsection{Mammalian cell lines and media composition}

Cell lines DU 145 (ACC 261), HEK 293 (ACC 305), HeLa (ACC 57), IPC 298 (ACC 251), IGR 39 (ACC 239), IMR 32 (ACC 165), and SH-SY5Y (ACC 209) were purchased from DSMZ (Braunschweig, Germany). MDA-MB 435S (HTB 129) were from ATCC (Manassas, VA, USA), PNT 2 (ECACC95012613) were obtained from ECACC (Salisbury, UK). GL15 cells were kindly provided by Dr. Fioretti (University of Perugia, Italy). Each cell line was propagated and maintained according to the provider's instructions: HEK 293 cells were maintained in Dulbecco's MEM/F12 1:1 (Gibco) supplemented with 10\% FCS (PAA); DU 145, PNT 2 and GL 15 in Dulbecco's MEM (Gibco) with 10\% FCS; HeLa, IPC 298, MDA-MB 435S and SH-SY5Y in RPMI 1640 (Gibco) with 10\% FCS. IMR 32 cells were cultured in RPMI 1640 complemented with non-essential amino acids (Gibco) and 20\% FCS; IGR 39 in Dulbecco's MEM with $15 \%$ FCS. The culture medium of the stably transfected HEK-pTRACER-K 10.1 cells was complemented with the antibiotic Zeocin (Invivogen) at a concentration of $3 \mu \mathrm{g} / \mathrm{ml}$.

\subsubsection{Cell cultures: routine handling}

Cells were routinely grown in T25 or T75 flask (Sarstedt) and incubated in a Heracell $240 \mathrm{CO}_{2}$ incubator (Thermo Scientific) at $37{ }^{\circ} \mathrm{C}$ and $5 \% \mathrm{CO}_{2}$. As cells reached $\sim 90 \%$ confluence, the culture medium was removed, and cells were firstly washed once with $10 \mathrm{ml}$ Phosphate Buffered Saline (PBS, Gibco), then $2 \mathrm{ml}$ Trypsin/EDTA solution $\left(0.05 \% / 0.2 \%(w / v)\right.$ in PBS without $\mathrm{Ca}^{2+} / \mathrm{Mg}^{2+}$, Biochrom) were added. Cells were then maintained for $4 \mathrm{~min}$ in the incubator, subsequently resuspended in $5 \mathrm{ml}$ culture medium and placed in a sterile centrifuge tube (Greiner Bio One) and finally centrifuged $2 \mathrm{~min}$ at $1,200 \mathrm{x} g$ at room temperature (RT). The supernatant was carefully 
removed and cell pellets were thoroughly resuspended in a suitable amount of fresh culture medium (usually 3-5 ml), according to the desired dilution, and seeded in new vessels. When needed, cells were counted using a Neubauer chamber: $10 \mu 1$ of cells resuspension were added to $30 \mu \mathrm{l}$ Trypan Blue solution (0.4\% in PBS, Sigma). Unstained (viable) cells in each of four large squares of the chamber were counted. The total number of live cells for each $\mathrm{ml}$ medium is represented by the number of counted cells multiplied by $1 \times 10^{4}$. When needed, cells were frozen according to the following procedure: the pellet derived from $\sim 1 \times 10^{6}$ trypsinized cells was resuspended in $500 \mu 1$ culture medium and added to a cryovial (Greiner Bio One) containing $500 \mu 1$ of freezing medium (50\% DMEM/F12; 25\% FCS; 25\% DMSO (Sigma)), which was immediately placed in a freezing container (Nalgene) and stored for 24 hours at $-80{ }^{\circ} \mathrm{C}$. Cells were then stored indefinitely in liquid nitrogen. To start a culture from frozen cells, cryovials were incubated $5 \mathrm{~min}$ at $37^{\circ} \mathrm{C}$; their content was added to a centrifuge tube containing $10 \mathrm{ml}$ of pre-warmed growth medium and centrifuged at $1,000 \times \mathrm{g}$ for $3 \mathrm{~min}$. The obtained cell pellet was resuspended and placed in a new vessel. The medium was replaced after 24 hours in order to eliminate any eventual DMSO residue.

\subsubsection{Transfections}

For all the experiments of this work two transfection modalities were employed: liposome-based (Lipofectamine 2000, Invitrogen) and electroporation technology (Nucleofector, Lonza). 80-90\% confluent cells cultivated in T25 flasks were generally used for Lipofectamine transfections. Briefly, tube A (containing 12.5 $\mu 1$ Lipofectamine in $250 \mu \mathrm{l}$ Opti-MEM (Gibco)) and tube B (containing $5 \mu \mathrm{g}$ DNA in $250 \mu \mathrm{l}$ Opti-MEM) were incubated $5 \mathrm{~min}$ at RT. Afterwards the content of A was added to tube B, followed by another 20 min RT incubation. In the meanwhile cells were washed in PBS and the growth medium was replaced with $3.5 \mathrm{ml}$ Opti-MEM medium. To the cells were finally added $520 \mu 1$ of the mixture Lipofectamine-DNA (proportion 2.5:1) in Opti-MEM and they were incubated for 5 hours. After this time the flask content was replaced with $4 \mathrm{ml}$ of growth medium. Regarding electroporation-based transfections, cells at 80-90\% confluence and grown on T25 or T75 flasks were trypsinized, washed once in PBS, counted and centrifuged. For each transfection $100 \mu$ nucleofection solution (solution 
$\mathrm{V}$, proprietary composition) and $4 \mu \mathrm{g}$ plasmidic DNA were added to $1-2 \times 10^{6}$ cells, and a current pulse (program A-23 for HEK cells, G-04 for SH-SY5Y cells) was applied to the mixture cells-DNA. Cells were finally plated at a suitable density in the chosen vessel. Transfection efficiency ranged between $30 \%$ and $90 \%$ depending on the cell type, transfection method, and sequence of plasmidic DNA. Transfected cells were used for further experiments 24-72 hours after transfections.

\subsubsection{Xenopus laevis oocyte preparations}

Oocytes were obtained by survival surgical laparotomy from anesthetized (tricaine $0.2 \%$ ) Xenopus laevis frogs (purchased from Nasco). They were defolliculated under collagenase digestion: oocytes were incubated for two hours with shaking motion at 18 ${ }^{\circ} \mathrm{C}$ in a solution containing $1.4 \mathrm{mg} / \mathrm{ml}$ collagenase (SERVA) diluted in calcium-free Barth's medium (88 mM NaCl; $1 \mathrm{mM} \mathrm{KCl} ; 2.4 \mathrm{mM} \mathrm{NaHCO}_{3} ; 0.82 \mathrm{mM} \mathrm{MgSO}$; 7.5 $\mathrm{mM}$ Tris- $\mathrm{HCl}, \mathrm{pH}$ 7.5). The oocytes were rinsed several times with calcium-free Barth's medium, then washed with Barth's medium including calcium (Barth-medium calciumfree complemented with $0.33 \mathrm{mM} \mathrm{Ca}\left(\mathrm{NO}_{3}\right)_{2}, 0.41 \mathrm{mM} \mathrm{CaCl}$ and $0.1 \mathrm{mM}$ gentamicin (Roth)). Oocytes were finally kept in ND96 medium (96mM NaCl; $2 \mathrm{mM} \mathrm{KCl} ; 0.2 \mathrm{mM}$ $\mathrm{CaCl}_{2} ; 2 \mathrm{mM} \mathrm{MgCl}$; $5 \mathrm{mM}$ HEPES; $0.5 \mathrm{mM}$ teophylline (Sigma), $0.1 \mathrm{mM}$ gentamicin, $\mathrm{pH}$ 7.5) and incubated at $18{ }^{\circ} \mathrm{C}$ (Memmert incubator). Stage VI oocytes were sorted and used for downstream applications within 24 hours after the preparation. $50 \mathrm{nl}$ cRNA solutions (corresponding to 0.025 - $1 \mathrm{ng}$ cRNA) were injected into each oocyte using a Nanoject and 3.5 inches long glass pipettes (both from Drummond); after this process, only oocytes with homogenous pigmentation and normal turgor were collected. All the experiments were performed between 24 and 72 hours after injections. 


\subsection{Molecular biology}

\subsubsection{Total RNA isolation.}

Cells in culture were trypsinized and counted as previously described. Aliquots of $\leq 5 \times 10^{6}$ cells were centrifuged at 1,200 $\mathrm{x} g$ for 2 min RT; supernatant was removed and the pellets were washed with $5 \mathrm{ml}$ PBS and centrifuged again at 1,200 $\mathrm{x} g$ for 2 min RT. Pellets derived from this process were immediately placed on ice and stored at $-80^{\circ} \mathrm{C}$ or directly processed to extract total RNA. In the latter case cells were lysed with $350 \mu 1$ RLT buffer (Qiagen) complemented with $143 \mathrm{mM}$ of $\beta$-mercaptoethanol (Sigma). The lysates were passed several times through a 25-gauge needle. To homogenize and eliminate insoluble debris from the lysates, these were placed in QIAshredder spin columns (Qiagen) and centrifuged 2 min at top speed (16,100 x $g$; all the centrifugations of this protocol were performed in a benchtop microcentrifuge at RT). Homogenized lysates were mixed with 1 volume of $70 \%$ ethanol in DEPC-treated water, loaded onto RNeasy Mini spin columns (Qiagen) and centrifuged 30s at 11,000 x $\mathrm{g}$. The flowthrough was discarded and the RNA binding the silica-gel membrane of the column was washed with $350 \mu \mathrm{l}$ of RW1 buffer and centrifuged 30s at 11,000 x $\mathrm{g}$. RNA samples were then treated with RNase free DNase (Qiagen) in order to eliminate genomic DNA. For each sample a solution containing $20 \mu \mathrm{l}$ (54 Kunitz units) of DNase and $140 \mu \mathrm{l}$ RDD buffer (supplied with the RNase-Free DNase Set) was prepared. $160 \mu$ of this solution were pipetted into the columns and incubated 30 min RT. Then $350 \mu 1$ of RW1 were added and, after further 5 min incubation, the samples were centrifuged $30 \mathrm{~s}$ at $11,000 \times \mathrm{g}$. Then, $500 \mu \mathrm{l}$ RPE buffer were added to the columns and centrifuged $30 \mathrm{~s}$ at $11,000 \times \mathrm{g}$; a second wash with $500 \mu \mathrm{l}$ RPE buffer was followed by $6 \mathrm{~min}$ centrifugation at top speed in order to dry the columns. These were incubated with $30 \mu 1$ DEPC-treated water for 6 min at RT and finally centrifuged again $6 \mathrm{~min}$ at top speed in order to elute RNA. The RNA amount and quality were assessed by spectrophotometric measurements (Nanophotometer, Implen): only RNA samples having $\mathrm{A}_{260} / \mathrm{A}_{280}$ and $\mathrm{A}_{260} / \mathrm{A}_{230} \geq 1.9$ were used for downstream applications. 


\subsection{2 mRNA isolation}

For isolation of mRNA, the Micro-FastTrack 2.0 Kit (Invitrogen) was used. Up to 500 $\mu \mathrm{g}$ of total RNA per sample were precipitated adding $1 / 10$ vol sodium acetate $5 \mathrm{M}$ and 2.5 vol ice-cold Ethanol $100 \%$. The samples were stored $60 \mathrm{~min}$ at $-20{ }^{\circ} \mathrm{C}$, then centrifuged 15 min at $4{ }^{\circ} \mathrm{C}$ top speed $(16,100 \times g)$. RNA pellets were washed once with $70 \%$ ethanol, and resuspended in $10 \mu \mathrm{l}$ Elution Buffer $(10 \mathrm{mM}$ Tris- $\mathrm{HCl}, \mathrm{pH} 7.5$ in DEPC-treated water). The solution was added to $1 \mathrm{ml}$ Binding Buffer (500 mM NaCl, $10 \mathrm{mM}$ Tris-HCl, $\mathrm{pH} 7.5$ in DEPC-treated water), heated up to $65{ }^{\circ} \mathrm{C}$ for $5 \mathrm{~min}$ and placed immediately on ice for $1 \mathrm{~min}$. The solution containing RNA was pipetted onto a vial of oligo(dT) cellulose. The tube was tightly sealed, allowing the oligo(dT) cellulose to swell for $2 \mathrm{~min}$. After that, it was incubated under rocking at room temperature for 20 $\min$. The oligo $(\mathrm{dT})$ cellulose was then centrifuged at $4,000 \times g$ in a microcentrifuge for $5 \mathrm{~min}$ at RT. The supernatant was carefully removed from the resin bed. The oligo(dT) cellulose was resuspended in $1.3 \mathrm{ml}$ Binding Buffer $(500 \mathrm{mM} \mathrm{NaCl}, 10 \mathrm{mM}$ Tris- $\mathrm{HCl}$, $\mathrm{pH} 7.5$ in DEPC $-\mathrm{H}_{2} \mathrm{O}$ ) and centrifuged again at $4,000 \times g$ for 5 min at RT. This washing step was repeated four more times, until the buffer appeared no longer cloudy. The resin was subsequently resuspended in $300 \mu$ l Binding Buffer, transferred to a spin column and centrifuged at $4,000 \times g$ for $30 \mathrm{~s}$ at RT. The latter resuspension/centrifugation step was repeated four more times. The resin was finally resuspended in $200 \mu$ Low Salt Wash Buffer (250 mM NaCl, $10 \mathrm{mM}$ Tris-HCl, pH 7.5 in DEPC-treated water) and centrifuged at $4,000 \times g$ for 30 s at RT. This last step was repeated once. The spin column was then placed into a new RNase-free microcentrifuge tube and $100 \mu$ Elution Buffer (10 mM Tris-HCl, pH 7.5 in DEPC-treated water) was mixed into the cellulose bed and centrifuged at $4,000 \times g$ for 30 s at RT. A second aliquot of $100 \mu$ l Elution Buffer was added to the column, mixed into the cellulose, and centrifuged again 30s at RT. In order to collect any remaining eluate, a centrifugation at 4,000 $\times g$ for $1 \mathrm{~min}$ at RT was performed. The eluted mRNA was precipitated with $10 \mu \mathrm{l}$ of $2 \mathrm{mg} / \mathrm{ml}$ glycogen carrier, $30 \mu \mathrm{l}$ of $2 \mathrm{M}$ sodium acetate, and $600 \mu \mathrm{l}$ of $100 \%$ ethanol. The samples were placed on dry ice for $20 \mathrm{~min}$, then centrifuged at maximum speed for $15 \mathrm{~min}$ at $4{ }^{\circ} \mathrm{C}$. The supernatant was carefully removed and discarded. The pellet was washed with $70 \%$ ethanol. The ethanol was removed, and the pellet was air-dried for 5-10 min. the mRNA pellet was finally resuspended in $10 \mu$ Elution Buffer (10 mM Tris-HCl, pH 7.5 
in DEPC-treated water). mRNA amount and purity were assessed by means of spectrophotometric measurements.

\subsubsection{Capped RNA (cRNA) synthesis}

This was obtained performing in vitro transcription using the T7 mMessage mMachine Kit (Ambion). pSGEM vector containing the gene of interest was linearized with SfiI (as described in 3.2.6.1). The digestion was terminated by adding $1 / 20$ vol $0.5 \mathrm{M}$ EDTA, $1 / 10$ vol $3 \mathrm{M}$ sodium acetate and 2 vol of $100 \%$ ethanol. The samples were mixed thoroughly and chilled at $-20{ }^{\circ} \mathrm{C}$ for one hour. DNA was then precipitated at $16,100 \mathrm{x} \mathrm{g}$ for $15 \mathrm{~min}$ at $4{ }^{\circ} \mathrm{C}$. The supernatant was removed, the tubes were recentrifuged for a few seconds, and the residual supernatant was disposed. Pellets were air-dried for $7 \mathrm{~min}$ and resuspended in a volume of TE buffer adequate to obtain a final DNA concentration of $0.5-1 \mu \mathrm{g} / \mu \mathrm{l}$. The reaction of in vitro transcription was assembled at RT, adding the following components in a sterile microcentrifuge tube: DEPC-water (to $20 \mu \mathrm{l}$ final volume), $10 \mu \mathrm{l}$ 2X NTP/CAP, $2 \mu \mathrm{l}$ 10X Reaction Buffer, $1 \mu \mathrm{g}$ linear template DNA, $2 \mu \mathrm{T} 7$ Enzyme Mix. The samples were incubated for 2 hours at $37{ }^{\circ} \mathrm{C}$. cRNA was then recovered by lithium chloride precipitation: $30 \mu \mathrm{DEPC}-\mathrm{H}_{2} \mathrm{O}$ and $30 \mu \mathrm{l}$ $\mathrm{LiCl}$ Precipitation Solution (7.5 M lithium chloride, $50 \mathrm{mM}$ EDTA) were added to the samples, mixed thoroughly and chilled for one hour at $-20{ }^{\circ} \mathrm{C}$. The tubes were microcentrifuged at $16,100 \times \mathrm{g}$ for $20 \mathrm{~min}$ at $4{ }^{\circ} \mathrm{C}$ to pellet the RNA and the supernatant was carefully removed. RNA pellets were washed with $\sim 500 \mu 170 \%$ ethanol, RNA pellet were air-dried for 7 min before being resuspended in $\sim 30 \mu \mathrm{DEPC}-\mathrm{H}_{2} \mathrm{O}$. After determined the RNA concentration and purity, the samples were frozen at $-80{ }^{\circ} \mathrm{C}$.

\subsection{4 cDNA synthesis}

SuperScript First-Strand Synthesis system (Invitrogen) was used for cDNA production. $5 \mu \mathrm{g}$ total RNA were added to $0.5 \mu$ gligodT $_{12-18 \text { mer }}$ and DEPC-water, till $12 \mu 1$ total volume. The mixture was incubated $10 \mathrm{~min}$ at $70{ }^{\circ} \mathrm{C}$, then placed for $1 \mathrm{~min}$ on ice. After that, $7 \mu \mathrm{l}$ of reaction buffer composed by RT Buffer $(57 \mathrm{mM}$ Tris- $\mathrm{HCl}, 143 \mathrm{mM} \mathrm{KCl}$, 
pH 8.4), $7 \mathrm{mM} \mathrm{MgCl} 2,29 \mathrm{mM}$ DTT (DL-Dithiothreitol; Clelands reagent), $1.4 \mathrm{mM}$ dNTP mix were added to the tubes, which were incubated 5 min at $42{ }^{\circ} \mathrm{C}$. Afterwards, $200 \mathrm{U}$ SuperScript II reverse transcriptase was added to each sample, and $1 \mu 1$ of DEPC-treated water was used in the -RT control samples. All the samples were then incubated $50 \mathrm{~min}$ at $42{ }^{\circ} \mathrm{C}$, followed by $15 \mathrm{~min}$ at $70{ }^{\circ} \mathrm{C}$. $2 \mathrm{U}$ RNase $\mathrm{H}$ were also used for each tube, which were incubated for $20 \mathrm{~min}$ at $37^{\circ} \mathrm{C}$. $29 \mu \mathrm{l}$ of DEPC-water were added, in order to obtain $50 \mu \mathrm{l}$ cDNA having concentration of $0.1 \mu \mathrm{g} / \mu \mathrm{l}$.

\subsubsection{Polymerase Chain Reaction (PCR)}

PCR reactions were performed using $10 \mathrm{ng}$ template plasmidic DNA (or $100 \mathrm{ng}$ first strand cDNA), $2.5 \mu \mathrm{l} 10 \mathrm{X}$ reaction buffer (containing $20 \mathrm{mM}$ Tris- $\mathrm{HCl}, 10 \mathrm{mM}$ (NH4)2SO4, $10 \mathrm{mM} \mathrm{KCl,} 2 \mathrm{mM} \mathrm{MgSO} 4,0.1 \%$ Triton $\mathrm{X}-100, \mathrm{pH}$ 8.8; from New England Biolabs), $200 \mu \mathrm{M}$ dNTP mix (New England Biolabs), $0.2 \mu \mathrm{M}$ of each specific primers (synthesized by Sigma), 1.2 U of Taq DNA polymerase (New England Biolabs) and sterile $\mathrm{H}_{2} \mathrm{O}$, up to $25 \mu$ f final volume. The thermocycler (Mastercycler, Eppendorf) was set up using the following amplification program: 20 cycles of amplification including, after an initial denaturation step of $3 \mathrm{~min}$ at $95{ }^{\circ} \mathrm{C}, 95{ }^{\circ} \mathrm{C}$ for $30 \mathrm{~s}, 59{ }^{\circ} \mathrm{C}$ (or different temperature, depending on the $\mathrm{T}_{\mathrm{m}}$ of the primers) for $30 \mathrm{~s}, 72{ }^{\circ} \mathrm{C}$ for $3 \mathrm{~min}$. Nested PCR reactions were performed using $150 \mathrm{ng}$ first strand cDNA, $2.5 \mu \mathrm{l} 10 \mathrm{X}$ reaction buffer (containing $20 \mathrm{mM}$ Tris- $\mathrm{HCl}, 10 \mathrm{mM}$ (NH4)2SO4, $10 \mathrm{mM} \mathrm{KCl,} 2 \mathrm{mM}$ MgSO4, 0.1\% Triton X-100, $\mathrm{pH} 8.8$ ), $200 \mu \mathrm{M}$ dNTP mix, $0.2 \mu \mathrm{M}$ of each specific primers, $1.2 \mathrm{U}$ of Taq DNA polymerase and sterile $\mathrm{H}_{2} \mathrm{O}$, up to $25 \mu 1$ final volume. The thermocycler settings were as follows: 20 cycles of amplification including, after an initial denaturation step of $3 \mathrm{~min}$ at $95{ }^{\circ} \mathrm{C}, 95{ }^{\circ} \mathrm{C}$ for $30 \mathrm{~s}, 59{ }^{\circ} \mathrm{C}$ for $2 \mathrm{~min}$ and 30s, 72 ${ }^{\circ} \mathrm{C}$ for $3 \mathrm{~min}$. After this, $1 \mu \mathrm{l}$ of the product of this reaction was used as template for the second round PCR. The reaction consisted now of 35 cycles: after an initial denaturation step of $3 \mathrm{~min}$ at $95^{\circ} \mathrm{C}, 95^{\circ} \mathrm{C}$ for $30 \mathrm{~s}, 59^{\circ} \mathrm{C}$ for $2 \mathrm{~min}$ and $30 \mathrm{~s}, 72{ }^{\circ} \mathrm{C}$ for 2 min). The amplification products were loaded on a $1.2 \%$ agarose gel containing $5 \mu 1$ (for each $100 \mathrm{ml}$ gel volume) Serva DNA stain G (SERVA). Electrophoresis was performed at $100 \mathrm{~V}$ for $\sim 40 \mathrm{~min}$; the electrophoretic mobility was visualized with UV light, and the relevant DNA amplicons were purified, cloned and sequenced. 


\begin{tabular}{|l|l|}
\hline \multicolumn{1}{|c|}{ Primer name } & \multicolumn{1}{c|}{ Sequence (5' ${ }^{\prime}{ }^{\prime}$ ') } \\
\hline E70 Forward & ATT GAA AAA GTG CGG CAA AC \\
\hline E70 Reverse & GGC ACC TGG TAG AGC TTC AG \\
\hline $\mathbf{K}_{\mathbf{v}} \mathbf{1 0 . 1}$ External Forward & TGT TCG GCG GTC CAA TGA TAC TAA \\
\hline $\mathbf{K}_{\mathbf{v}} \mathbf{1 0 . 1}$ External Reverse & TCC CGG CCC CCT CTC TCA \\
\hline $\mathbf{K}_{\mathbf{v}} \mathbf{1 0 . 1}$ Internal Forward & TTG GGG AAT GCT CAG ATA GTG G \\
\hline $\mathbf{K}_{\mathbf{v}} \mathbf{1 0 . 1}$ Internal Reverse & GGC CTC ATT CTT TCG TTT CAT \\
\hline
\end{tabular}

Table 1 List of the primers used for PCR and nested PCR amplification.

Real-time PCR experiments were also performed. For this purpose a LightCycler 480 (Roche) thermocycler and the TaqMan probes system were used. Each PCR reaction consisted of $200 \mathrm{ng}$ first strand cDNA sample, $5 \mu$ l hot-start-PCR-mix (containing FastStart Taq DNA polymerase, reaction buffer, $\mathrm{MgCl}_{2}$ and dNTP mix, from Roche), 0.5 U Uracil-DNA-glycosylase (New England Biolabs), $1 \mu 1$ primer mix (containing $900 \mathrm{nM}$ forward and reverse primers, plus $250 \mathrm{nM}$ TaqMan probe) and DEPC-water, up to $10 \mu \mathrm{l}$ final volume. The oligonucleotides used are listed in table 2. PCR amplification protocol was set as follows: initial denaturation steps $\left(2 \mathrm{~min}\right.$ at $50{ }^{\circ} \mathrm{C}$ and $10 \mathrm{~min}$ at 95 ${ }^{\circ} \mathrm{C}$ ) were followed by 50 cycles made by $10 \mathrm{~s}$ at $95{ }^{\circ} \mathrm{C} ; 15 \mathrm{~s}$ at $56{ }^{\circ} \mathrm{C} ; 1 \mathrm{~min}$ at $60{ }^{\circ} \mathrm{C}$. The program ended at $40{ }^{\circ} \mathrm{C}$ for $30 \mathrm{~s}$. The resulting amplification data for each target gene were standardized to the amount of the housekeeping gene, the human transferrin receptor type 1 . 


\begin{tabular}{|c|c|c|c|}
\hline Name & Taqman probe $\left(5^{\prime}-3^{\prime}\right)$ & Primer Forward (5'-3') & Primer Reverse (5'-3') \\
\hline hEag1 & $\begin{array}{l}\text { (6-Fam-) } \\
\text { AACGTGGTTGAGGGCAT } \\
\text { CAGCAGCCT(-6-Tamra) }\end{array}$ & $\begin{array}{l}\text { TCTGTCCTGTTTGCCAT } \\
\text { ATGATGT }\end{array}$ & CGGAGCAGCCGGACAA \\
\hline E65 VR & $\begin{array}{l}\text { (6-Fam-) } \\
\text { TACAAGAAGAACAGAA } \\
\text { AAGGAGACG(-6-Tamra) }\end{array}$ & $\begin{array}{l}\text { ACTGATAAAGACACGA } \\
\text { TTGAA }\end{array}$ & $\begin{array}{l}\text { TCACATGCAGATCACA } \\
\text { GTAG }\end{array}$ \\
\hline $\begin{array}{l}\text { E70 } \\
\text { VR3 }\end{array}$ & $\begin{array}{l}(6-\text { Fam- }) \\
\text { CAAGAAGAACACACTTC } \\
\text { TCTATGCCA(-6-Tamra) }\end{array}$ & $\begin{array}{l}\text { TGA CTG ATA AAG ACA } \\
\text { CGA TTG A }\end{array}$ & $\begin{array}{l}\text { CATACATCTGTTGGAA } \\
\text { AATAGTC }\end{array}$ \\
\hline $\begin{array}{l}\text { hTransf } \\
\text {-errin } \\
\text { receptor }\end{array}$ & $\begin{array}{l}\text { (Joe-) } \\
\text { TGAATGGCTAGAGGGTA } \\
\text { CCTTTCGTCCC(-6-Tamra) }\end{array}$ & $\begin{array}{l}\text { GACTTTGGATCGGTTGG } \\
\text { TGC }\end{array}$ & $\begin{array}{l}\text { CCAAGAACCGCTTTAT } \\
\text { CCAGAT }\end{array}$ \\
\hline
\end{tabular}

Table 2 List of the TaqMan probes and primers used for real-time PCR. The human transferrin receptor was used to control for RNA integrity.

\subsubsection{Cloning}

DNA derived from nested PCR experiment possess A-overhanging ends which, after purification, can be easily cloned into pGEM-T vector (Promega), having Toverhanging ends and provided in linearized state by the manufacturer. In the other cases the cloning procedure implies digestion using one or more restriction enzymes (NEB) and purification of the products before performing the ligation.

\subsubsection{Restriction enzyme digestion}

All the digestions were performed using restriction enzymes and reaction buffers provided by New England Biolabs. $8 \mu \mathrm{g}$ DNA from vector and insert plasmids were digested with 1-2 $\mu 1$ restriction enzyme(s), together with the appropriate buffer. The following component were added to a sterile tube placed on ice: $8 \mu \mathrm{g}$ DNA template to digest, 1-2 $\mu$ l enzyme(s), $3 \mu \mathrm{l}$ buffer; $\mathrm{dH}_{2} \mathrm{O}$ up to a final volume of $30 \mu \mathrm{l}$. Time and temperature of incubation were depending on the type of enzymes used. 


\subsubsection{Dephosphorylation}

It was necessary to perform dephosphorylation in order to avoid recircularization of the plasmid if the enzymes would generate compatible ends after digestion. For this, the tubes were heated to $65{ }^{\circ} \mathrm{C}$ for $20 \mathrm{~min}$ in order to inactivate the enzymes after the digestion; subsequently $3.45 \mu \mathrm{l}$ of 10X Antartic Phosphatase Buffer and $1 \mu$ l Antartic phosphatase enzyme (New England Biolabs) were added. Finally the tubes were incubated $20 \mathrm{~min}$ at $37^{\circ} \mathrm{C}$ (60 min if the restriction enzyme leaved $3^{\prime}$ extensions) and heat-inactivated $5 \mathrm{~min}$ at $70{ }^{\circ} \mathrm{C}$. All the digestion products were run on a $0.8 \%$ agarose gel containing Serva DNA stain G for $\sim 40$ min at $100 \mathrm{~V}$, excised using a clean scalpel under UV light, and collected in a sterile tube for the purification.

\subsubsection{DNA purification}

The fragment of agarose gel containing the amplified DNA of interest or the digested DNA was weighted, and either stored at $+4{ }^{\circ} \mathrm{C}$ or processed immediately for DNA purification. For this purpose, the NucleoSpin Extract II kit (Macherey Nagel) was employed. To start, $200 \mu \mathrm{l}$ of NTI binding buffer provided with the kit was added for each $100 \mathrm{mg}$ gel containing the DNA. The mixture was incubated $10 \mathrm{~min}$ at $50{ }^{\circ} \mathrm{C}$ and vortexed at intervals of two minutes in order to facilitate the agarose melting. The content of the tube was pipetted into a NucleoSpin column and centrifuged $30 \mathrm{~s}$ at $11,000 \times g$ (all the centrifugations of this protocol were performed at RT). Subsequently, $700 \mu 1$ of buffer NT3 were added to the column and centrifuged again; this washing/centrifugation step was repeated one more time before performing a final centrifugation $3 \mathrm{~min}$ at $16,100 \mathrm{x} g$ in order to dry the silica membrane. The NucleoSpin column was then placed in a sterile microcentrifuge tube. Depending on the expected amount of DNA recovered, $20-30 \mu 1 \mathrm{NE}$ buffer ( $5 \mathrm{mM}$ Tris- $\mathrm{HCl}, \mathrm{pH} 8.5$ ) were added to the silica membrane; the columns were incubated for $3 \mathrm{~min}$ and afterwards centrifuged 3 min at $16,100 \times g$ to elute DNA. The quality and amount of the purified DNA were

estimated loading $1 \mu \mathrm{l}$ of the eluted in a $1 \%$ agarose gel and performing densitometry analysis: after electrophoretic run performed for $\sim 40 \mathrm{~min}$ at $100 \mathrm{~V}$, gel was exposed under UV illumination and, using the software Quantity One (Bio-Rad), the amount of 
signal derived from the purified DNA was compared to the one from DNA band at $3 \mathrm{~kb}$ (containing $125 \mathrm{ng}$ DNA) of the $1 \mathrm{~kb}$ ladder (New England Biolabs).

\subsubsection{Ligation}

A mass ratio 1/3 between vector DNA and insert DNA was generally used for ligation. The enzyme used was T4 ligase (New England Biolabs). As an example, in a sterile microcentrifuge tube were added $1 \mu \mathrm{l}$ of 10X T4 DNA Ligase buffer (50 mM Tris-HCl, $10 \mathrm{mM} \mathrm{MgCl} 2,10 \mathrm{mM}$ Dithiothreitol, $1 \mathrm{mM}$ ATP, pH 7.5), 0.05 pmol pGEM-T vector DNA having $3 \mathrm{~kb}$ length, $0.15 \mathrm{pmol}$ of a purified DNA fragment $1 \mathrm{~kb}$ long and autoclaved water, reaching $10 \mu \mathrm{l}$ final volume. The reaction was carried out incubating samples at $16^{\circ} \mathrm{C}$ overnight.

\subsubsection{Transformation}

Competent DH5 $\alpha$ E. coli (Life technology) were thawed on ice and $5 \mu$ DNA from ligation samples was added to them. Cells were incubated on ice for $30 \mathrm{~min}$, heatshocked for exactly $45 \mathrm{~s}$ at $42{ }^{\circ} \mathrm{C}$, then placed back on ice for additional $2 \mathrm{~min}$. After this, $200 \mu \mathrm{LB}$ medium (Luria Bertani broth: 1\% Peptone 140; 0.5\% Yeast extract; $1 \%$ $\mathrm{NaCl}$; from Invitrogen) were added to the tubes, which were subsequently incubated at $300 \mathrm{rpm}$ at $37{ }^{\circ} \mathrm{C}$ for one hour. The transformed bacteria were spread on pre-warmed LB-agar plates containing ampicillin $(100 \mu \mathrm{g} / \mathrm{ml})$ or kanamycin $(50 \mu \mathrm{g} / \mathrm{ml})$ and eventually containing X-Gal $20 \mathrm{mg} / \mathrm{ml}$ and IPTG $100 \mathrm{mM}$ for the blue/white selection of the colonies. The plates were incubated overnight at $37^{\circ} \mathrm{C}$.

\subsubsection{Small scale plasmid DNA preparation (Mini-prep)}

NucleoSpin Plasmid QuickPure kit (Macherey Nagel) was used in order to isolate small scale plasmid DNA from transformed competent bacteria. A single transformed colony was added to a tube containing $5 \mathrm{ml}$ LB medium complemented with ampicillin (100 $\mu \mathrm{g} / \mathrm{ml})$ or kanamycin $(50 \mu \mathrm{g} / \mathrm{ml})$ and incubated overnight in an orbital shaker at $200 \mathrm{rpm}$ $37{ }^{\circ} \mathrm{C}$. The tube was then centrifuged at $5,000 \times \mathrm{g}$ for $10 \mathrm{~min}$ at $4{ }^{\circ} \mathrm{C}$. The supernatant was discarded and the pellet was resuspended in $250 \mu$ resuspension buffer provided 
with the kit (A1) and transferred to a microcentrifuge tube. Subsequently $250 \mu \mathrm{l}$ buffer lysis buffer (A2) were added and the content of the tube was gently mixed by inverting it 8 times. After 5 min incubation RT, $300 \mu$ neutralization buffer (A3) were further added, the tube was inverted again 8 times and then centrifuged at 11,000 $\mathrm{x} g$ for $5 \mathrm{~min}$ at RT. The supernatant was placed in a NucleoSpin Plasmid QuickPure column previously mounted on a collection tube and centrifuged for $1 \mathrm{~min}$ at 11,000 $\mathrm{x} g \mathrm{RT}$. The flow-through was discarded and $450 \mu \mathrm{l}$ wash buffer (AQ) were added; a centrifuge of $3 \mathrm{~min}$ at $11,000 \times \mathrm{g}$ RT was performed in order to wash and dry the column, which was then placed on top of a sterile microcentrifuge tube. $30 \mu$ lelution buffer (AE, $5 \mathrm{mM}$ Tris- $\mathrm{HCl}, \mathrm{pH} 8.5$ ) were added, and then finally the tube was incubated for 2 min at RT and centrifuged at 11,000 $\mathrm{x} g$ for $2 \mathrm{~min}$ at RT. Amount and purity of the eluted DNA was assessed by spectrophotometric analysis.

\subsubsection{Endotoxin-free plasmid DNA preparation}

Endotoxin-free plasmidic DNA for transfection of mammalian cells was obtained using NucleoBond Xtra Midi EF kit (Macherey Nagel). A single transformed colony was added to a tube containing $5 \mathrm{ml} \mathrm{LB}$ medium complemented with ampicillin $(100 \mu \mathrm{g} / \mathrm{ml})$ or kanamicin $(50 \mu \mathrm{g} / \mathrm{ml})$ and incubated 6-8 hours in an orbital shaker at $200 \mathrm{rpm} 37{ }^{\circ} \mathrm{C}$. This starter culture was subsequently diluted in a flask containing $100 \mathrm{ml}$ LB medium complemented with the appropriate antibiotic and incubated overnight in an orbital shaker at $220 \mathrm{rpm} 37^{\circ} \mathrm{C}$. Each culture was subdivided in $2 \times 50 \mathrm{ml}$ tubes, which were centrifuged at $5,000 \times \mathrm{x}$ for $10 \mathrm{~min}$ at $4{ }^{\circ} \mathrm{C}$. Pellets were resuspended in $8 \mathrm{ml}$ resuspension buffer (RES-EF), lysed by adding $8 \mathrm{ml}$ lysis buffer (LYS-EF) and gently mixed by inverting the tubes six times. The mixture was incubated for $5 \mathrm{~min}$ at RT; in the meanwhile a filter was inserted into a NucleoBond Xtra column aiming to avoid to clog the column with insoluble cell debris. The columns was equilibrated using $15 \mathrm{ml}$ equilibration buffer EQU-EF. After the $5 \mathrm{~min}$ incubation, $8 \mathrm{ml}$ neutralization buffer (NEU-EF) was applied to the suspension, the tubes were gently mixed by inverting 12 times and incubated $5 \mathrm{~min}$ on ice before loading the whole content into the equilibrated NucleoBond Xtra Column Filter. The first wash was performed using $5 \mathrm{ml}$ washing buffer (FIL-EF), the filter was then carefully removed from the column, which was now 
washed first with $35 \mathrm{ml}$ washing buffer (ENDO-EF) and afterwards with $15 \mathrm{ml}$ washing buffer (WASH-EF). The column was allowed to empty by gravity flow and then loaded with $5 \mathrm{ml}$ elution buffer (ELU-EF): the plasmidic DNA was eluted in a sterile $15 \mathrm{ml}$ tube, precipitated using $3.5 \mathrm{ml}$ isopropanol and centrifuged at 15,000 x $\mathrm{g}$ for $30 \mathrm{~min}$ at 4 ${ }^{\circ} \mathrm{C}$. The supernatant was carefully discarded and pellet was washed with $2 \mathrm{ml} 70 \%$ ethanol and centrifuged at $15,000 \times \mathrm{g}$ for $5 \mathrm{~min}$ at $4{ }^{\circ} \mathrm{C}$. The ethanol was carefully removed from the tube and the DNA was dried for $10 \mathrm{~min}$ at RT before being reconstituted using a suitable amount of TE-EF buffer (100-300 $\mu$, depending on the pellet size, in order to obtain a final DNA concentration of $2 \mu \mathrm{g} / \mu \mathrm{l})$. Amount and purity of the eluted DNA were assessed by spectrophotometric analysis.

\subsubsection{Site-directed mutagenesis}

In order to obtain the desired point mutation (leucine was replaced with tyrosine in the TCC of $\mathrm{K}_{\mathrm{V}} 10.1$ channels), the QuikChange II XL Site-Directed Mutagenesis Kit (Agilent technologies) was used. The plasmidic DNA to be mutated was first diluted to a concentration of $5 \mathrm{ng} / \mu \mathrm{l}$. The reaction assembled in a sterile microcentrifuge tube placed on ice consisted of $10 \mathrm{ng}$ plasmidic DNA, $125 \mathrm{ng}$ of each primer L20Y F (5'AGGAGGACATCAAGGCCTACAACGCCAAAATGACCAATA-3') and L20Y R (5'-TATTGGTCATTTTGGCGTTGTAGGCCTTGATGTCCTCCT-3'), $2.5 \mu$ l 10X reaction buffer, $1.5 \mu \mathrm{l}$ QuikSolution reagent (to improve amplification efficiency), $1 \mu \mathrm{l}$

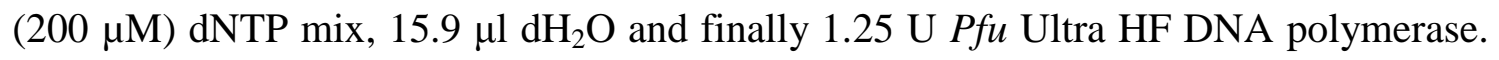
The samples were thermocycled according to the following settings: initial denaturation step of 1 min at $95{ }^{\circ} \mathrm{C}, 18$ cycles of amplification at $95{ }^{\circ} \mathrm{C}$ for $50 \mathrm{~s},, 60^{\circ} \mathrm{C}$ for $50 \mathrm{~s}, 68^{\circ} \mathrm{C}$ for $8 \mathrm{~min} 30 \mathrm{~s}$ and a final extension step at $68{ }^{\circ} \mathrm{C}$ for $7 \mathrm{~min} .3 \mu \mathrm{l}$ of the amplified sample were loaded on a $0.8 \%$ agarose gel to check whether the amplification was successful. The remaining amplified DNA was incubated $60 \mathrm{~min}$ at $37{ }^{\circ} \mathrm{C}$ with $10 \mathrm{U}$ of the restriction enzyme DpnI which digested the parental (methylated) dsDNA. $3 \mu \mathrm{l}$ of the digested DNA were used to transform an aliquot of DH5 $\alpha$ cells, as described in paragraph 3.2.6.5. In order to confirm the success of the mutagenesis, the resulting purified DNA was sequenced. 


\subsubsection{Probe preparation for RNase protection assays and in vitro transcription}

The 200 bp region spanning the area between exon 3 and exon 8 of $K_{V} 10.1$ was used as E70 probe (Fig. 7). This sequence was amplified by PCR using pcDNA3-E70Venus as DNA template and the E70 specific primers listed in table 1. The amplified E70 probe DNA was then cloned into pGEM-T and linearized using the restriction enzyme SacI HF overnight at $37^{\circ} \mathrm{C}$. These procedures are described in paragraphs 3.2.6 and 3.2.6.1. Linearized DNA was precipitated and purified as follows: $10 \mu \mathrm{l} 0.5 \mathrm{M}$ EDTA, $20 \mu \mathrm{l} 5 \mathrm{M}$ ammonium acetate and $130 \mu \mathrm{l}$ ethanol were added to a sterile tube, mixed thoroughly, and chilled one hour at $-20{ }^{\circ} \mathrm{C}$. Samples were then centrifuged at $16,100 \times \mathrm{g}$ for $15 \mathrm{~min}$ at $4{ }^{\circ} \mathrm{C}$. DNA pellet was washed in $70 \%$ ethanol, centrifuged at $16,100 \times \mathrm{g}$ for $2 \mathrm{~min}$ at $4{ }^{\circ} \mathrm{C}$. Pellet was allowed to air-dry $10 \mathrm{~min}$ and finally resuspended with 10 $\mu$ sterile, nuclease-free $\mathrm{H}_{2} \mathrm{O}$.

The reaction of in vitro transcription was carried out using the MAXIscript kit (Ambion). In parallel with the E70 probe, in each experiment a sample containing mouse actin sequence (validated probe provided by the kit supplier) was also used, as well as RNA ladder (from Ambion) to estimate the size of the probes. The in vitro transcription reaction was assembled at RT in sterile microcentrifuge tubes, consisting of $1 \mu \mathrm{g}$ template DNA (or $0.5 \mu \mathrm{g}$ RNA ladder), $2 \mu \mathrm{l} 10 \mathrm{X}$ transcription buffer; $500 \mu \mathrm{M}$ each of ATP, CTP and GTP solutions; $50 \mu \mathrm{Ci} \alpha-\left[{ }^{32} \mathrm{P}\right] \mathrm{UTP}\left(15 \mu \mathrm{Ci} \alpha-\left[{ }^{32} \mathrm{P}\right] \mathrm{UTP}\right.$ for RNA ladder), providing a final concentration of $\sim 3.125 \mu \mathrm{M}$ radiolabeled-UTP $(\sim 0.94$ $\mu \mathrm{M}$ for RNA ladder). $30 \mathrm{U}$ T7 Enzyme Mix and nuclease-free water to $20 \mu \mathrm{l}$ were finally added. The components were mixed and, after a brief centrifugation, incubated for one hour at $37^{\circ} \mathrm{C}$.

In order to digest the remaining DNA eventually present in the tubes, $2 \mathrm{U}$ TURBO DNase (included in the kit) were added to the reactions, followed by incubation $15 \mathrm{~min}$ at $37{ }^{\circ} \mathrm{C}$. $1 \mu \mathrm{l}$ of $0.5 \mathrm{M}$ EDTA solution was then added to stop the reaction. $0.5 \mu \mathrm{l}$ solution were taken from each tube and the amount of radiolabel incorporated was measured at a scintillation counter (Beckman LS 6000). One million counts-per-minute (cpm) was the threshold value indicating a satisfactory $\left[{ }^{32} \mathrm{P}\right] \mathrm{UTP}$ incorporation. Radiolabeled probes having a radioactivity level below this value were not used for downstream procedures. 
Figure 7 Nucleotide sequence of the RNA antisense probe targeting E70 transcripts. The antisense RNA sequence length is $292 \mathrm{nt}$, while the E70 probe length is $197 \mathrm{nt}) .1-51$ : T7 promoter start region and multi cloning site; 52-175: exon 8 antisense part; 176-248: exon 3 antisense part; 249-292: final part of the probe, ending with SacI-HF restriction site.

Before proceeding with ribonuclease protection assay, the freshly produced RNA probes were gel purified in order to exclude prematurely terminated transcription products, as well as unincorporated nucleotides. For this purpose, a denaturing 5\% polyacrylamide gel was prepared. In a sterile vial were added $7.2 \mathrm{~g}$ urea, $1.5 \mathrm{ml} \mathrm{10X}$ TBE solution, $1.9 \mathrm{ml} \mathrm{40 \%} \mathrm{Acrylamide} \mathrm{and} \mathrm{dH}_{2} \mathrm{O}$ to $15 \mathrm{ml}$ final volume. The mixture was stirred at RT to completely dissolved the urea, then $120 \mu 10 \%$ ammonium persulfate and $16 \mu \mathrm{l}$ TEMED were added, and immediately the gel was poured in a suitable gel cassette. After the polymerization (usually $30 \mathrm{~min}$ ) the gel was placed into an electrophoresis cell filled with TBE buffer. At the end of gel preparation, $15 \mu \mathrm{lgel}$ loading buffer II (95\% Formamide, 0.025\% xylene cyanol, $0.025 \%$ bromophenol blue, $18 \mathrm{mM}$ EDTA, $0.025 \%$ SDS) were added to the samples ( $5 \mu \mathrm{l}$ of loading buffer to $5 \mu \mathrm{l}$ the RNA ladder aliquot), heated for $3 \mathrm{~min}$ at $95{ }^{\circ} \mathrm{C}$, briefly centrifuged and finally loaded and run at $150 \mathrm{~V}$ for $\sim 45 \mathrm{~min}$. After this time, the gel was extracted from the cassette, covered with transparent plastic wrap, pasted into a X-ray cassette and exposed for 30s to a X-ray film (Fujifilm). The film was finally developed using a Curix 60 device (Agfa healthcare). The expected full-length probe sizes were 304 nucleotides (nt) for pTRI-Actin-Mouse and $292 \mathrm{nt}$ for pGEM-T E70 probe (Fig. 8 A). The areas of the gel containing full-length transcripts were excised with a scalpel, transferred to a RNase-free microfuge tube, submerged in $350 \mu \mathrm{l}$ of Probe Elution buffer $(500 \mathrm{mM}$ ammonium acetate/1 mM EDTA/ 0.2\% SDS) and incubated overnight at $37{ }^{\circ} \mathrm{C}$. Another X-ray film was exposed to the gel to ensure that the whole amount of fulllength probes had been recovered (Fig. 8 B). 

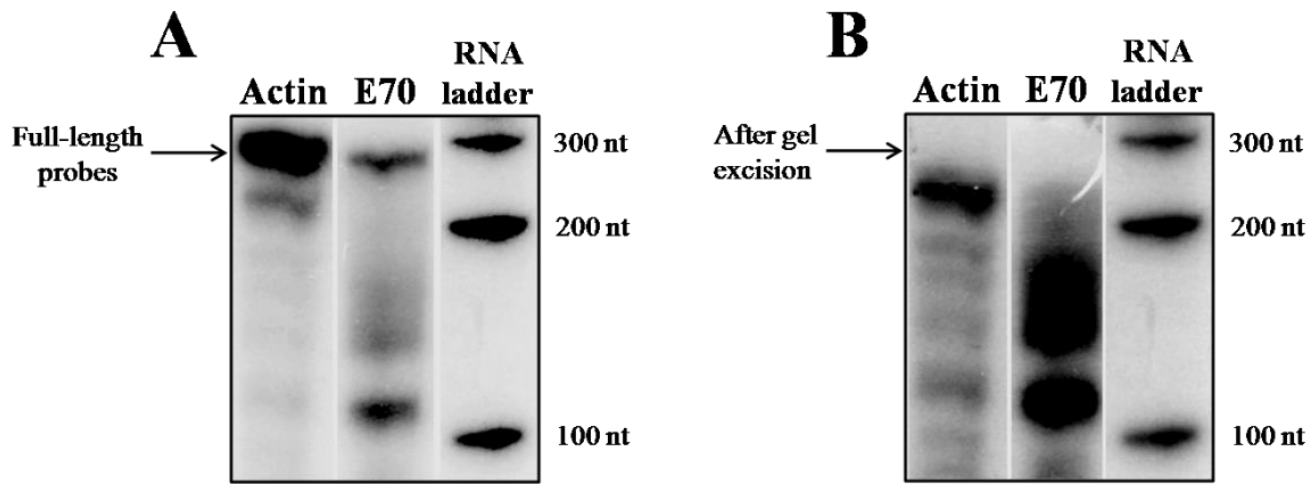

Figure 8 Gel purification of RNA probes for RNase protection assay. X-ray plate before (A) and after (B) excision of the full-length RNA probes.

Purification from unincorporated radionucleotides was performed also in RNA ladder samples, using IllustraMicroSpin G-50 columns (GE Healthcare). Briefly, the columns were prepared for the experiment as suggested by the manufacturer, subsequently $15 \mu \mathrm{l}$ of the freshly synthesized ladder were applied to the column placed upon a fresh sterile microcentrifuge tube. Purified RNA ladder was eluted by centrifugation at $735 \mathrm{x} g$ for 2 min at RT. The amount of radioactive label of the eluted RNA antisense probes and RNA ladder was assessed by scintillation counting of $1 \mu \mathrm{l}$ of each solution. The detected values were in the range between $50,000-100,000 \mathrm{cpm} / \mu \mathrm{l}$ for the probes and about $250,000-300,000 \mathrm{cpm} / \mu$ f for the RNA ladder.

\subsubsection{RNase Protection Assay (RPA)}

RPA experiments were performed using the RPA III kit (Ambion). Each experiment was carried out including both positive and negative controls provided by the manufacturer, constituted respectively by an actin probe-hybridizing mouse liver RNA and yeast RNA, to eventually reveal any unspecific background signal.

To start the experiment, $3 \mu \mathrm{g}$ mRNA (equivalent to and 200,000 cpm purified RNA antisense probes were placed in sterile, RNase-free microcentrifuge tubes. 1/10 vol of 5 $\mathrm{M}$ ammonium acetate and $2.5 \mathrm{vol}$ of ethanol were subsequently added; tubes were mixed thoroughly and stored at $-20{ }^{\circ} \mathrm{C}$ for one hour, allowing RNA to precipitate. The samples were then centrifuged at $16,100 \times \mathrm{g}$ for $20 \mathrm{~min}$ at $4{ }^{\circ} \mathrm{C}$. The supernatant was 
discarded and RNA pellets were washed with $70 \%$ ethanol, briefly centrifuged and airdried for $\sim 5 \mathrm{~min}$.

Each pellet was resuspended in $10 \mu$ hybridization III buffer provided with the kit, heated for $4 \mathrm{~min}$ at $93{ }^{\circ} \mathrm{C}$ to denaturate RNA, and then incubated overnight at $42{ }^{\circ} \mathrm{C}$ to allow probes to hybridize.

Unprotected RNA was digested after incubation using enzyme mix RNase A/RNase T1 Mix diluted 1/100 in RNase digestion III buffer; $150 \mu \mathrm{l}$ of this solution were added to each sample. Additionally, $150 \mu \mathrm{l}$ of digestion III buffer were added to the no-RNase control tube(s), as a control for probe integrity. The RNA digestion was performed for $30 \mathrm{~min}$ at $37{ }^{\circ} \mathrm{C}$, and was followed by addition of $230 \mu \mathrm{l}$ RNase Inactivation/Precipitation III solution.

The samples were mixed thoroughly, chilled at $-20{ }^{\circ} \mathrm{C}$ for one hour and centrifuged at $16,100 \times \mathrm{g}$ for $20 \mathrm{~min}$ at $4{ }^{\circ} \mathrm{C}$. In the meantime a $5 \%$ polyacrylamide gel was prepared, as described in paragraph 3.2.10. After centrifugation the supernatant was removed and RNA pellets were washed with $70 \%$ ethanol, briefly centrifuged and air-dried for $\sim 5$ min. RNA pellets were resuspended in $10 \mu \mathrm{l}$ gel loading buffer II (95\% Formamide, $0.025 \%$ xylene cyanol, $0.025 \%$ bromophenol blue, 18 mM EDTA, 0.025\% SDS), vigorously vortexed and heated for $4 \mathrm{~min}$ at $93{ }^{\circ} \mathrm{C}$ before being loaded into the gel. The amount of RNA ladder loaded was $40,000 \mathrm{cpm}$ (corresponding to $\sim 1.5 \mu \mathrm{l}$ of a $1 / 10$ diluition of a $300,000 \mathrm{cpm} / \mu$ column-purified solution), complemented with $5 \mu \mathrm{gel}$ Loading Buffer II. Only $20 \%$ of the No-RNase tube content was loaded, since a higher radioactivity level is expected compared to the other samples. Electrophoretic separation was carried out at $150 \mathrm{~V}$ for $\sim 45 \mathrm{~min}$. After this time, the gel was placed on Whatman paper, wrapped into a plastic foil, pasted into a X-ray cassette and exposed to a X-ray film at $-80{ }^{\circ} \mathrm{C}$ for a time ranging between overnight to four days, depending on the amount of hybridized probe on target RNA. The film was finally developed using a Curix 60 device (Agfa). The expected sizes of the protected probes were $245 \mathrm{nt}$ for pTRI-Actin-Mouse and 197 nt for pGEM-T E70 probe. 


\subsection{Biochemistry}

\subsubsection{Western blotting (WB)}

\subsubsection{Cells lysis for SDS-PAGE}

80-90\% confluent cells cultivated in T75 flasks were washed twice in PBS, scraped off the flasks using $3 \mathrm{ml} \mathrm{PBS}$, and centrifuged at $800 \times \mathrm{x}$ for $3 \mathrm{~min}$ at RT. Pellets were resuspended in $400 \mu \mathrm{l}$ ice-cold lysis buffer $(50 \mathrm{mM}$ Tris- $\mathrm{HCl} \mathrm{pH}$ 7.4; $300 \mathrm{mM} \mathrm{NaCl} ; 5$ mM EDTA; $1 \%$ Triton X-100; a tablet of cOmplete protease inhibitor (PI) cocktail (Roche) was used for each $10 \mathrm{ml}$ solution) and passed several times through a 25-gauge needle, incubated $20 \mathrm{~min}$ on ice and finally centrifuged at top speed for $20 \mathrm{~min}$ at $4{ }^{\circ} \mathrm{C}$. The supernatant was carefully removed, placed in fresh tubes and either stored at $-20{ }^{\circ} \mathrm{C}$ or directly used for downstream application.

\subsubsection{Oocyte lysis for SDS-PAGE}

For each experimental group, fifteen Xenopus laevis oocytes were resuspended in 300 $\mu \mathrm{l}(20 \mu \mathrm{l}$ each cell) oocyte lysis buffer $(150 \mathrm{mM} \mathrm{NaCl}, 20 \mathrm{mM}$ Tris-HCl, $5 \mathrm{mM} \mathrm{MgCl}$, 5 mM EDTA, 1\% Triton X-100; a PI cocktail tablet was used for each $10 \mathrm{ml}$ solution) and incubated $15 \mathrm{~min}$ on ice. Lysates were then centrifuged at $11,000 \times \mathrm{g}$ for $5 \mathrm{~min}$ at 4 ${ }^{\circ} \mathrm{C}$. The supernatant was carefully removed with a fine tip and placed in a fresh microcentrifuge tube. Samples were again incubated $15 \mathrm{~min}$ on ice and centrifuged at $11,000 \times \mathrm{g}$ for $5 \mathrm{~min}$ at $4{ }^{\circ} \mathrm{C}$. The supernatant was carefully removed, placed in fresh tubes and either stored at $-20{ }^{\circ} \mathrm{C}$ or directly used for downstream application.

\subsubsection{Cells lysis for protein analysis under native conditions}

80-90\% confluent cells cultured in T25 flasks were washed twice in PBS, scraped off the flasks using in $1 \mathrm{ml}$ PBS solution containing PI cocktail and $200 \mathrm{ng} / \mu \mathrm{l}$ PefaBlock solution (a serine protease inhibitor, from Sigma), and transferred to microcentrifuge tubes. The samples were centrifuged at $1,500 \times \mathrm{g}$ for $3 \mathrm{~min}$ at $4{ }^{\circ} \mathrm{C}$. After supernatant was removed, the pellet was resuspended in $800 \mu$ lice-cold hypotonic buffer $(10 \mathrm{mM}$ Tris-HCl, 2 mM EDTA, PI and 200 ng/ $\mu$ l PefaBlock in $\mathrm{H}_{2} \mathrm{O}$ ), passed through a 26- 
gauge needle ten times and incubated $20 \mathrm{~min}$ on ice. The homogenate was subsequently centrifuged at $400 \mathrm{x} \mathrm{g}$ for $10 \mathrm{~min}$ at $4{ }^{\circ} \mathrm{C}$, to precipitate nuclei. Supernatant was placed in a ultracentrifuge tubes and centrifuged at $50,000 \times \mathrm{g}$ for $30 \mathrm{~min}$ at $4{ }^{\circ} \mathrm{C}$ in a TL-100 ultracentrifuge equipped with a rotor TLA 100.3 (Beckman Coulter). Supernatant was carefully removed and pellet were either frozen at $-80{ }^{\circ} \mathrm{C}$, or directly processed for the native PAGE analysis.

\subsubsection{Protein quantitation}

Protein amount was quantified using the Pierce BCA protein assay kit (Thermo Scientific), $7 \mu \mathrm{l}$ of each sample derived from the previous procedure were added to 28 $\mu 1$ autoclaved $\mathrm{H}_{2} \mathrm{O}$ and $10 \mu \mathrm{l}$ of this mixture were loaded in triplicates on a 96 well plate, together with triplicates of $10 \mu \mathrm{l}$ diluted BSA (bovine serum albumin) standard, as listed in table 3.

\begin{tabular}{|c|c|c|c|}
\hline $\begin{array}{c}\text { BSA dilution } \\
\text { sample label }\end{array}$ & $\mathbf{d H}_{2} \mathbf{O} \mu \mathrm{l}$ & $\mathbf{B S A} \mu \mathrm{l}$ & $\begin{array}{c}\text { Final BSA } \\
\text { concentration } \\
(\mu \mathrm{g} / \mu \mathrm{l})\end{array}$ \\
\hline $\mathrm{A}$ & 0 & 35 & 2 \\
\hline B & 17,5 & 52,5 & 1,5 \\
\hline C & 35 & 35 & 1 \\
\hline D & 30 & 30 from sample B & 0,75 \\
\hline E & 35 & 35 from sample C & 0,50 \\
\hline F & 35 & 35 from sample E & 0,25 \\
\hline G & 30 & 30 from sample F & 0,125 \\
\hline H & 32 & 8 from sample G & 0,0025 \\
\hline I & 60 & 0 & 0 \\
\hline
\end{tabular}

Table 3 BSA dilution pattern used for protein quantization experiments. 
Reagent B (4\% cupric sulfate) was diluted 1/50 in Reagent A (sodium carbonate, sodium bicarbonate, bicinchoninic acid and sodium tartrate in $0.1 \mathrm{M}$ sodium hydroxide) and mixed thoroughly. $200 \mu \mathrm{l}$ of this mixture was added to each sample in the 96-well plate, which was then incubated $30 \mathrm{~min}$ at $37^{\circ} \mathrm{C}$. The absorbance of the samples at 562 $\mathrm{nm}$ was measured using a Wallac VICTOR ${ }^{2}$ plate reader (Perkin Elmer). With these data we could draw a titration curve, which allowed us to estimate the protein amount relative to our samples.

\subsubsection{SDS-PAGE and protein blotting on nitrocellulose membrane}

NuPAGE Tris-Acetate SDS Buffer Kit (Invitrogen) was used for all SDS-PAGE experiments. Running buffer was prepared diluting $50 \mathrm{ml}$ of $20 \mathrm{X}$ Tris-acetate Running buffer (containing $1 \mathrm{M}$ Tricine, $1 \mathrm{M}$ Tris Base, $70 \mathrm{mM}$ SDS in $\mathrm{H}_{2} \mathrm{O}$, pH 8.25) in one liter distilled water; from this, $200 \mathrm{ml}$ were placed into another vessel and complemented with $500 \mu \mathrm{l}$ Antioxidant (containing N,N-Dimethylformamide and sodium bisulfate). A Pre-cast gel NuPAGE Novex 3-8 \% Tris-acetate (Invitrogen) was loaded into a XCell SureLock electrophoresis cell (Invitrogen). $200 \mathrm{ml}$ of freshly prepared buffer containing antioxidant were poured in the inner part of the chamber, with the running buffer placed the outer part. A maximal volume of $45 \mu$ sample was loaded per well, along with $10 \mu \mathrm{l}$ of pre-stained ladder (New England Biolabs), and electrophoresis was performed at $150 \mathrm{~V}$ for one hour. In the meantime, 1.2 liters of transfer buffer were prepared, consisting of $10 \mathrm{mM} \mathrm{NaHCO} 3,3 \mathrm{mM} \mathrm{Na} \mathrm{CO}_{3}, 20 \%$ methanol and $0.01 \%$ SDS solutions at $\mathrm{pH}$ 9.22. After the electrophoretic separation, proteins were transferred from gel to a nitrocellulose membrane (Amersham Hybond ECL - GE Healthcare) using a tank transfer method: both membrane and gel were incubated in transfer buffer and shaked for $10 \mathrm{~min}$. The 'sandwich' for the transfer consisted on the gel containing the protein placed in tight contact with the membrane, surrounded by two pieces of Whatman paper and a sponge for each side of the sandwich. This complex was placed into the transfer tank Mini Trans-Blot Cell (BioRad) within a gel holder cassette (Bio-Rad). The transfer protocol consisted of a voltage gradient from 10 to $40 \mathrm{~V}$, increased by steps of $10 \mathrm{~V}$ every $10 \mathrm{~min}$, and followed by a final step of $40 \mathrm{~min}$ at $50 \mathrm{~V}$. The nitrocellulose membrane was removed from the sandwich and air-dried overnight at RT. 


\subsubsection{Blue Native PAGE (BN-PAGE) and protein blotting on PVDF membrane}

BN-PAGE is a sensitive and high resolution tool for analysis of the molecular mass and oligomeric state of proteins in native conformation (Schägger and von Jagow, 1991). All the components (detergent, running buffers, protein ladder) used in BN-PAGE experiments were purchased from Invitrogen. Frozen pellets derived from cell lysates (procedure described in paragraph 3.3.1.3) were thawed on ice and resuspended in 200 $\mu 1$ sample buffer (50 mM BisTris-propane, $750 \mathrm{mM}$ 6-aminocaproic acid, $\mathrm{pH} 7$ complemented with PI/10 ml solution). The protein concentration was measured as described in paragraph 3.3.1.4. In fresh microcentrifuge tubes, $250 \mathrm{ng}$ of protein lysate were mixed with $12 \mu \mathrm{l}$ (6\% final concentration) $n$-Dodecyl $\beta$-D-Maltopyranoside (DDM, a mild detergent) and diluted with sample buffer in order to achieve $14 \mu \mathrm{l}$ final volume. The mixture was incubated for $60 \mathrm{~min}$ on ice. After that, $6 \mu 1$ (1.5\% final concentration) Coomassie G 250 were added and the samples were centrifuged at $16,100 \times \mathrm{g}$ for $10 \mathrm{~min}$ at $4{ }^{\circ} \mathrm{C}$. Anionic dye Coomassie blue $\mathrm{G} 250$ binds the negative charges of the amino acids, replacing SDS as charge-shift molecule, and maintaining in this case the protein structures in their native state. During the time of incubation with the detergent, a Native PAGE Novex 3-12\% Bis-Tris pre-cast gel was loaded into a XCell SureLock electrophoresis cell, which was then filled in the outer part with NativePAGE Running Buffer (50 ml NativePAGE Running Buffer 20X containing 950 $\left.\mathrm{ml} \mathrm{dH}_{2} \mathrm{O}\right)$ and internally with Dark Blue buffer $(10 \mathrm{ml}$ Cathode Additive, $10 \mathrm{ml}$

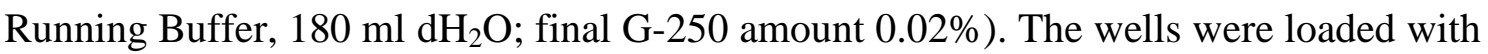
$10 \mu \mathrm{l}$ of sample supernatant and $7 \mu 1$ NativeMark protein ladder (Life technologies). Electrophoretic separation lasted for one hour at $150 \mathrm{~V}$ at $4{ }^{\circ} \mathrm{C}$; after this time, the Dark Blue buffer was replaced with Light Blue buffer $(1 \mathrm{ml}$ Cathode Additive, $10 \mathrm{ml}$

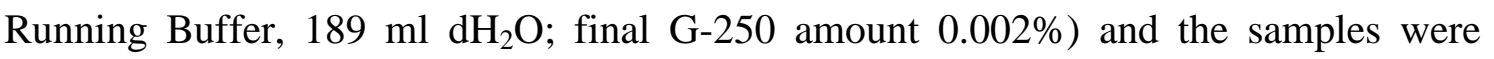
allowed to run for additional 3 hours at $250 \mathrm{~V}$. After that, the proteins were transferred onto a PVDF membrane (Amersham Hybond-P; GE healthcare) using the Trans-Blot SD Semi-Dry Transfer Cell (Bio-Rad). Three Whatman paper pieces were placed on the transfer apparatus: the first pre-soaked in Buffer I (300 mM Tris-HCl, pH 10.4 and 10\% methanol), and two pre-soaked in Buffer II (25 mM Tris- $\mathrm{HCl}, \mathrm{pH} 10.4$ and 10\% methanol). The PVDF membrane (previously incubated in methanol for $1 \mathrm{~min}$, then 3 min in $\mathrm{dH}_{2} \mathrm{O}$, finally in Buffer II immediately before loading), and the gel were then 
added. Finally the last 3 pieces of Whatman pre-soaked in Buffer III (25 mM Tris-HCl $\mathrm{pH} \mathrm{10.4;} 40 \mathrm{mM}$ aminocaprionic acid; 20\% methanol) were applied on top of the gel. The transfer time was $30 \mathrm{~min}$ at $2.5 \mathrm{~mA} / \mathrm{cm}^{2}$ of membrane. After blotting, the membrane was incubated in $8 \%$ acetic acid for $15 \mathrm{~min}$ and air-dried overnight at RT. The lane containing the unstained ladder was separated from the other samples, incubated $10 \mathrm{~min}$ in methanol, washed 5 times with $\mathrm{dH}_{2} \mathrm{O}$ and incubated 30 min with Ponceau S (Merck Millipore) solution $0.1 \%$ in $1 \%$ acetic acid. The excess of staining was removed by several washes in $\mathrm{dH}_{2} \mathrm{O}$, until the ladder bands could be detected and promptly marked on the PVDF membrane containing the samples lanes.

\subsubsection{Two-dimensional Blue Native PAGE (2D BN-PAGE)}

The macromolecular composition of $\mathrm{K}_{\mathrm{V}} 10.1$ complexes derived from BN-PAGE experiments was investigated using a SDS-PAGE approach as second dimension following a BN-PAGE (Schägger et al., 1993). The sample preparation and the BNPAGE procedures were carried out as described in paragraph 3.3.1.3 and 3.3.1.6. After the electrophoresis, the lane containing the sample of interest was excised from the native gel with a scalpel and incubated in equilibrating solution (ES; made of $1 \%$ SDS in $0.125 \mathrm{mM}$ Tris-HCl, $\mathrm{pH} 7.0$ ) for $20 \mathrm{~min}$, then in ES complemented with $100 \mathrm{mM}$ Dithiothritol (DTT) for $25 \mathrm{~min}$. After that, gel was incubated in ES with $60 \mathrm{mM}$ Iodoacetamide for $25 \mathrm{~min}$ and finally pure ES for $10 \mathrm{~min}$. The equilibrated lane was placed in the 2D well of a NuPAGE Novex-Tris Acetate 3-8 \% SDS gel. $10 \mu \mathrm{l}$ of prestained protein marker (Bio-Rad) were loaded in the ladder lane. The SDS-PAGE and protein blotting on nitrocellulose membrane were performed as described in 3.3.1.5.

\subsubsection{Membrane blocking and protein signal detection}

The dried nitrocellulose membrane was incubated in $\mathrm{dH}_{2} \mathrm{O}$ (or in methanol for PVDF membranes, followed by $3 \mathrm{x} \mathrm{dH}_{2} \mathrm{O}$ washes) for $15 \mathrm{~min}$. The Pierce Western Blot Signal (Thermo Scientific) Enhancer was used: solution A was applied to the membrane for 2 min then $5 \mathrm{x}$ washed with $\mathrm{dH}_{2} \mathrm{O}$. Then the solution $\mathrm{B}$ was added, incubated for $10 \mathrm{~min}$ and finally washed again $5 \mathrm{x}$ with $\mathrm{dH}_{2} \mathrm{O}$. To block unspecific binding sites of the antibody, the blotted membrane was incubated for 1 hour with $0.1 \%$ Casein (Roche) in TBS-T (TBS containing $0.1 \%$ Tween 20 ) solution. After that, a primary antibody 
diluted in $0.1 \%$ casein TBS-T (see table 4) was applied for $90 \mathrm{~min}$, followed by 7x washes with deionized $\mathrm{H}_{2} \mathrm{O}$ and 5 min incubation in TBS-T. Subsequently the membrane was incubated for one hour with secondary ECL anti-rabbit (or anti-mouse, depending on the primary antibody species) IgG antibody horseradish peroxidase (HRP)-linked (GE Healthcare), diluted 1/7000 in $0.1 \%$ casein TBS-T. The membrane was washed again seven times with deionized $\mathrm{H}_{2} \mathrm{O}$ and incubated in TBS-T for 5 min. For the detection of the protein signal, the membrane was incubated for 5 min with Immobilon Western Chemiluminescent HRP Substrate (Millipore) and luminescence was imaged using a Chemi-Doc XRS system (Bio-Rad).

\subsubsection{Immunoprecipitation (IP)}

An amount of 100 to $500 \mu \mathrm{g}$ protein lysates (isolated and quantified as described in 3.3.1.1 and 3.3.1.4), together with respectively 15 to $25 \mu \mathrm{l}$ of Protein G magnetic beads (New England Biolabs) was first incubated for 1 hour at $4{ }^{\circ} \mathrm{C}$ in order to pre-clear the crude cell extract, excluding from the experiment non-specific binding to the beads. A magnetic field was applied to the mixture for 30s and the beads were trapped in one side of the tube. The supernatant was then placed in a fresh tube, where $2 \mu \mathrm{g}$ of a monoclonal antibody (see table 4) were also added. The tube content was mixed and incubated for one hour or ON (depending on the antibody) at $4{ }^{\circ} \mathrm{C} .25 \mu$ of magnetic beads were added to the suspension, vortexed and incubated for one hour at $4{ }^{\circ} \mathrm{C}$. The beads were recovered in a magnetic field, washed 3 times with $400 \mu$ l protease-free wash solution $(0.1 \%$ Triton $\mathrm{X}-100,50 \mathrm{mM}$ Tris- $\mathrm{HCl}, 300 \mathrm{mM} \mathrm{NaCl}, 5 \mathrm{mM}$ EDTA, complemented with PI tablet for each $10 \mathrm{ml}$ solution). Finally, an additional wash with $400 \mu \mathrm{l}$ protease-free TBS (TRIS buffered saline: $50 \mathrm{mM}$ TRIS, $150 \mathrm{mM} \mathrm{NaCl}, \mathrm{pH}$ 7.6) was performed. The beads were resuspended in 16.25 $\mu \mathrm{l}$ TBS, $2.5 \mu$ 10X Sample Reducing Agent (500 mM DTT, from Invitrogen) and $6.25 \mu \mathrm{l}$ of 4X LDS sample buffer (40\% glycerol, $6.8 \%$ Tris-Base, $6.6 \%$ Tris- $\mathrm{HCl}, 8 \%$ LDS, $0.06 \%$ EDTA, $0.75 \%$ Serva Blue G250, 0.25\% Phenol Red, from Invitrogen), till reaching a final volume of $25 \mu \mathrm{l}$. For each sample, a no-IP (input) tube, containing 10\% of the immunoprecipitated amount of protein, together with 1/4 vol LDS and 1/10 vol SRA was also prepared. All the samples were incubated for $10 \mathrm{~min}$ at $70{ }^{\circ} \mathrm{C}$ and then exposed to a magnetic field to 
separate beads from supernatant. The IP supernatant, input and a protein ladder (New England Biolabs) were finally loaded on the appropriate polyacrylamide gel.

\begin{tabular}{|c|c|c|c|c|c|}
\hline Label & $\begin{array}{c}\text { Clonality, } \\
\text { host }\end{array}$ & $\begin{array}{c}\text { Target } \\
\text { epitope }\end{array}$ & $\begin{array}{c}\text { Dilution, final } \\
\text { concentration }\end{array}$ & Experiment & $\begin{array}{c}\text { Provider (or } \\
\text { reference) }\end{array}$ \\
\hline $\mathbf{3 3}$ & $\begin{array}{c}\text { Monoclonal, } \\
\text { mouse }\end{array}$ & $\begin{array}{c}\text { C-terminus } \\
\mathrm{K}_{\mathrm{V}} 10.1\end{array}$ & $\begin{array}{c}2 \mu \mathrm{g}(\mathrm{IP}) ; \\
2 \mu \mathrm{g} / \mathrm{ml} \\
\text { (ELISA) }\end{array}$ & Ip, ELISA & $\begin{array}{c}\text { L.A. Pardo; } \\
\text { (Hemmerlein } \\
\text { et al, 2006). }\end{array}$ \\
\hline $\mathbf{4 9 , 5 6 , 6 2 , 6 6}$ & $\begin{array}{c}\text { Monoclonal, } \\
\text { mouse }\end{array}$ & $\begin{array}{c}\text { Pore region } \\
\mathrm{K}_{\mathrm{V}} 10.1\end{array}$ & $0.5 \mu \mathrm{g}$ each & IP & $\begin{array}{c}\text { L.A. Pardo; } \\
\text { (Hemmerlein } \\
\text { et al., 2006). }\end{array}$ \\
\hline $\mathbf{1 2 1 8}$ & $\begin{array}{c}\text { Monoclonal, } \\
\text { mouse }\end{array}$ & $\begin{array}{c}\text { GFP (used for } \\
\text { mVenus) }\end{array}$ & $2 \mu \mathrm{g}$ & IP & Abcam \\
\hline $\mathbf{6 5 5 6}$ & $\begin{array}{c}\text { Polyclonal, } \\
\text { mouse }\end{array}$ & $\begin{array}{c}\text { GFP (used for } \\
\text { mVenus) }\end{array}$ & $1 / 1000$ & WB & Abcam \\
\hline $\mathbf{9 3 9 1}$ & $\begin{array}{c}\text { Polyclonal, } \\
\text { rabbit }\end{array}$ & $\begin{array}{c}\text { C-terminus } \\
\mathrm{K}_{\mathrm{V}} 10.1\end{array}$ & $1 / 1500$ & WB & $\begin{array}{c}\text { L.A. Pardo; } \\
\text { (Napp et al., } \\
\text { 2005). }\end{array}$ \\
\hline
\end{tabular}

Table 4 List of primary antibodies used in IP, ELISA and WB.

\subsubsection{Glycosidase digestion}

$200 \mu \mathrm{g}$ of protein lysate were immunoprecipitated, as described in 3.3.2. After the overnight antibody incubation and the addition of protein $G$ magnetic beads, the magnetic beads were resuspended in $2 \mu \mathrm{l}$ Beads Release solution (100 mM $\beta$ mercaptoethanol in $0.1 \%$ SDS), in order to release the proteins complexes bound to the beads. Samples were heated up to $99{ }^{\circ} \mathrm{C}$ for $10 \mathrm{~min}$, briefly centrifuged, and exposed to a magnetic field in order to trap the beads at one side of the tube. At this point, the $21 \mu \mathrm{l}$ supernatant from each sample were distributed in three microcentrifuge tubes, for treatment with Endo H, PNGase F (both from Sigma), and a control tube (CTL), containing immunoprecipitated samples not treated with enzyme (table 5). 


\begin{tabular}{|c|c|c|c|}
\hline & EndoH sample & PNGase F sample & CTL sample \\
\hline $100 \mu \mathrm{g}$ protein lysate & $7 \mu \mathrm{l}$ & $7 \mu \mathrm{l}$ & $7 \mu 1$ \\
\hline $\mathbf{d H}_{2} \mathrm{O}$ & $9,5 \mu 1$ & $\begin{array}{c}\text { Diluted with its own } \\
\text { buffer }\end{array}$ & $18 \mu \mathrm{l}$ \\
\hline Buffer & $5 \mu \mathrm{l}$ & $12 \mu \mathrm{l}$ & - \\
\hline Denaturing solution & $2,5 \mu 1$ & $2,5 \mu \mathrm{l}$ & - \\
\hline \multicolumn{4}{|c|}{ Samples denaturated at $100^{\circ} \mathrm{C}$ for $5 \mathrm{~min}$, then placed on ice $1 \mathrm{~min}$ and finally treated with } \\
\hline Detergent solution & - & $2,5 \mu 1$ & - \\
\hline Enzyme & $1 \mu \mathrm{l}$ & $1 \mu \mathrm{l}$ & - \\
\hline
\end{tabular}

Table 5 Endo $H$ and PNGase $F$ digestions: list, and used amount of the components for each sample.

The tubes were incubated $\mathrm{ON}$ at $37{ }^{\circ} \mathrm{C}$ and then mixed with SRA and LDS buffers for SDS-PAGE, as described in paragraph 3.3.1.5.

\subsection{4 $K_{V} 10.1$-BBS system for quantification of surface $K_{V} 10.1$}

\subsubsection{Sample preparation}

Insertion of a BBS at the extracellular part of $\mathrm{K}_{\mathrm{V}} 10.1$ allows specific labeling of membranous $\mathrm{K}_{\mathrm{V}} 10.1-\mathrm{BBS}$ in intact cells (Kohl et al., 2011). HEK-K $\mathrm{V}_{\mathrm{V}} 10.1-\mathrm{BBS}$ cells cultured on T75 flasks were washed once with $10 \mathrm{ml}$ PBS. For each flask, $4 \mathrm{ml}$ PBS containing $\alpha$-Bungarotoxin (BTX)-Biotin (Invitrogen) at final concentration of 2.5 $\mu \mathrm{g} / \mathrm{ml}$ were added, followed by incubation on ice for $10 \mathrm{~min}$. The $\alpha$-BTX-Biotin solution was removed and the flasks were washed twice with ice-cold PBS. Cells were scraped in $4 \mathrm{ml}$ ice-cold PBS, centrifuged at $800 \times \mathrm{g}$ for $3 \mathrm{~min}$. Cell pellets were resuspended with $400 \mu \mathrm{l}$ lysis buffer $(20 \mathrm{mM}$ Tris- $\mathrm{HCl}, 150 \mathrm{mM} \mathrm{NaCl}, 5 \mathrm{mM} \mathrm{MgCl}$, 
$1 \%$ Nonidet- P40, pH 7.4, containing a PI tablet each $10 \mathrm{ml}$ solution). The lysates were passed several times through a 25-gauge needle and placed in microcentrifuge tubes, incubated for $20 \mathrm{~min}$ on ice and finally centrifuged at $16,100 \mathrm{x} \mathrm{g}$ for $15 \mathrm{~min}$ at $4{ }^{\circ} \mathrm{C}$. Supernatants were placed in fresh tubes and the protein concentration was quantified as described in paragraph 3.3.1.4.

\subsubsection{Enzyme-Linked ImmunoSorbent Assay (ELISA)}

The entire procedure was performed on ice. 96-well streptavidin-coated plates (Thermo Scientific) were washed twice with PBS containing 0.05\% Tween 20,0.1\% BSA and $0.1 \%$ Triton X-100. Each sample was placed in six wells of the 96-well plate (triplicates of 30 and $150 \mu \mathrm{g}$ of protein) and incubated $30 \mathrm{~min}$. The plates were washed twice and then incubated for $30 \mathrm{~min}$ with $100 \mu \mathrm{l}$ NPE $(150 \mathrm{mM} \mathrm{NaCl}, 5 \mathrm{mM}$ EDTA, $50 \mathrm{mM}$ Tris, $5 \mathrm{mM} \mathrm{KCl}, 1 \% \mathrm{NP}-40 ; \mathrm{pH} 7.5)$ blocking solution containing $1 \%$ casein to remove unspecific binding sites of the antibody. $50 \mu \mathrm{l}$ for each well of primary antibody anti$\mathrm{K}_{\mathrm{V}} 10.1$ diluted in NPE with $0.1 \%$ casein (final antibody concentration $2.5 \mu \mathrm{g} / \mathrm{ml}$ ) were then added to the wells and incubated $90 \mathrm{~min}$. The samples were washed 3 times with $100 \mu \mathrm{l}$ NPE buffer containing $0.1 \%$ casein and incubated again with $100 \mu \mathrm{l}$ NPE blocking solution (with $1 \%$ casein) for $30 \mathrm{~min}$. At this point, $50 \mu 1 /$ well of secondary ECL HRP-linked anti-mouse IgG (GE Healthcare) (diluted 1/500 in NPE with $0.1 \%$ casein) were added to the wells and the mixture was incubated 90 min. After this, each well was washed 7 times with $100 \mu \mathrm{l}$ NPE buffer containing $0.1 \%$ casein. Finally, 200 $\mu 1$ substrate 3-ethylbenzothiazoline-6-sulphonic acid (ABTS, from Invitrogen) were added for each well. The chromogenic peroxidase reaction was measured using a plate reader at $405 \mathrm{~nm}$ with a reference wavelength of $490 \mathrm{~nm}$.

\subsubsection{Cell fixation for fluorescent proteins imaging}

Confluent CHO cells ( $~ 80-90 \%)$ were plated on poly-L-lysine coated $25 \mathrm{~mm}$ coverslips in 6-well plates and transfected as described in paragraph 3.1.3. About 24 hours after transfection, the medium was removed and wells were washed twice with $2 \mathrm{ml}$ PBS. Cells were fixed in formalin solution (Sigma) for $10 \mathrm{~min}$ at $4{ }^{\circ} \mathrm{C}$, then washed twice $(5$ min each) in PBS. Permeabilization of the membrane was performed incubating cells in 
PBS with $0.5 \%$ Triton X-100 (Sigma) for 5 min RT. Samples were afterwards washed twice (5 min each) with PBS-T (PBS with 0.1\% Tween-20 (Merck-Millipore)). ProLong Gold antifade reagent (Invitrogen) containing the membrane-impermeable nuclear staining DAPI was finally used to mount the coverslips on microscope slides Superfrost Plus (Thermo scientific). Mounted coverslips were air-dried for at least one hour at RT and finally stored overnight at $4{ }^{\circ} \mathrm{C}$ before analysis.

\subsection{Electrophysiology}

\subsubsection{Two-electrode voltage clamp}

Voltage clamp recordings of cRNA-injected Xenopus laevis oocytes (Stühmer, 1998) were performed 24-48 hours after injection, using a Turbo TEC-10CD amplifier (npi Electronics). Currents derived from cRNA-injected oocytes and DEPC- $\mathrm{H}_{2} \mathrm{O}$ injected oocytes (negative control) were all recorded at RT. The intracellular electrodes having a resistance of 0.7-1.5 $\mathrm{M} \Omega$ were filled with $2 \mathrm{M} \mathrm{KCl}$. The external solution (Normal Frog Ringer, NFR) contained $115 \mathrm{mM} \mathrm{NaCl}, 2.5 \mathrm{mM} \mathrm{KCl}, 1.8 \mathrm{mM}, \mathrm{CaCl}_{2}, 10 \mathrm{mM}$ Hepes, pH 7.2. Data were acquired with PULSE software (HEKA Electronics) and analyzed with IgorPro (Wavemetrics). For all protocols, the currents were filtered at $2 \mathrm{kHz}$ and then sampled at a frequency of $10 \mathrm{kHz}$. The membrane potential was held at $-80 \mathrm{mV}$. In order to characterize current-voltage relationships, an I-V protocol was used, generally consisting of $250 \mathrm{~ms}$ voltage pulses, ranging from $+80 \mathrm{mV}$ to $-60 \mathrm{mV}$, with $20 \mathrm{mV}$ decrements. To compare voltage-elicited current response between different groups of oocytes, the average steady state current from 80 to $95 \%$ time of the pulse was plotted against the voltage. As mentioned in section 1.4.1, the activation kinetics deceleration under hyperpolarized holding potentials is a hallmark of the $\mathrm{K}_{\mathrm{V}} 10.1$ channel (Terlau et al., 1996). This was determined using the following protocol: $+40 \mathrm{mV}$ pulses were applied for $500 \mathrm{~ms}$ after hyperpolarizing conditioning pulses $(5000 \mathrm{~ms})$ at $-120 \mathrm{mV}$ and $-60 \mathrm{mV}$. The rise time of activation was established as the time required from $20 \%$ to $80 \%$ of the maximal current. 


\subsubsection{Whole cell patch clamp electrophysiology}

HEK-K $\mathrm{V}_{\mathrm{V}} 10.1$ cells were transfected (as described in paragraph 3.1.3) and plated in 24well plates, ( 20,000 cells/ well) each containing a 12-mm coverslips coated with polyL-lysine. Recordings were performed 24-72 hours after transfections. Only cells showing green signal (due to the transfection of the fluorescent protein mVenus) under epifluorescence illumination passing through a suitable dichromatic beamsplitter (Excitation BP 450-490 nm; Emission LP $515 \mathrm{~nm}$ ) were analyzed. Macroscopic $\mathrm{K}_{\mathrm{V}} 10.1$ currents were recorded in the whole-cell configuration of the patch-clamp technique (Hamill et al., 1981), using an EPC-9 amplifier and Patchmaster software (both from HEKA). Patch pipettes were pulled (with a List-Medical vertical puller) from WPI PG10165-4 glass (World precision Instruments): the pipette resistance ranged between 2.5 and 3.5 $\mathrm{M} \Omega$. The intracellular solution contained $100 \mathrm{mM} \mathrm{KCl}, 1 \mathrm{mM} \mathrm{MgCl}{ }_{2}, 5 \mathrm{mM}$ BAPTA, 5 mM EGTA, 45 mM NMDG (N-methyl- $D$-glucamine), 10 mM HEPES; pH 7.4, osmolarity $290 \mathrm{mOsm}$. Extracellular solution was made of $2.5 \mathrm{mM} \mathrm{KCl}, 160 \mathrm{mM}$ $\mathrm{NaCl}, 2 \mathrm{mM} \mathrm{CaCl} 2,1 \mathrm{mM} \mathrm{MgCl}_{2}, 8 \mathrm{mM}$ Glucose, 10mM HEPES, pH 7.4, osmolarity $\sim 300 \mathrm{mOsm}$. For all the experiments, the membrane potential was held at $-80 \mathrm{mV}$. Fast capacity $\left(\mathrm{C}_{\text {fast }}\right)$, slow capacity $\left(\mathrm{C}_{\text {slow }}\right)$ and series resistance $\left(\mathrm{R}_{\mathrm{S}}\right)$ compensations (at 70-90 $\%)$ were also applied. Signals were filtered at $4 \mathrm{kHz}$ and sampled at $20 \mathrm{kHz}$. I-V protocol consisted of $250 \mathrm{~ms}$ (or $500 \mathrm{~ms}$ ) voltage pulses, ranging from $+80 \mathrm{mV}$ to -60 $\mathrm{mV}$, with $20 \mathrm{mV}$ decrements. To compare voltage-elicited current response between different groups of cells, the current was first normalized to the cell size (as measured by $\left.\mathrm{C}_{\text {slow }}\right)$. The resulting current density was averaged from 80 to $90 \%$ time of each pulse and plotted against the voltage. A high potassium-content extracellular solution was also used (60 mM KCl, $102.5 \mathrm{mM} \mathrm{NaCl}, 2 \mathrm{mM} \mathrm{CaCl} 2,1 \mathrm{mM} \mathrm{MgCl}_{2}, 8 \mathrm{mM}$ Glucose, $10 \mathrm{mM}$ HEPES, pH 7.4, osmolarity $\sim 320 \mathrm{mOsm}$ ) in order to check the voltage dependence of the conductance ( $\mathrm{G}$ versus $\mathrm{V})$, using a tail current protocol: each of 500 ms voltage pulses (ranging from $+80 \mathrm{mV}$ to $-80 \mathrm{mV}$, with $20 \mathrm{mV}$ decrements) was followed by $300 \mathrm{~ms}$ hyperpolarization at $-120 \mathrm{mV}$. The exponential current-decay after the peak tail was fitted, and the extrapolated amplitude at time zero (i.e. at the beginning of hyperpolarization pulse) was considered as peak tail current. $G / G_{\max }$ values were obtained by normalizing the extrapolated peak tail current against $+80 \mathrm{mV}$ tail currents, and plotted versus voltage. Conductance-voltage curves were then fitted with a 
Boltzmann sigmoidal function to describe the voltage dependence of $\mathrm{K}_{\mathrm{V}} 10.1$ activation, according to Equation 1:

Equation 1:

$$
\mathrm{G}=\frac{\mathrm{G}_{\max }}{1+e^{-\left(V-V_{\text {Half }}\right) / k}}
$$

Where $G_{\max }$ is the maximal conductance, $V_{\text {half }}$ represents the voltage for half-maximal activation, and $k$ is the slope factor.

\subsubsection{Outside-out patch clamp recordings for noise analysis}

Non-stationary noise analysis was carried out in the outside-out configuration on macropatches of Xenopus oocytes (Heinemann and Conti, 1992). Briefly, 24-72 hours after cRNA injections, the oocyte to be analyzed was immersed $\sim 5 \mathrm{~min}$ in skinning solution (200 mM L-Aspartic acid, $20 \mathrm{mM} \mathrm{KCl,} 1 \mathrm{mM} \mathrm{MgCl}_{2}, 5 \mathrm{mM}$ EGTA, $10 \mathrm{mM}$ HEPES, pH 7.4), which provided the osmotic pressure to facilitate the removal of the vitelline membrane. This operation was performed under a strong illumination using a pair of fine tip forceps. The oocyte was then placed in a recording chamber containing NFR (external measuring solution), and allowed to attach to the bottom for 10-15 min before measurement. All the experiments were performed at RT, with oocytes from at least two different animals. Pulled patch pipettes (WPI - PG10165-4 glasses), having resistance 0.9 - $2 \mathrm{M} \Omega$ were filled with intracellular solution containing $100 \mathrm{mM} \mathrm{KCl}, 10$ mM EGTA, 10 mM HEPES, pH 7.2. EPC9 amplifier and Patchmaster software were used for the measurements. Patches were held at a holding potential of $-80 \mathrm{mV}$. Signals were filtered at $4 \mathrm{kHz}$ and sampled at $20 \mathrm{kHz}$. After establishing the outside-out configuration, fast capacity was compensated. Non-stationary noise analysis data were acquired by applying short $(50 \mathrm{~ms}$ ) depolarization pulses to $+40 \mathrm{mV}$ for several hundred times. Variance was calculated with PulseTools software (HEKA). Number of channels $N$, and single channel currents $i$ were determined from the variance $\sigma^{2}$ versus current amplitude $I$ plot using the following equation 2:

Equation 2

$$
\sigma^{2}-\sigma_{0}^{2}=i * I-I^{2} / N
$$


Where $\sigma_{0}^{2}$ represents the baseline variance. The total current $I$ flowing through an ion channel results from the combination of three parameters: the unitary current through a single channel $i$, the total number of available channels $N$, and the probability of a channel being open $P_{o}$ (Equation 3).

Equation 3

$$
I=i * N * P_{o}
$$

\subsection{Imaging}

\subsubsection{Epifluorescence microscopy}

In order to estimate the cell transfection efficiency, fluorescence derived from transfected fluorophores was visualized with a Zeiss Axiovert 200M equipped with a Hg-arc lamp (HBO $100 \mathrm{~W}$, Osram) using an appropriate dichromatic beamsplitter filter set:

- Excitation band pass (BP) 450-490; emission BP 515-565 nm for mVenus transfected cells, and

- Excitation BP 546/12; emission long pass (LP) $590 \mathrm{~nm}$ for mCherry transfected cells.

\subsubsection{Confocal microscopy}

Confocal images (from samples prepared as described in paragraph 3.3.5) were acquired with a Leica TCS SP2 system; the scan head is mounted on a Leica DMIRE2 inverted microscope. Images were taken using a $63 \mathrm{X}$ oil immersion objective having numerical aperture 1.4. The scanned stacks had $\sim 0.3 \mu \mathrm{m}$ thickness. Laser line and filter range to detect the emission of each fluorophore were: DAPI (Laser line $405 \mathrm{~nm}$, emission 418$477 \mathrm{~nm}$ ); mVenus (laser line $514 \mathrm{~nm}$; emission, 526-585 nm) and mCherry (laser line 
$594 \mathrm{~nm}$; emission 607-655 nm). Acquired image stacks were converted to TIFF files and imported into Fiji (Fiji Is Just ImageJ) software (Schindelin et al., 2012). Quantitative colocalization analysis were performed with the plugin JACoP (Just Another Colocalization Plugin) (Bolte and Cordelières, 2006), based on Pearson's correlation coefficient (Adler and Parmryd, 2010).

\subsubsection{Live imaging}

IncuCyte Zoom (Essen BioScience) device was used for monitoring cell growth. After transfections (described in 3.1.3), the cells were plated on a suitable vessel at a confluence of $30-40 \%$. The cells were loaded in the Incucyte Zoom placed into a cell incubator at $37{ }^{\circ} \mathrm{C}$ and $5 \% \mathrm{CO}_{2}$. Under these conditions, 16 images/well (using a $10 \mathrm{X}$ objective, Nikon) were acquired at intervals of $60 \mathrm{~min}$, until confluence reached $100 \%$ (or for a maximal time of 100 hours after transfections). The growth curve was obtained using the IncuCyte ZOOM 2013A software (Essen BioScience): a confluency mask was used to track the cell growth, which was then plotted on a line graph against the incubation time.

\subsection{Flow cytometry}

To estimate the fraction of cells retained in different cell cycle phases, a kit based on DNA intercalating agent Propidium iodide (Pi) was used, the CycleTEST plus DNA from BD Biosciences. 48 hours post-transfections cells were trypsinized, centrifuged at $800 \mathrm{x} g$ for $3 \mathrm{~min}$ at RT and counted. The pellets from $\sim 1 \times 10^{6}$ cells were washed once in PBS, and centrifuged again at $800 \mathrm{x} g$ for $3 \mathrm{~min}$ at RT. The samples were resupended in $250 \mu \mathrm{l}$ solution A (containing trypsin in a spermine tetrahydrochloride detergent buffer, to lysate the cell membranes and cytoskeletons), mixed and incubated for $10 \mathrm{~min}$ at RT. After that, $200 \mu \mathrm{l}$ solution B (containing trypsin inhibitor and ribonuclease A, to inhibit the trypsin activity and to digest the RNA) were added, mixed and incubated for 10 min at RT. Finally $200 \mu 1$ solution C cold (containing Pi, staining the DNA) were 
applied to the samples, which were mixed and incubated 10' on ice in dark conditions. The samples were analyzed in a FACSAria flow cytometer (BD Biosciences) using an Ar $488 \mathrm{~nm}$ laser for excitation. The fluorescence emission was collected using 585/42 BP filters. Linear forward and side scatter gates were used to discriminate single cells from cell clumps and debris. After gating, a minimum of $1 \times 10^{4}$ events was recorded for each sample. FACS Diva software v5.0 (BD Biosciences) was used for data acquisition. The resulting fluorescence histograms were analyzed with FlowJo v7.5.5 software (Tree Star). The cell cycle statistics were obtained using the Watson algorithm (Watson et al., 1987).

\subsection{Statistics}

Statistical analysis was performed using the software Prism (GraphPad) and Igor (Wavemetrics). Sample values and current amplitudes were compared by two-tailed unpaired Student's t test. Pvalues below 0.05 were considered statistically significant. Asterisks in the figures indicate $p$-values $(* \mathrm{p} \leq 0.05 ; * * \mathrm{p} \leq 0.01 ; * * * \mathrm{p} \leq 0.005)$. Unless differently stated, data are represented as means \pm standard error of the mean (SEM). 


\section{Results}

\section{1 $K_{V} 10.1^{\Delta 4-9}$ and $K_{V} 10.1^{\Delta 4-7}$ splice isoforms expression in diverse cell lines}

Recent findings in our laboratory revealed the existence of two $\mathrm{K}_{\mathrm{V}} 10.1$ truncated isoforms in the human brain and in the melanoma cancer cell lines IGR 39 and IPC 298. These splice variants have been termed E65 and E70, based on their predicted molecular weight. Both the isoforms are derived from exon skipping events and are devoid of the whole transmembrane domains, therefore predictably non-channel proteins, lacking respectively exons four to nine and four to seven compared to the fulllength $K_{V} 10.1$ sequence (Ramos Gomes, 2010). In order to provide a more intuitive distinction between $\mathrm{K}_{\mathrm{V}} 10.1$ full-length channel and its short isoforms in terms of nomenclature, in this section we will always refer at them as $K_{V} 10.1, K_{V} 10.1^{\Delta 4-9}$ and $\mathrm{K}_{\mathrm{V}} 10.1^{\Delta 4-7}$, respectively, based on their exon composition.

Here, nested PCR experiments were carried out in order to consolidate previous findings and to verify the expression of $K_{V} 10.1^{\Delta 4-9}$ and $K_{V} 10.1^{\Delta 4-7}$ in a panel of $K_{V} 10.1$-positive cell lines. Since $K_{V} 10.1$ (full-length and $K_{V} 10.1^{\Delta 4-7}$ ) is also expressed in brain under physiological conditions, human brain samples were also tested for short isoforms expression. For each nested PCR experiment, two sets of specific primers amplifying $\mathrm{K}_{\mathrm{V}} 10.1$ (external and internal primers, whose sequences described in table 1 of materials and methods section) were used. The external primers anneal respectively to the boundary between exon 1 and 2 (forward), and exon 11 (reverse) of $\mathrm{K}_{\mathrm{V}} 10.1$ sequence. The internal primers are located at exon 2 (forward) and exon 11 (reverse). Since all these primers target regions contained in both $\mathrm{K}_{\mathrm{V}} 10.1$ and its short isoforms sequences, we expected to distinguish $K_{V} 10.1^{\Delta 4-9}$ and $K_{V} 10.1^{\Delta 4-7}$ expression from the full-length based on the differences in amplicon length.

PCR products were separated on agarose gel electrophoresis. A band compatible with $\mathrm{K}_{\mathrm{V}} 10.1$, having electrophoretic mobility corresponding at about $1.9 \mathrm{~kb}$, was present in all the tested cell lines. Additionally in certain samples amplified DNA having sizes of $\sim 500$ bp and $\sim 900$ bp were detected (Fig. 9). 


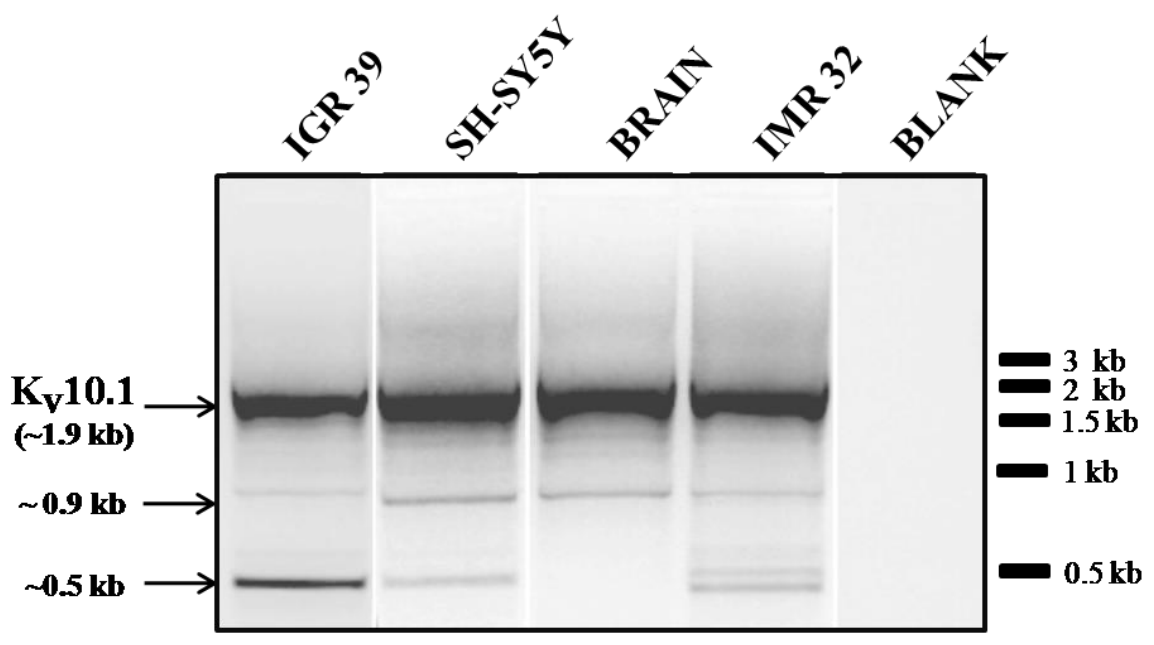

Figure $9 K_{V} 10.1$-expressing cells exhibit $K_{V} 10.1^{\Delta 4-9}$ - and $K_{V} 10.1^{\Delta 4-7}$ - compatible bands. Electrophoresis of DNA samples amplified with nested PCR. $\mathrm{K}_{\mathrm{V}} 10.1$ was visualized in all the samples. Additional amplified products having length of $\sim 500$ and $\sim 900$ bp appeared in IGR 39, SH-SY5Y and IMR 32 cells. The $\sim 900$ bp fragment was also detected in total human brain. Blank sample contains $\mathrm{H}_{2} \mathrm{O}$ instead of template cDNA.

Positive bands were excised from the gel, DNA was purified and cloned into pGEM-T for sequencing using vector-specific primers. Sequencing was carried out using the Sanger method, with a forward primer annealing to the T7 promoter region (5'TGTAAAACGACGGCCAGT-3') and a reverse primer for the SP6 promoter region (5'-AACAGCTATGACCATGATTACG-3'). Sequence analysis of the amplified fragments revealed that the shortest was a $488 \mathrm{bp}$ fragment in which the end of exon 3 was joined with the beginning exon 10 of $K_{V} 10.1$, thus representing $K_{V} 10.1^{\Delta 4-9}$. The second additional amplicon was 933 bp long and represented the $K_{V} 10.1^{\Delta 4-7}$ isoform, where the end of exon 3 was joined with the beginning exon 8 of $K_{V} 10.1$. The results of all the nested PCR experiments are summarized in table $6: \mathrm{K}_{\mathrm{V}} 10.1^{\Delta 4-9}$ expression was observed in prostate cancer cells DU 145, but also in normal prostate epithelium cells PNT 2. Moreover $\mathrm{K}_{\mathrm{V}} 10.1^{\Delta 4-9}$ was detected in melanoma cancer cells IGR 39 and IPC 298, and neuroblastoma SH-SY5Y cells. $\mathrm{K}_{\mathrm{V}} 10.1^{\Delta 4-7}$ was detected in the neuroblastoma cancer cell lines SH-SY5Y and IMR 32 cells, and also human brain extracts. 


\begin{tabular}{|c|c|c|c|}
\hline $\begin{array}{c}\text { Cell line (or tissue) } \\
\text { investigated }\end{array}$ & $\begin{array}{c}\text { Full-length } \\
K_{V} 10.1\end{array}$ & $\mathbf{K}_{\mathrm{V}} \mathbf{1 0 . 1}^{\Delta 4-9}$ & $\mathbf{K}_{\mathrm{V}} \mathbf{1 0 . 1}^{\Delta 4-7}$ \\
\hline DU 145 & ++ & + & - \\
\hline IGR 39 & +++ & + & - \\
\hline IPC 298 & ++ & + & - \\
\hline PNT 2 & ++ & + & + \\
\hline SH-SY5Y & +++ & - & + \\
\hline Human brain & ++ & - & - \\
\hline IMR 32 & +++ & - & - \\
\hline GL 15 & + & - & - \\
\hline HEK-K 10.1 & +++ & - & - \\
\hline HeLa & +++ & - & - \\
\hline MDA-MB 435S & ++ & - & + \\
\hline MCF 7 & ++ & & + \\
\hline
\end{tabular}

Table 6 Summary of the results from nested PCR experiments followed by sequencing analysis. $\mathrm{K}_{\mathrm{V}} 10.1^{\Delta 4-9}$ expression has been found in DU 145, IGR 39, IPC 298, PNT 2 and SH-SY5Y cells. $\mathrm{K}_{\mathrm{V}} 10.1^{\Delta 4-7}$ was detected in SH-SY5Y, human total brain and IMR 32 cells.

Aiming to achieve a quantitative detection of $K_{V} 10.1^{\Delta 4-9}$ and $K_{V} 10.1^{\Delta 4-7}$ transcripts, which would not be feasible with nested PCR, TaqMan probes and primers for real-time PCR were designed and tested. With this system we could successfully amplify both short isoforms using as template $K_{V} 10.1^{\Delta 4-9}$ and $K_{V} 10.1^{\Delta 4-7}$ sequences embedded in plasmidic DNA, with a detection limit of $\sim 0.1$ femtograms (Fig. 10). These primers had also high specificity as not amplifying $\mathrm{K}_{\mathrm{V}} 10.1$ full-length plasmid DNA (data not shown). 


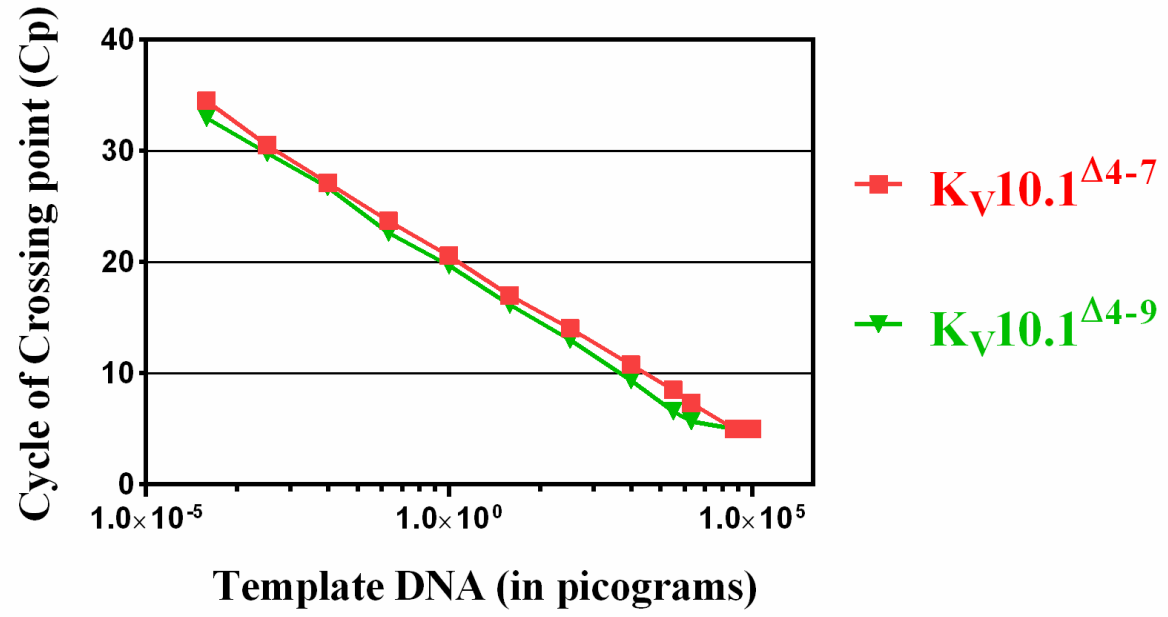

Figure $10 K_{V} 10.1^{\Delta 4-9}$ and $K_{V} 10.1^{\Delta 4-7}$ TaqMan probes amplification efficiency. Real-time PCR with increasing dilutions plasmidic DNA. Both $\mathrm{K}_{\mathrm{V}} 10.1^{\Delta 4-7}$ (squares) and $\mathrm{K}_{\mathrm{V}} 10.1^{\Delta 4-9}$ (triangles) are successfully amplified starting from 0.1 femtograms DNA template. Cp (Crossing point) represents the cycle number where fluorescence emitted from the probe increases above the threshold.

Once the system was validated, real-time PCR experiments were performed using cell lines positive for $\mathrm{K}_{\mathrm{V}} 10.1^{\Delta 4-9}$ and $\mathrm{K}_{\mathrm{V}} 10.1^{\Delta 4-7}$ expression in the previous nested PCR experiments. Unfortunately, the resulting amplification rate of both splice isoforms was poor $(\mathrm{Cp} \geq 35)$ in all the cell lines and brain extract samples tested (data not shown), suggesting scarce expression for both $K_{V} 10.1^{\Delta 4-9}$ and $K_{V} 10.1^{\Delta 4-7}$. The clear positive detection of $K_{V} 10.1^{\Delta 4-9}$ and $K_{V} 10.1^{\Delta 4-7}$ in nested PCR could be explained by the fact that real-time PCR is less sensitive (Guo et al., 2002).

In general, the methodology of PCR amplification is very sensitive, but on the other hand is also prone to give artifacts (Cocquet et al., 2006). For this reason, to unequivocally prove the existence of $\mathrm{K}_{\mathrm{V}} 10.1$ short isoforms in native expression systems, we sought to determine $K_{V} 10.1^{\Delta 4-9}$ and $K_{V} 10.1^{\Delta 4-7}$ mRNA presence in a PCRfree system. Therefore, ribonuclease protection assays were performed. mRNAs isolated from diverse $\mathrm{K}_{\mathrm{V}}$ 10.1-positive cancer cell lines were hybridized with radiolabeled antisense probes specifically targeting $K_{V} 10.1^{\Delta 4-9}$ and $K_{V} 10.1^{\Delta 4-7}$ transcripts (large amounts of human brain RNA necessary for RPA could not be obtained for obvious ethic issues). Single-stranded, unprotected mRNAs were digested and the result of the digestion was separated on a polyacrylamide gel. A $342 \mathrm{nt}$ band, corresponding to length of the $\mathrm{K}_{\mathrm{V}} 10.1^{\Delta 4-9}$ hybridized probe was detected in IGR 39 
cells. $\mathrm{K}_{\mathrm{V}} 10.1^{\Delta 4-7}$ was detected in IMR 32 and SH-SY5Y cell extracts (Fig. 11). Findings derived from these experiments unequivocally demonstrated the expression of $\mathrm{K}_{\mathrm{V}} 10.1^{\Delta 4-9}$ and $\mathrm{K}_{\mathrm{V}} 10.1^{\Delta 4-7}$ transcripts in native expression systems, as previous results from nested PCR experiments already suggested.

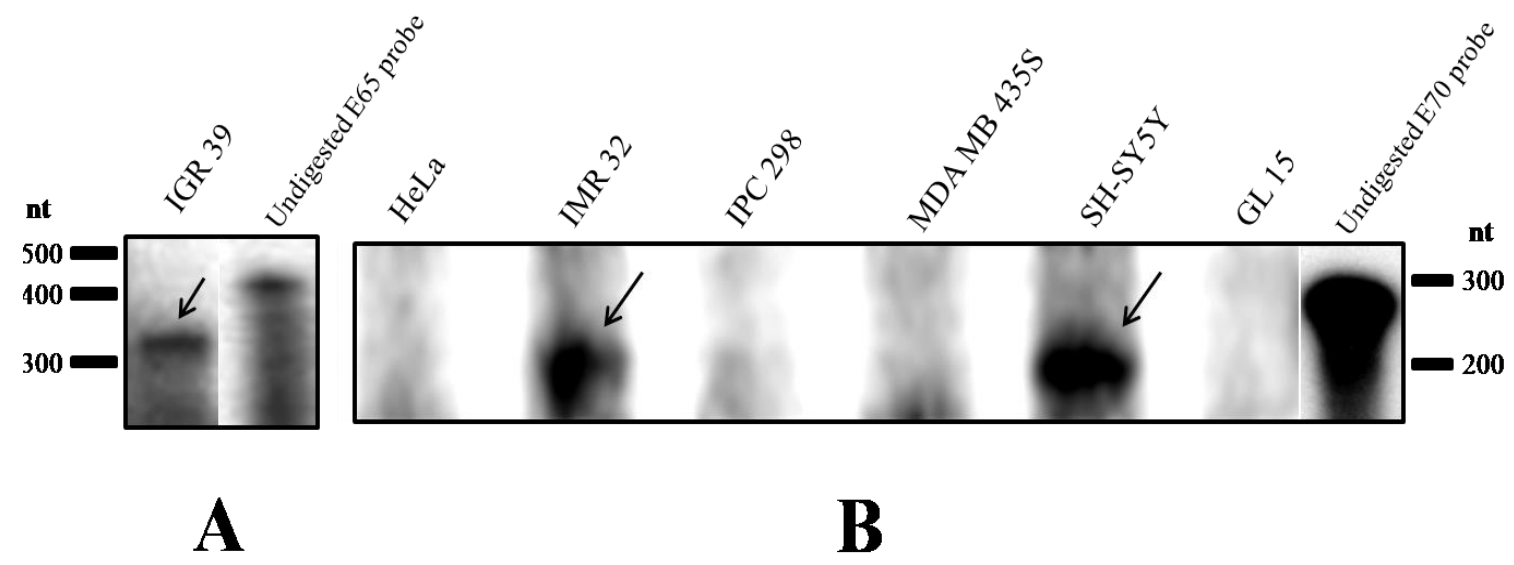

Figure $11 K_{V} 10.1^{\Delta 4-9}$ and $K_{V} 10.1^{\Delta 4-7}$ transcripts detected with RNase protection assay. Left panel: $\mathrm{K}_{\mathrm{V}} 10.1^{\Delta 4-9}$ transcript was detected in IGR 39 cell line. The protected probe size is $342 \mathrm{nt}$ and undigested probe size $437 \mathrm{nt}$ (experiment performed by Dr. Fernanda Ramos Gomes). Right panel: $\mathrm{K}_{\mathrm{V}} 10.1^{\Delta 4-7}$ transcript expressed in IMR 32 and SH-SY5Y cells. The protected probe size is $197 \mathrm{nt}$ (undigested size $297 \mathrm{nt}$ ). The results of the RNase protection assay represent two independent experiments with identical outcome.

\section{2 $K_{V} 10.1^{\Delta 4-9}$ and $K_{V} 10.1^{\Delta 4-7}$ interaction with full-length $K_{V} 10.1$ channel}

In a wide range of ion channels, splice variants may interact with the full-length channel, modulating its function (see for example Chiu, et al., 2010; Veale et al., 2010; Ohya et al., 2011; Tan et al., 2012). Here we asked whether also $\mathrm{K}_{\mathrm{V}} 10.1^{\Delta 4-9}$ and $\mathrm{K}_{\mathrm{V}} 10.1^{\Delta 4-7}$ would interact with $\mathrm{K}_{\mathrm{V}} 10.1$ and we addressed this experimental question in a heterologous expression system, and with the use of biochemical and microscopy tools. First, co-immunoprecipitation (co-IP) experiments were performed. For this purpose, HEK cells stably transfected with $\mathrm{K}_{\mathrm{V}} 10.1$ were transiently co-transfected with $\mathrm{K}_{\mathrm{V}} 10.1^{\Delta 4-9}$ and $\mathrm{K}_{\mathrm{V}} 10.1^{\Delta 4-7}$ constructs tagged with the fluorescent protein mVenus (Ramos Gomes, PhD thesis 2010). The use of such a fusion protein allowed us to 
overcome the lack of specific antibody available for $K_{V} 10.1^{\Delta 4-9}$ or $K_{V} 10.1^{\Delta 4-7}$, since an anti-GFP antibody could specifically target mVenus. Therefore, immunoprecipitation of $\mathrm{K}_{\mathrm{V}} 10.1^{\Delta 4-9}$ and $\mathrm{K}_{\mathrm{V}} 10.1^{\Delta 4-7} \mathrm{mVenus}$ using an anti-GFP antibody was followed by blotting the membrane with an antibody against $\mathrm{K}_{\mathrm{V}} 10.1$ (targeting $\mathrm{C}$-terminus region of the channel and recognizing also the short isoforms epitopes). Anti- $\mathrm{K}_{\mathrm{V}} 10.1$ immunoblot of GFP-immunoprecipitated extracts expressing $\mathrm{K}_{\mathrm{V}} 10.1$ alone did not give rise to detectable bands. In contrast, in IP of extracts co-expressing $\mathrm{K}_{\mathrm{V}} 10.1^{\Delta 4-9}$ with full-length channel, signals compatible with $\mathrm{K}_{\mathrm{V}} 10.1$ protein $(\sim 130 \mathrm{kDa})$ were detected. The same was true for extracts of cells expressing full-length together with $K_{V} 10.1^{\Delta 4-7}$, albeit quantitative and qualitative differences were present. First, the yield of full-length co-IP was much higher for $K_{V} 10.1^{\Delta 4-9}$ than for $K_{V} 10.1^{\Delta 4-7}$. Second, the bands compatible with $K_{V} 10.1$ were also qualitatively different: $K_{V} 10.1^{\Delta 4-9}$ coprecipitated a diffuse band similar to the majoritarian form present in the inputs, while $K_{V} 10.1^{\Delta 4-7}$ pulled down two sharper bands of smaller size, indicative of non-mature forms of the channel (see Fig. 12 A, right panel). Input (not immunoprecipitated) samples were also used. Here, the $\sim 75 \mathrm{kDa}$ signal corresponding to the $\mathrm{K}_{\mathrm{V}} 10.1^{\Delta 4-9}-\mathrm{mV}$ enus protein was less intense than the $\sim 85 \mathrm{kDa}$ one derived from the $\mathrm{K}_{\mathrm{V}} 10.1^{\Delta 4-7}$-mVenus protein. This is probably due to a less efficient transfection rate for the DNA coding for $\mathrm{K}_{\mathrm{V}} 10.1^{\Delta 4-9}$ compared with the DNA coding for $K_{V} 10.1^{\Delta 4-7}$. Moreover, a band having size compatible with $K_{V} 10.1^{\Delta 4-7}$ was detected in the $K_{V} 10.1+K_{V} 10.1^{\Delta 4-9}$ sample: this is probably unspecific, since it also appears in the $\mathrm{K}_{\mathrm{V}} 10.1$ sample (Fig. $12 \mathrm{~A}$, left panel).

In vitro interaction between $\mathrm{K}_{\mathrm{V}} 10.1$ and its short isoforms was confirmed by reverse coIP using a monoclonal anti- $\mathrm{K}_{\mathrm{V}} 10.1$ antibody directed against the pore region (that therefore does not bind to any of the shorter variants) and developing the immunoblot with anti-GFP antibody. Full-length $K_{\mathrm{V}} 10.1$ coprecipitated with both $\mathrm{K}_{\mathrm{V}} 10.1^{\Delta 4-9}$ and $\mathrm{K}_{\mathrm{V}} 10.1^{\Delta 4-7}$ (Fig. $12 \mathrm{~B}$ ). 


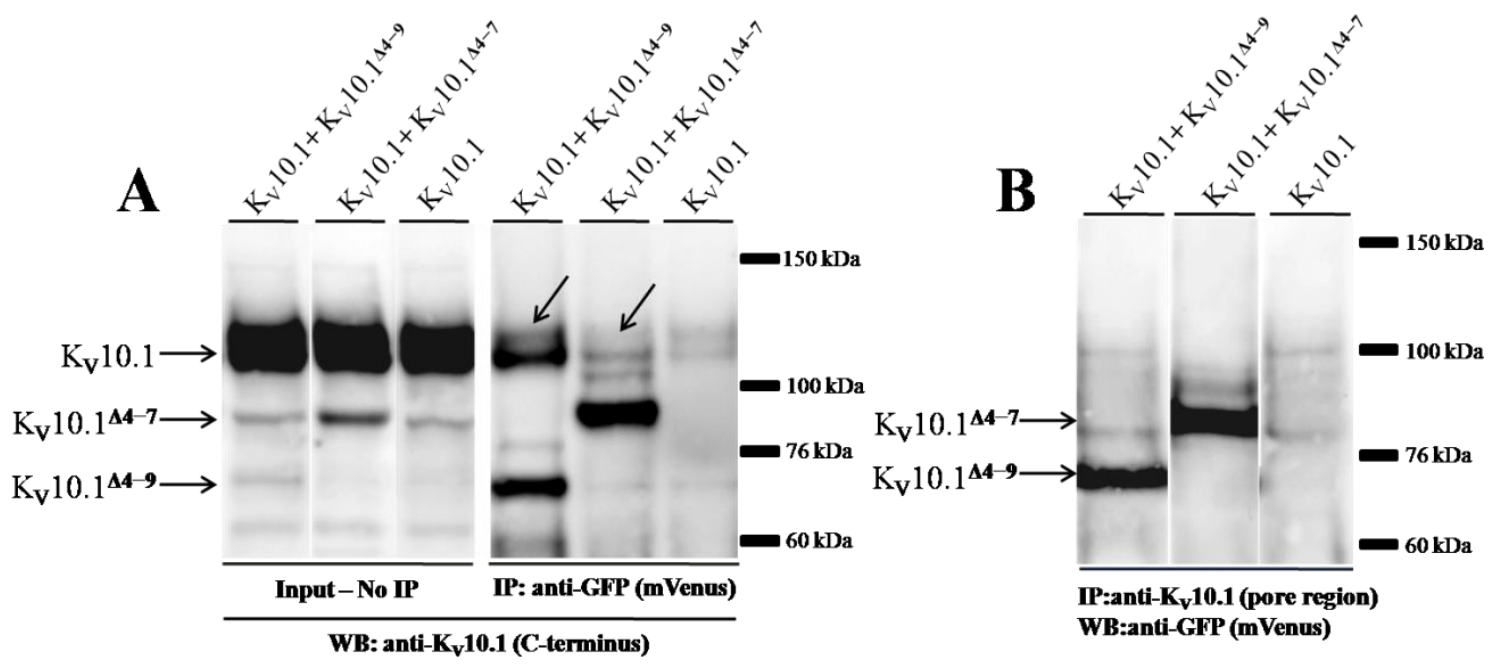

Figure $12 K_{V} 10.1^{\Delta 4-9}$ and $K_{V} 10.1^{\Delta 4-7}$ coprecipitate with $K_{V} 10.1$. Co-IP experiments: (A) Right panel: immunoprecipitation of mVenus co-precipitated $\mathrm{K}_{\mathrm{V}} 10.1$ protein of $\sim 130 \mathrm{kDa}$ in $\mathrm{K}_{\mathrm{V}} 10.1+\mathrm{K}_{\mathrm{V}} 10.1^{\Delta 4-9}$ samples and $\mathrm{K}_{\mathrm{V}} 10.1$ protein of $\sim 110 \mathrm{kDa}$ in $\mathrm{K}_{\mathrm{V}} 10.1+\mathrm{K}_{\mathrm{V}} 10.1^{\Delta 4-7}$. Left panel: input samples consisting of $10 \%(20 \mu \mathrm{g})$ not immunoprecipitated cell extracts. (B) Immunoprecipitation of $\mathrm{K}_{\mathrm{V}} 10.1$ with a transmembrane domain-targeting antibody coprecipitated $K_{V} 10.1^{\Delta 4-9}$ and $K_{V} 10.1^{\Delta 4-7}$.

To further test for interaction occurring between $\mathrm{K}_{\mathrm{V}} 10.1$ channel and its short isoforms $\mathrm{K}_{\mathrm{V}} 10.1^{\Delta 4-9}$ and $\mathrm{K}_{\mathrm{V}} 10.1^{\Delta 4-7}$, confocal microscopy analyses were performed to check the existence (and eventually quantify the amount) of colocalization. For this purpose, CHO cells co-transfected with fluorescently tagged $\mathrm{K}_{\mathrm{V}} 10.1$ and short isoforms $\left(\mathrm{K}_{\mathrm{V}} 10.1\right.$ mCherry and $\mathrm{K}_{\mathrm{V}} 10.1^{\Delta 4-9}$-mVenus) were used. Images of formalin-fixed cells were acquired using a laser scanning confocal microscope (Fig. $13 \mathrm{~A}$ ). The same experiments were carried out on cells co-transfected $\mathrm{K}_{\mathrm{V}} 10.1$-mCherry and $\mathrm{K}_{\mathrm{V}} 10.1^{\Delta 4-7}$-mVenus (Fig. 13 B). A plot profile of the two channels intensities drawn along the images already suggested the presence of a spatial overlap between the two fluorescent labels (Fig. 13 $\mathrm{C}$ and D). More precisely, the degree of colocalization between mVenus and mCherry channels was quantified using the Pearson's correlation, a statistical approach describing the correlation of the intensity distribution between channels: values between 0.5 and 1 are indicative of significant correlation (Adler and Parmryd, 2010). In our experiments values of $0.73 \pm 0.09$ were measured regarding interaction $\mathrm{K}_{\mathrm{V}} 10.1^{\Delta 4-9}$ $\mathrm{K}_{\mathrm{V}} 10.1$, while an average coefficient of $0.80 \pm 0.08$ was obtained for $\mathrm{K}_{\mathrm{V}} 10.1^{\Delta 4-7}$ $\mathrm{K}_{\mathrm{V}} 10.1$. These statistics are representative of at least 8 cells/group. 
A

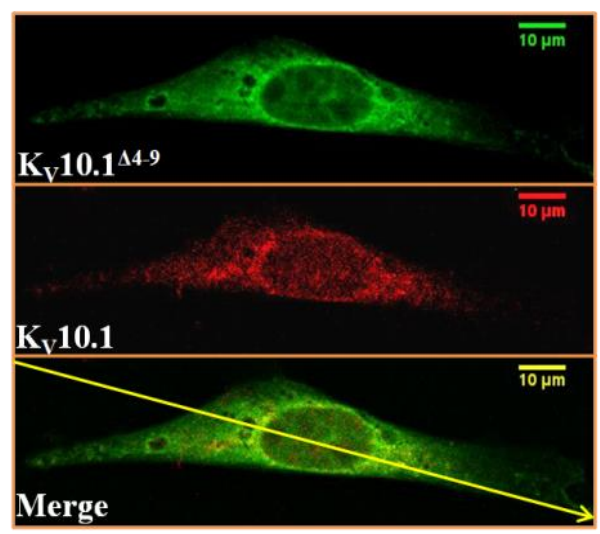

C

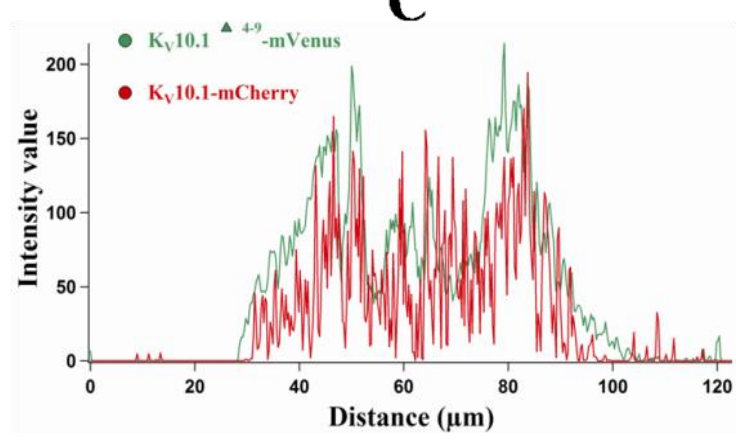

B

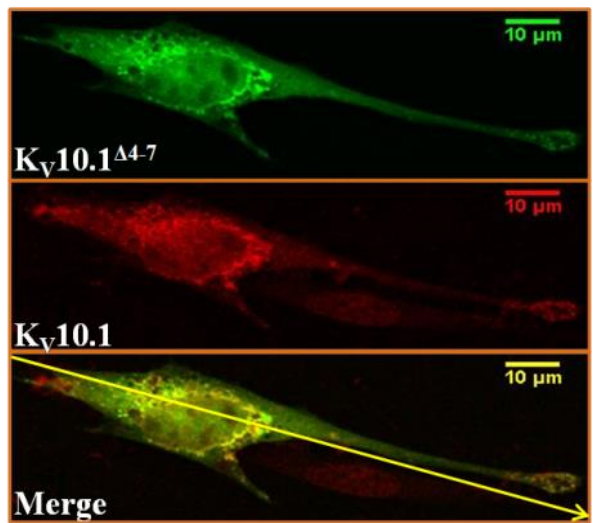

D

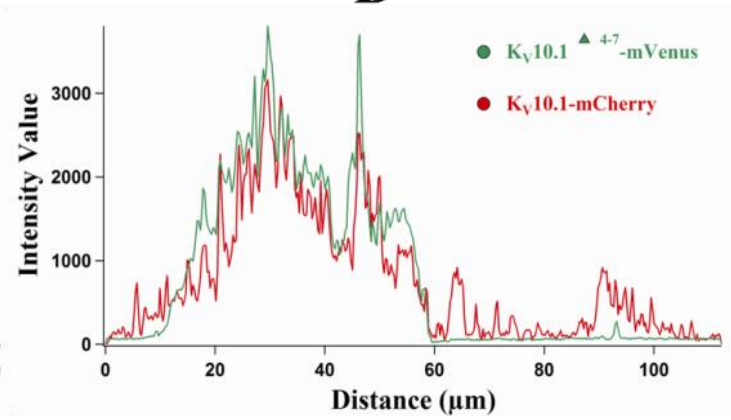

Figure $13 K_{V} 10.1^{\Delta 4-9}$ and $K_{V} 10.1^{\Delta 4-7}$ colocalize with $K_{V} 10.1$. Confocal microscopy experiments: (A) Images of $K_{V} 10.1^{\Delta 4-9}$-mVenus and $K_{V} 10.1$-mCherry and the merge of the two channels. (B) Images of $\mathrm{K}_{\mathrm{V}} 10.1^{\Delta 4-7}$-mVenus, $\mathrm{K}_{\mathrm{V}} 10.1-\mathrm{mCherry}$ and the merge of the two channels. (C) Plot profile of $\mathrm{K}_{\mathrm{V}} 10.1^{\Delta 4-9}$ and $K_{V} 10.1$ channels derived from the yellow cursor in panel A. (D) Plot profile of $K_{V} 10.1^{\Delta 4-7}$ and $\mathrm{K}_{\mathrm{V}} 10.1$ channels derived from the yellow cursor in panel $\mathrm{B}$.

\subsection{Impact of $K_{V} 10.1^{\Delta 4-9}$ and $K_{V} 10.1^{\Delta 4-7}$ on $K_{V} 10.1$ electrophysiological properties in the Xenopus laevis expression system}

After having ascertained that $\mathrm{K}_{\mathrm{V}} 10.1^{\Delta 4-9}$ and $\mathrm{K}_{\mathrm{V}} 10.1^{\Delta 4-7}$ are interaction partners of fulllength $\mathrm{K}_{\mathrm{V}} 10.1$ channels, the next experimental task was to assess whether the short isoforms would affect the electrophysiological properties of the channel. In order to test this, Xenopus laevis oocytes were injected with RNA coding for $\mathrm{K}_{\mathrm{V}} 10.1$, or a mixture of RNA coding for $K_{V} 10.1$ together with $K_{V} 10.1^{\Delta 4-9}$ or $K_{V} 10.1^{\Delta 4-7}$, at ratio $1: 1$ or $1: 10$ (Fig. 14 A). The macroscopic $K_{V} 10.1$ current was measured using the two-electrode voltage clamp (TEVC) technique, using a protocol where the voltage was driven from - 
$60 \mathrm{mV}$ to $+80 \mathrm{mV}$, with voltage steps of $20 \mathrm{mV}$. In these experiments $\mathrm{K}_{\mathrm{V}} 10.1$ current amplitude was significantly down-regulated by either co-injection with $K_{V} 10.1^{\Delta 4-9}$ or with $\mathrm{K}_{\mathrm{V}} 10.1^{\Delta 4-7}$ splice isoforms (Fig. $14 \mathrm{~B}$ ). At $80 \mathrm{mV}$ the average current reduction was $43.8 \pm 8.4 \%(\mathrm{p}<0.001)$ and $36.1 \pm 9.5 \%(\mathrm{p}=0.005)$, respectively. The $\mathrm{K}_{\mathrm{V}} 10.1$ current reduction was even more pronounced at higher $\mathrm{K}_{\mathrm{V}} 10.1^{\Delta 4-9}$ or $\mathrm{K}_{\mathrm{V}} 10.1^{\Delta 4-7}$ concentration (1:10 ratio samples): $67.8 \pm 8.3 \%$ ( $\mathrm{p}<0.001)$ and $65.5 \pm 7.4 \%(\mathrm{p}<0.001)$ (Fig. 14 C), respectively. It is important to note that the current reduction detected in the cells under co-expression of $\mathrm{K}_{\mathrm{V}} 10.1$ with $\mathrm{K}_{\mathrm{V}} 10.1^{\Delta 4-9}$ or $\mathrm{K}_{\mathrm{V}} 10.1^{\Delta 4-7}$ was not caused by the increased cRNA concentration or overloading of protein translation system since oocytes injected with higher quantity of $\mathrm{K}_{\mathrm{V}} 10.1 \mathrm{cRNA}$ (up to $10 \mathrm{ng} / \mu \mathrm{l}$ ), showed considerable increase in current magnitude (reaching up to $30 \mu \mathrm{A}$ ), already one day after injection (data not shown).

A

$\mathrm{K}_{\mathbf{v}} 10.1$
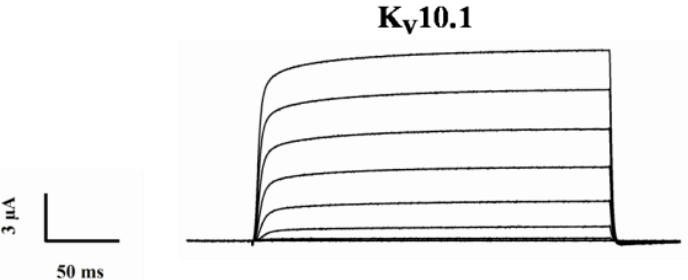

$50 \mathrm{~ms}$

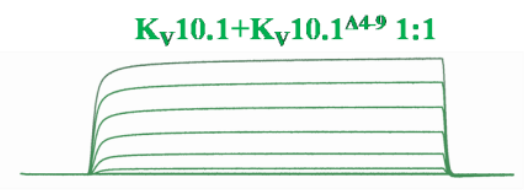

$K_{\mathbf{V}} 10.1+K_{V} 10.1^{\Lambda 4-7} 1: 1$

$K_{V} 10.1+K_{V} 10.1^{\wedge 4-9} 1: 10$
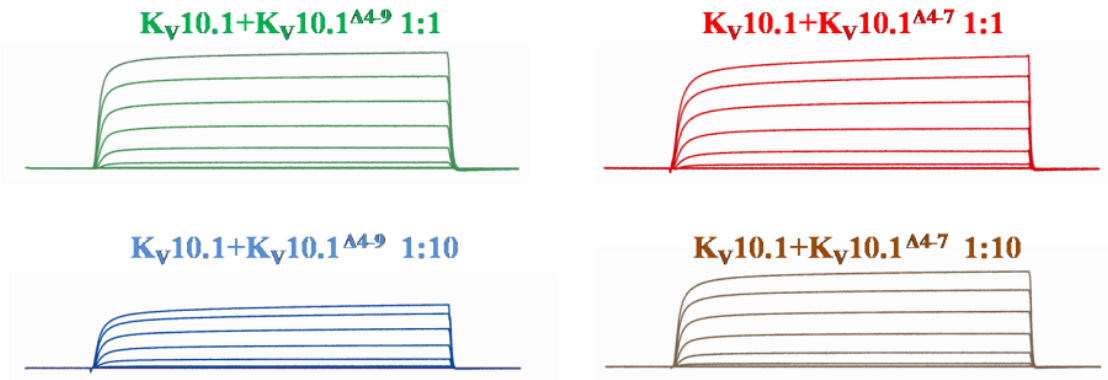

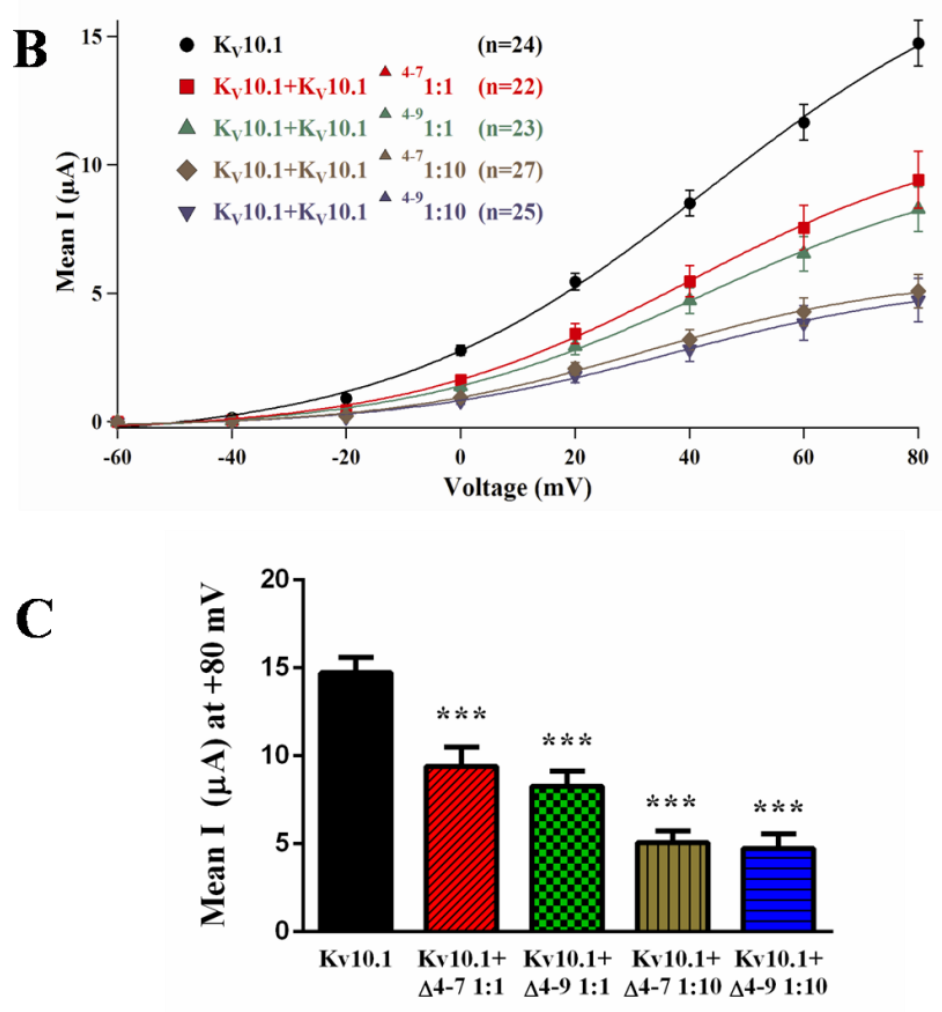

Figure $14 K_{V} 10.1$ current is down-regulated under co-expression with $K_{V} 10.1^{\Delta 4-9}$ and $K_{V} 10.1^{\Delta 4-7}$ in a dose-dependent manner. Two-electrode voltage clamp recordings: (A) $\mathrm{K}_{\mathrm{V}} 10.1$ macroscopic current traces recorded in $\mathrm{K}_{\mathrm{V}} 10.1, \mathrm{~K}_{\mathrm{V}} 10.1$ with $\mathrm{K}_{\mathrm{V}} 10.1^{\Delta 4-9}$ or with $\mathrm{K}_{\mathrm{V}} 10.1^{\Delta 4-7}$ samples at 1:1 and 1:10 ratios. (B) $\mathrm{I}-\mathrm{V}$ graph representing the macroscopic $\mathrm{K}_{\mathrm{V}} 10.1$ current at each voltage step. (C) Bar graph resuming the macroscopic $\mathrm{K}_{\mathrm{V}} 10.1$ current values at $+80 \mathrm{mV}$.

A defining electrophysiological feature of $\mathrm{K}_{\mathrm{V}} 10.1$ channel consists in a progressive deceleration of activation kinetics at increasing hyperpolarizing pre-pulses, reminiscent of Cole-Moore shift (Ludwig et al., 1994). To estimate the influence of splice isoforms on $\mathrm{K}_{\mathrm{V}} 10.1$ activation kinetics, a depolarization pulse after conditioning at two different negative holding potentials was applied, and the rise time of activation from $20 \%$ to $80 \%$ of maximal current was calculated for both $-60 \mathrm{mV}$ and $-120 \mathrm{mV}$ pre-pulses potentials for all the samples. All the recordings of cells expressing $\mathrm{K}_{\mathrm{V}} 10.1$ channels, either alone or in combination with $\mathrm{K}_{\mathrm{V}} 10.1^{\Delta 4-9}$ and $\mathrm{K}_{\mathrm{V}} 10.1^{\Delta 4-7}$ splice isoforms, showed strong dependence of activation kinetics on pre-pulse potentials (Fig. 15 A). In particular, no difference was detected between samples expressing $K_{V} 10.1$ and expressing $K_{V} 10.1^{\Delta 4-9}$ or $K_{V} 10.1^{\Delta 4-7}$ in $1: 1$ ratio with the full-length channel, having rise time of $45.8 \pm 8 \mathrm{~ms}, 36.9 \pm 5 \mathrm{~ms}(\mathrm{p}=0.38)$ and $47.02 \pm 7 \mathrm{~ms}(\mathrm{p}=0.91)$ at $-120 \mathrm{mV}$ prepulse potential, respectively. At $-60 \mathrm{mV}$ the rise time values for $\mathrm{K}_{\mathrm{V}} 10.1, \mathrm{~K}_{\mathrm{V}} 10.1+$ 
$\mathrm{K}_{\mathrm{V}} 10.1^{\Delta 4-9}$ and $\mathrm{K}_{\mathrm{V}} 10.1+\mathrm{K}_{\mathrm{V}} 10.1^{\Delta 4-7}$ were: $5.9 \pm 1 \mathrm{~ms}, 9.12 \pm 1 \mathrm{~ms}(\mathrm{p}=0.09)$ and $9.41 \pm 3$ ms (p=0.11) (Fig. 15 B), respectively. On the other hand, when co-expressed in 1:10 proportions, both $\mathrm{K}_{\mathrm{V}} 10.1^{\Delta 4-9}$ and $\mathrm{K}_{\mathrm{V}} 10.1^{\Delta 4-7}$ caused significant deceleration of the channel activation after $-60 \mathrm{mV}$ conditioning: $257 \pm 47 \%(\mathrm{p}<0.0001)$ and $220 \pm 37 \%$ ( $\mathrm{p}<0.0001$ ), while at $-120 \mathrm{mV}$ the increase of the rise time did not reach statistical significance $(20 \pm 27 \%$; $=0.46$ and $41 \pm 24 \%$; $=0.09)$ (Fig. $15 \mathrm{~B})$.
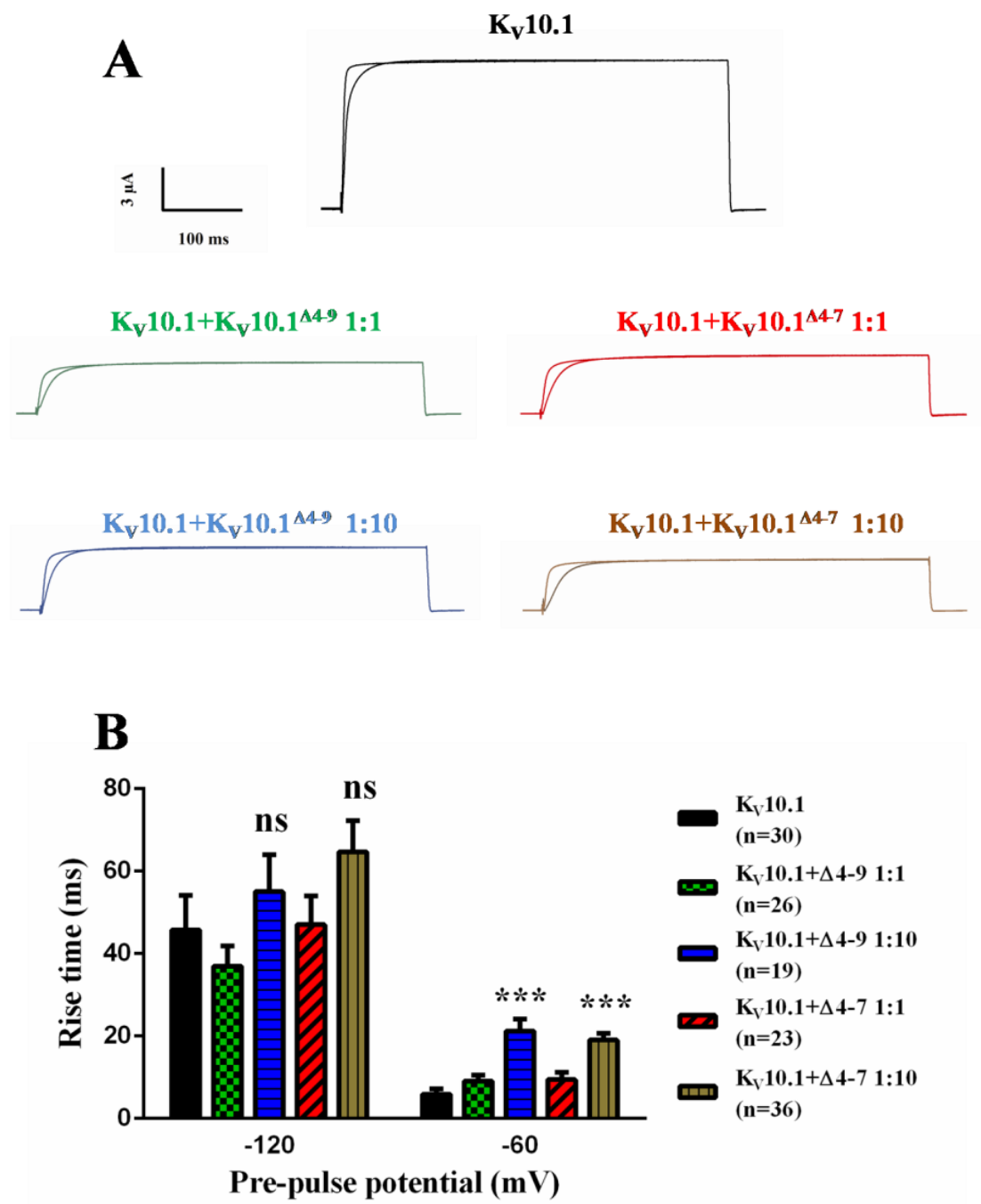

Figure $15 K_{\mathrm{v}} 10.1$ activation kinetics result decelerated under co-expression (in 1:10 ratio) with $K_{V} 10.1^{\Delta 4-9}$ and $K_{V} 10.1^{\Delta 4-7}$. Two-electrode voltage clamp recordings: (A) Representative traces of $\mathrm{K}_{\mathrm{V}} 10.1$ activation kinetics after pre-pulse potentials sweeps of $-120 \mathrm{mV}$ and $-60 \mathrm{mV}$. (B) Bar graph describing the rise times of $\mathrm{K}_{\mathrm{V}} 10.1$ activation from $20 \%$ to $80 \%$ of maximal current for each pre-pulse potential. 


\section{4 $K_{V} 10.1^{\Delta 4-9}$ and $K_{V} 10.1^{\Delta 4-7}$ impact on $K_{V} 1.4$-elicited currents}

In order to determine if the dominant-negative effect exerted by $K_{V} 10.1^{\Delta 4-9}$ and $\mathrm{K}_{\mathrm{V}} 10.1^{\Delta 4-7}$ on $\mathrm{K}_{\mathrm{V}} 10.1$ current are specific to $\mathrm{K}_{\mathrm{V}} 10.1$ channel, TEVC recordings on oocytes co-expressing $\mathrm{K}_{\mathrm{V}} 10.1^{\Delta 4-9}$ or $\mathrm{K}_{\mathrm{V}} 10.1^{\Delta 4-7}$ with $\mathrm{K}_{\mathrm{V}} 1.4$ channel were carried out; the same voltage step protocol to study the current-voltage relation previously described was applied (Fig. $16 \mathrm{~A}$ ). $\mathrm{K}_{\mathrm{V}} 1.4$ is a voltage-gated potassium channel from Shakerrelated subfamily, encoded by KCNA4 gene (Bett and Rasmusson, 2004). Unlike $\mathrm{K}_{\mathrm{V}} 10.1, \mathrm{~K}_{\mathrm{V}} 1.4$ undergoes rapid N-type inactivation (Fan et al., 2013). $\mathrm{K}_{\mathrm{V}} 10.1^{\Delta 4-9}$ and $\mathrm{K}_{\mathrm{V}} 10.1^{\Delta 4-7}$ splice isoforms expression did not result in any consistent effect on $\mathrm{K}_{\mathrm{V}} 1.4$ current, with the exception of the $\mathrm{K}_{\mathrm{V}} 10.1^{\Delta 4-9}$ co-expression in 1:10 ratio group, where a significant reduction of $37 \pm 16 \%(\mathrm{p}=0.02)$ of $\mathrm{K}_{\mathrm{V}} 1.4$ current at $80 \mathrm{mV}$ was detected (Fig. $16 \mathrm{~B})$. Overall, the effects on current magnitude mediated by $\mathrm{K}_{\mathrm{V}} 10.1^{\Delta 4-9}$ and $\mathrm{K}_{\mathrm{V}} 10.1^{\Delta 4-7}$ splice isoforms are likely to be specific for $\mathrm{K}_{\mathrm{V}} 10.1$ channel family.

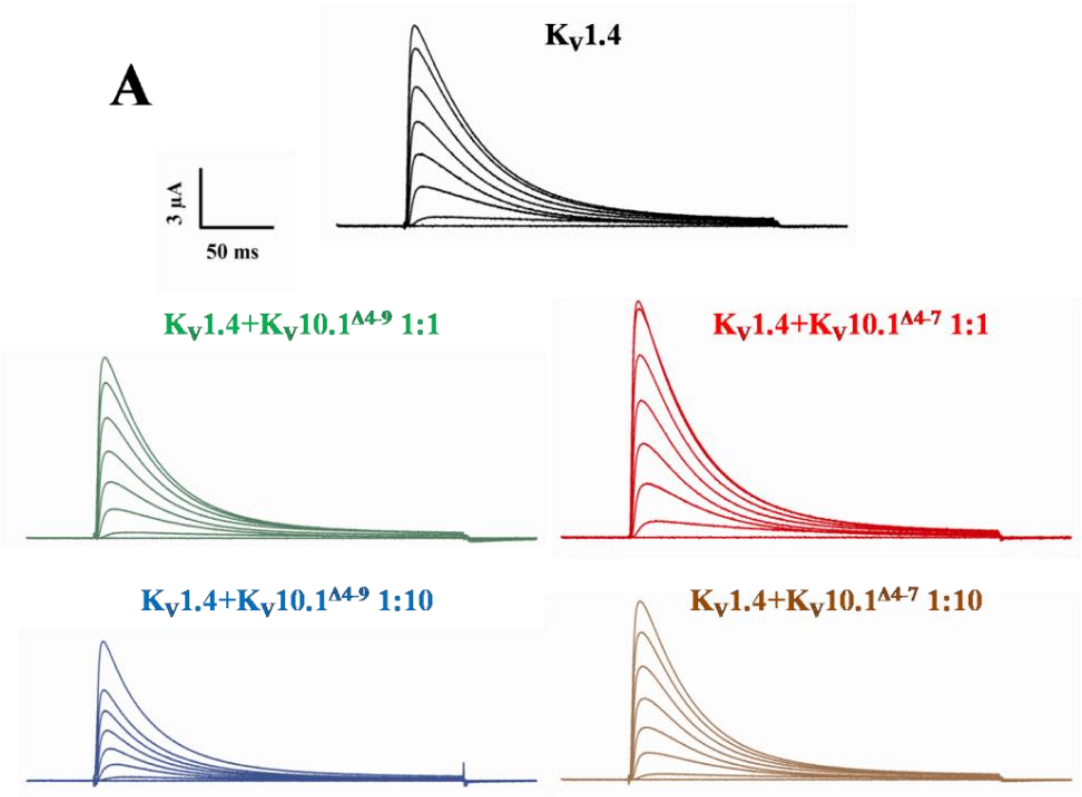




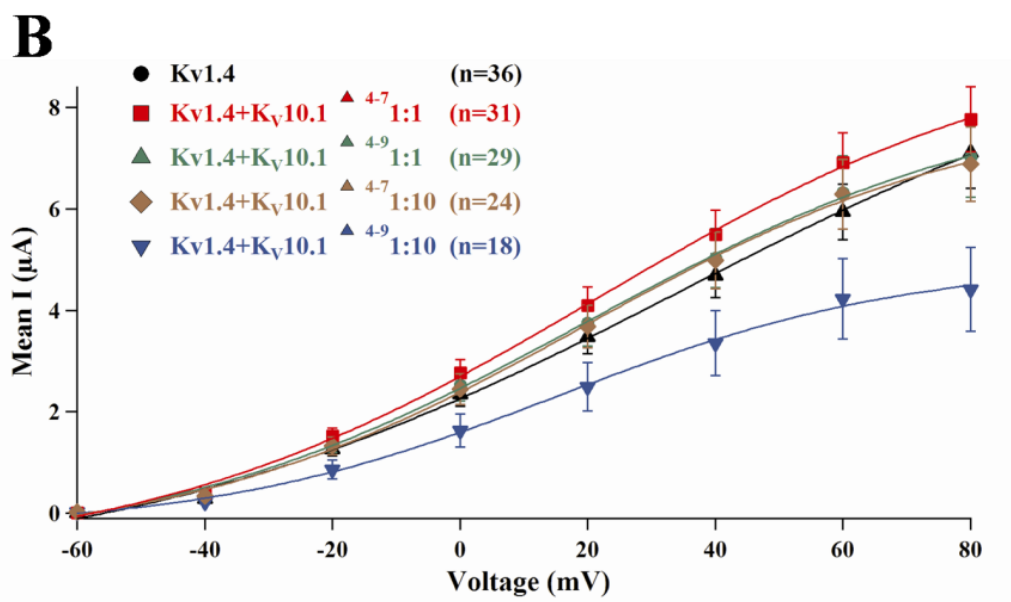

Figure $16 K_{V} 1.4$ current is not altered by co-expression with $K_{V} 10.1^{\Delta 4-9}$ and $K_{V} 10.1^{\Delta 4-7}$ (except for $K_{\mathbf{V}} 1.4 / K_{\mathbf{V}} 10.1^{\Delta 4-9}$ samples in $\mathbf{1 / 1 0}$ ratio). Two-electrode voltage clamp recordings: (A) $K_{V} 1.4$ macroscopic current traces recorded in $\mathrm{K}_{\mathrm{V}} 1.4, \mathrm{~K}_{\mathrm{V}} 1.4$ with $\mathrm{K}_{\mathrm{V}} 10.1^{\Delta 4-9}$ or with $\mathrm{K}_{\mathrm{V}} 10.1^{\Delta 4-7}$ samples at 1:1 and 1:10 ratios. (B) I-V graph representing the mean $\mathrm{K}_{\mathrm{V}} 1.4$ current at each voltage step.

\section{5 $K_{V} 10.1^{\Delta 4-9}$ and $K_{V} 10.1^{\Delta 4-7}$ effects on $K_{V} 10.1$ currents in a heterologous expression system of human origin.}

Studies on the impact of $K_{V} 10.1$ splice isoforms on the electrophysiological properties of the channel were also performed using a mammalian cell line system: HEK cells stably transfected with $\mathrm{K}_{\mathrm{V}} 10.1$ were transiently co-transfected with DNA constructs encoding $K_{V} 10.1^{\Delta 4-9}$ and $K_{V} 10.1^{\Delta 4-7}$ fused with the fluorescent protein mVenus. As control group, HEK-K 10.1 cells co-transfected with a plasmid containing mVenus alone were used. The patch clamp technique under whole cell configuration was the method used for recordings of $\mathrm{K}_{\mathrm{V}} 10.1$ macroscopic currents. Current traces were obtained using the following protocol: discrete depolarization pulses between $-60 \mathrm{mV}$ and $+80 \mathrm{mV}$ (in $20 \mathrm{mV}$ increments) of $300 \mathrm{~ms}$ length were applied from a holding potential of $-80 \mathrm{mV}$ (Fig. $17 \mathrm{~A}$ ). $\mathrm{K}_{\mathrm{V}} 10.1$ produced slowly activating, outward rectifying currents, which did not inactivate; an inward rectification was observed with strong depolarizations. This is compatible with a block exerted by intracellular sodium (Pardo at al., 1998). The detected steady state current was averaged (between $80 \%$ and $90 \%$ of the time of the depolarization pulse) and normalized by the size of cell membrane before analysis. As already observed in TEVC experiments, also in this context 
$\mathrm{K}_{\mathrm{V}} 10.1^{\Delta 4-9}$ and $\mathrm{K}_{\mathrm{V}} 10.1^{\Delta 4-7}$ co-expression with the full-length channel resulted in a marked $\mathrm{K}_{\mathrm{V}} 10.1$ current reduction of $41.7 \pm 20.5 \%(\mathrm{p}=0.04)$ for $\mathrm{K}_{\mathrm{V}} 10.1^{\Delta 4-9}$ and 53.8 $\pm 21.1 \%$ ( $\mathrm{p}=0.01$ ) for $\mathrm{K}_{\mathrm{V}} 10.1^{\Delta 4-7}$ (Fig. $17 \mathrm{~B}$ and C), respectively.

A
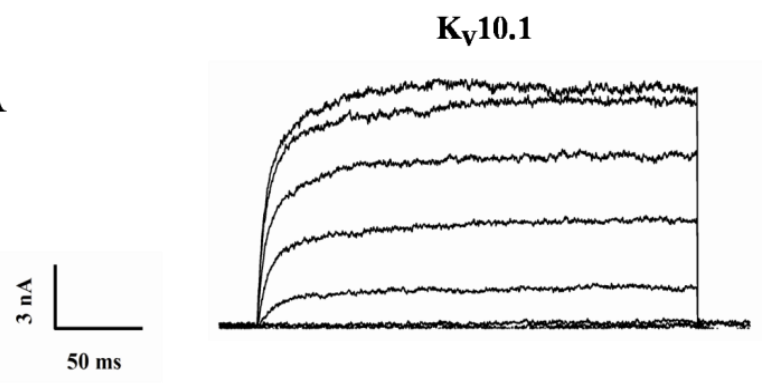

$K_{v} 10.1+K_{v} 10.1^{\wedge 4.9}$

$K_{\mathbf{V}} 10.1+K_{V} 10.1^{\Lambda 4-7}$
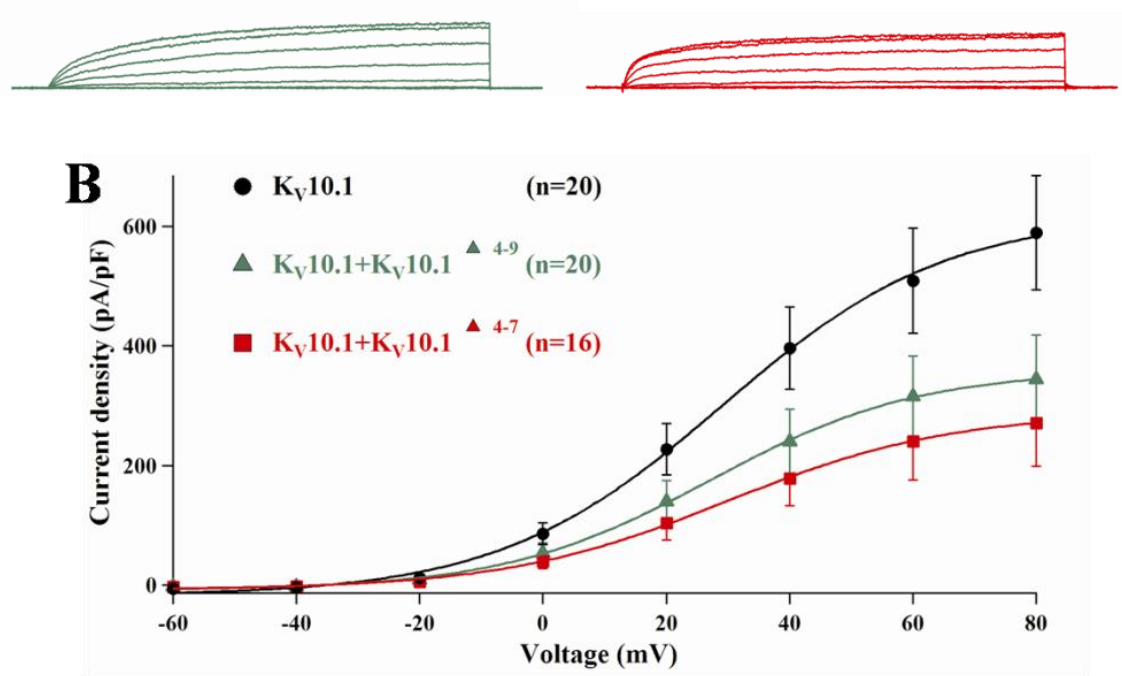

C

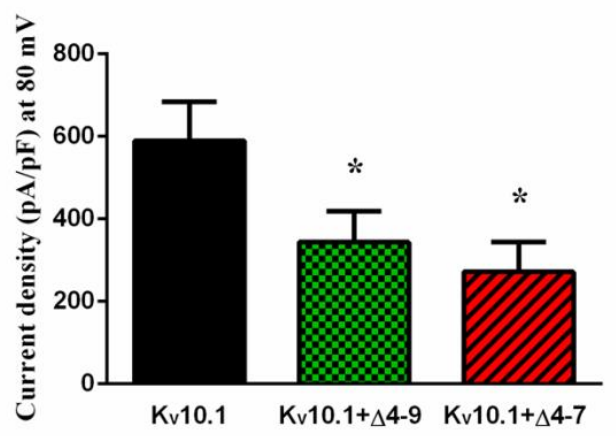

Figure $17 K_{\mathrm{V}} 10.1$ current is down-regulated under co-expression with $K_{\mathrm{v}} 10.1^{\Delta 4-9}$ and $K_{\mathrm{V}} 10.1^{\Delta 4-7}$ in a human-derived heterologous expression system. Patch clamp experiments: HEK cells expressing $\mathrm{K}_{\mathrm{V}} 10.1$ co-expressing either mVenus (depicted in black), $\mathrm{K}_{\mathrm{V}} 10.1^{\Delta 4-9} \mathrm{mVenus}$ (in green) or $\mathrm{K}_{\mathrm{V}} 10.1^{\Delta 4-7}$ $\mathrm{mVenus} \mathrm{(in} \mathrm{red).} \mathrm{Only} \mathrm{green} \mathrm{fluorescent} \mathrm{cells} \mathrm{visualized} \mathrm{under} \mathrm{epifluorescence} \mathrm{microscope} \mathrm{were} \mathrm{used} \mathrm{for}$ recordings. (A) Representative current traces. (B) To determine the current-voltage relationship, the steady-state current was measured at the end of each pulse and normalized against cell size. (C) Bar graph resuming the $\mathrm{K}_{\mathrm{v}} 10.1$ current density values at $+80 \mathrm{mV}$. 


\subsubsection{Investigations on the voltage dependence of the $K_{v} 10.1$ conductance under co-expression with $K_{V} 10.1^{\Delta 4-9}$ and $K_{V} 10.1^{\Delta 4-7}$}

To determine the impact of co-expression with $K_{V} 10.1^{\Delta 4-9}$ and $K_{V} 10.1^{\Delta 4-7}$ on the voltage dependence of $\mathrm{K}_{\mathrm{V}} 10.1$, tail current protocols in high extracellular potassium were used. The membrane potential was depolarized for $300 \mathrm{~ms}$ to a range of voltages between +80 and $-80 \mathrm{mV}$ in $20 \mathrm{mV}$ decrements, followed by a hyperpolarization step to $-120 \mathrm{mV}$ for $300 \mathrm{~ms}$ (Fig. $18 \mathrm{~A}$ ). The relative conductance $\left(\mathrm{G} / \mathrm{G}_{\max }\right)$ values were obtained by extrapolating the peak tail current amplitudes for each voltage (as described in section 3.4.2 of materials and methods) and normalizing them against the peak tail current recorded at $+80 \mathrm{mV}$.

Normalized current amplitude plotted was against the voltage then fitted with a Boltzmann sigmoid function. The resulting $V_{\text {half }}$ (voltage of half-maximal activation) was $21 \pm 1.7 \mathrm{mV}$ for $\mathrm{K}_{\mathrm{V}} 10.1$ control, $23 \pm 7.3 \mathrm{mV}$ for $\mathrm{K}_{\mathrm{V}} 10.1+\mathrm{K}_{\mathrm{V}} 10.1^{\Delta 4-9}$ and $20 \pm 1.3$ $\mathrm{mV}$, for $\mathrm{K}_{\mathrm{V}} 10.1+\mathrm{K}_{\mathrm{V}} 10.1^{\Delta 4-7}$. The slope factor $k$ obtained were $19 \pm 1.5 \mathrm{mV}, 20 \pm 3.3$ $\mathrm{mV}$ and $19 \pm 1.2 \mathrm{mV}$ (Fig. $18 \mathrm{~B}$ ), respectively. In conclusion, no significant changes in voltage dependence of $\mathrm{K}_{\mathrm{V}} 10.1$ conductance were detected upon co-expression with $\mathrm{K}_{\mathrm{V}} 10.1^{\Delta 4-9}$ and $\mathrm{K}_{\mathrm{V}} 10.1^{\Delta 4-7}$.

A

$K_{V} 10.1$

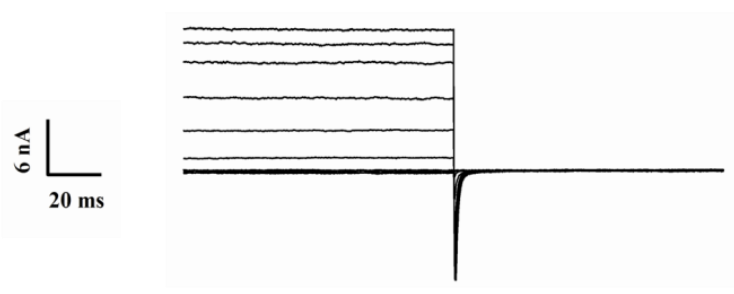

$K_{\mathrm{V}} \mathbf{1 0 . 1 + K _ { \mathrm { V } }} \mathbf{1 0 . 1} \mathbf{1}^{\mathrm{A49}}$

$K_{V} 10.1+K_{V} 10.1^{\Delta 4-7}$
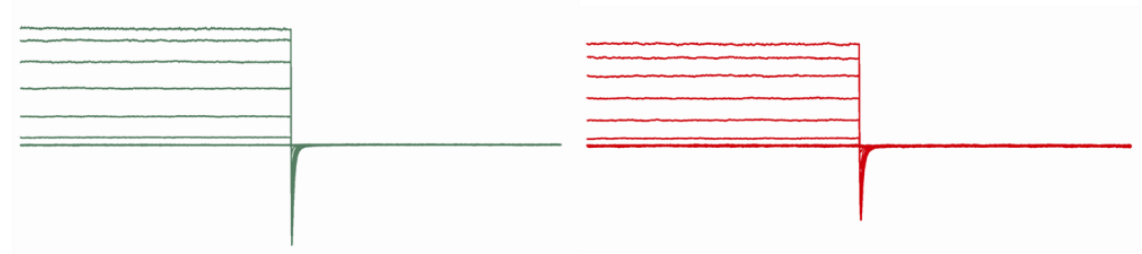


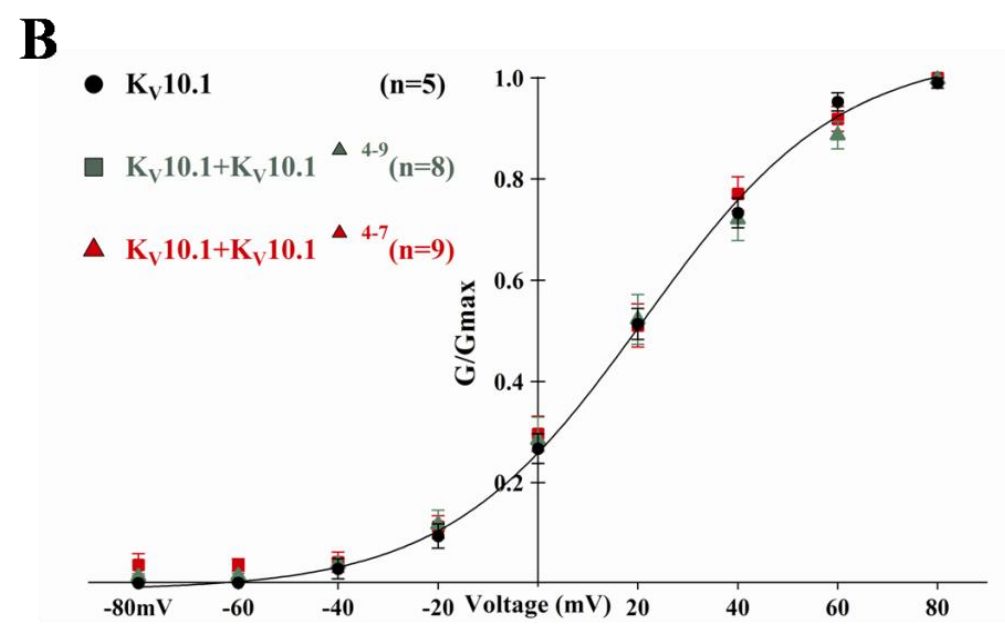

Figure 18 Voltage dependence of the $K_{V} 10.1$ conductance is not affected by co-expression with $K_{\mathbf{V}} 10.1^{\Delta 4-9}$ and $K_{\mathbf{V}} 10.1^{\Delta 4-7}$. Patch clamp recordings of HEK cells: samples expressing $K_{V} 10.1$ and coexpressing either mVenus are depicted in black, $\mathrm{K}_{\mathrm{V}} 10.1^{\Delta 4-9} \mathrm{mVenus}$ (in green) or $\mathrm{K}_{\mathrm{V}} 10.1^{\Delta 4-7} \mathrm{mVenus}$ (in red). Only green fluorescent cells visualized under epifluorescence microscope were used for recordings. (A) Representative $\mathrm{K}_{\mathrm{V}} 10.1$ tail currents. (B) G-V graph was generated from tail current analyses utilizing the Boltzmann function, representing the mean of $\mathrm{K}_{\mathrm{V}} 10.1$ conductance versus the maximal conductance at each voltage step.

\subsection{Mechanism of current amplitude reduction of $K_{V} 10.1$ channels induced by $K_{V} 10.1^{\Delta 4-9}$ or $K_{V} 10.1^{\Delta 4-7}$ co-expression}

The changes in total current $I$ occurring when the short isoforms $\mathrm{K}_{\mathrm{V}} 10.1^{\Delta 4-9}$ and $\mathrm{K}_{\mathrm{V}} 10.1^{\Delta 4-7}$ are expressed together with the full-length channel may result from altered number of channel surface expression $(N)$, changed single channel conductance $(I)$ or open probability $\left(P_{o}\right)$ or by a combination of these (see equation 3 in materials and methods). To distinguish between these possibilities, non-stationary noise analysis was performed on excised Xenopus laevis oocyte macropatches in the outside-out configuration, in order to quantify single channel conductance $i$, probability $P_{o}$ at a given voltage, as well as the number of channels $N$ in the patch. However, due to the tendency of the channels to be clustered on the membrane surface of the cell, the detected number of channels in each patch would have a different ratio with the total number of channels. This would make pointless to compare or to average $N$ between different patches. Therefore, changes in the amount of $\mathrm{K}_{\mathrm{V}} 10.1$ channel expressed at the 
surface under co-expression with $\mathrm{K}_{\mathrm{V}} 10.1^{\Delta 4-9}$ and $\mathrm{K}_{\mathrm{V}} 10.1^{\Delta 4-7}$ will be quantified using a biochemical approach (section 4.7).

Noise analysis recordings were carried out applying to the membrane patch several hundreds of depolarizing stimuli to $40 \mathrm{mV}$. Then the variance of each trace with respect to the average trace was determined, and a parabola function was fitted to the current against the variance data (Fig. 19 A). The results of the fitting in terms of single channel current $i$ showed unaltered values between $\mathrm{K}_{\mathrm{V}} 10.1(985 \pm 322 \mathrm{fA})$ and $\mathrm{K}_{\mathrm{V}} 10.1$ coinjected with $\mathrm{K}_{\mathrm{V}} 10.1^{\Delta 4-7}$ (872 $\pm 69 \mathrm{fA}, \mathrm{p}=0.86$, Fig. $19 \mathrm{~B}$ ) samples, whereas in the case of $\mathrm{K}_{\mathrm{V}} 10.1^{\Delta 4-9}$ co-injection, the single channel currents showed a reduction reaching statistical significance (596 $\pm 236 \mathrm{fA}, \mathrm{p}=0.041$, Fig. 19 B).

The extrapolated open probability at $40 \mathrm{mV}$ did not show significant changes between the $\mathrm{K}_{\mathrm{V}} 10.1(47.5 \pm 17 \%), \mathrm{K}_{\mathrm{V}} 10.1$ co-injected with $\mathrm{K}_{\mathrm{V}} 10.1^{\Delta 4-9}(45.7 \pm 13 \%$; $\mathrm{p}=0.94$, Fig. $19 \mathrm{C})$ and $\mathrm{K}_{\mathrm{V}} 10.1$ co-expressing $\mathrm{K}_{\mathrm{V}} 10.1^{\Delta 4-7}$ samples ( $42 \pm 15 \%$; $\mathrm{p}=0.71$, Fig. $\left.19 \mathrm{C}\right)$. The lack of changes for ' $i$ ' and ' $P_{o}$ ' under co-expression with $\mathrm{K}_{\mathrm{V}} 10.1^{\Delta 4-7}$ suggest that the previously recorded reduction in macroscopic channel both in oocytes and HEK cells would be caused by a reduced amount of channel $N$. On the other hand, the interaction of $\mathrm{K}_{\mathrm{V}} 10.1^{\Delta 4-9}$ with $\mathrm{K}_{\mathrm{V}} 10.1$ mediating total current $I$ reduction is likely to be related (at least in part) to the reduced $i$ detected applying noise analysis recordings.

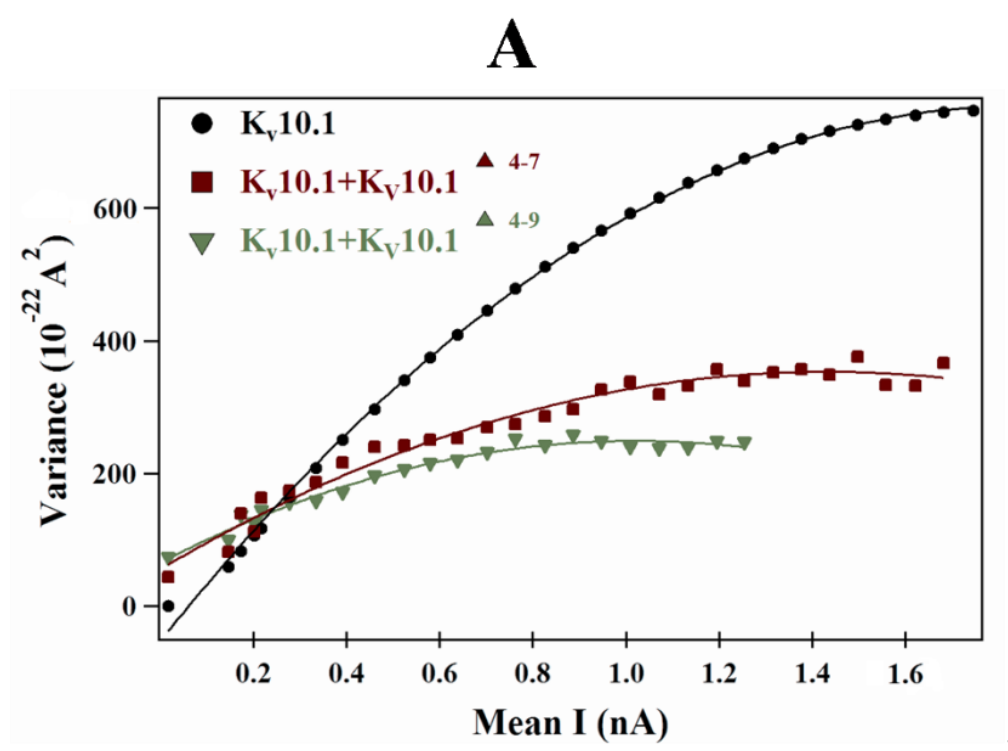



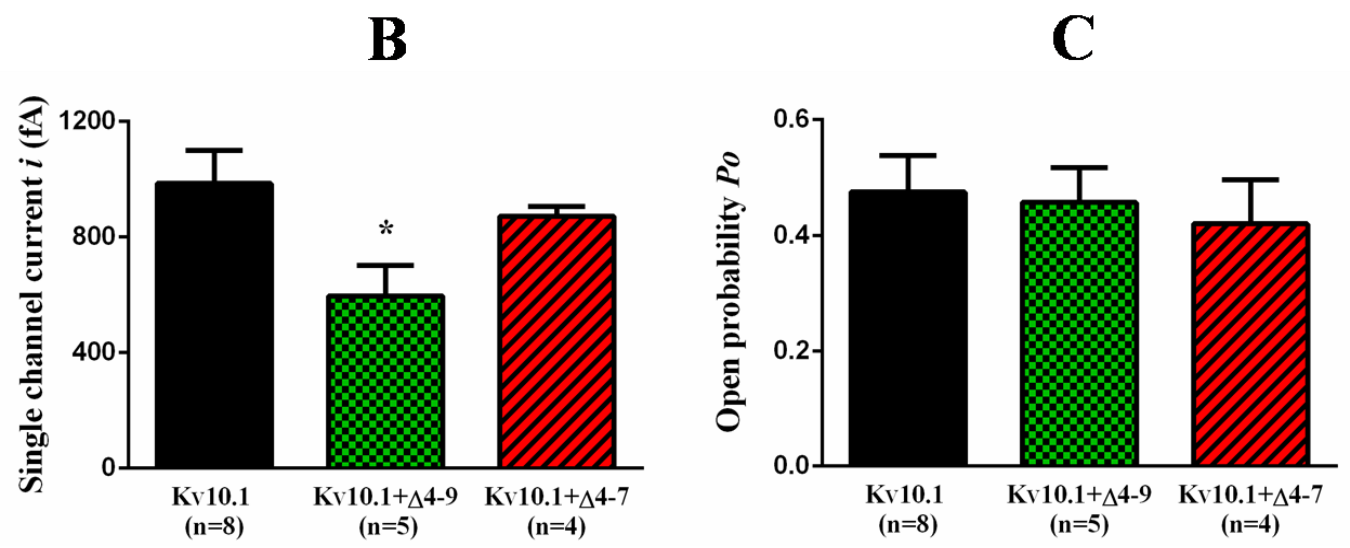

Figure 19 Impact of $K_{V} 10.1^{\Delta 4-9}$ and $K_{V} 10.1^{\Delta 4-7}$ co-expression on $K_{V} 10.1$ single channel current and open probability. Non-stationary noise analysis of $\mathrm{K}_{\mathrm{V}} 10.1$-mediated currents. Variance of several hundreds of depolarization pulses at $+40 \mathrm{mV}$ was calculated from excised Xenopus laevis oocyte macropatches in the outside-out configuration. (A) Representatives plots of the variance versus the mean current for $K_{V} 10.1$ (depicted in black), $K_{V} 10.1+K_{V} 10.1^{\Delta 4-9}$ (in green) and $K_{V} 10.1+K_{V} 10.1^{\Delta 4-7}$ (in red) samples, with the corresponding fitting parabola. (B) Bar graph showing the mean single channel current ' $i$ ' for each recorded group. (C) Bar graph showing the mean open probability $P_{o}$ for each recorded group.

\section{7 $K_{V} 10.1$ Surface amount modification in presence of $K_{V} 10.1^{\Delta 4-9}$ and $K_{V} 10.1^{\Delta 4-7}$}

The neurotoxin $\alpha$-bungarotoxin (BTX) binds with high affinity the nicotinic acetylcholine receptor (AChR)(Changeux et al., 1970). Researchers took advantage of the fact that BTX can also bind with high affinity a small 13 amino acids peptide that is homologous to the binding region of the subunit of AChR (Harel et al., 2001) and inserted this sequence (bungarotoxin-binding site, BBS) into AMPA receptor subunits. Using fluorescent and biotinylated BTX allowed for specific and quantitative surface labeling of the AMPA receptor (Sekine-Aizawa and Huganir, 2004). Kohl and coworkers adapted this approach to $\mathrm{K}_{\mathrm{V}} 10.1$ channels, generating the $\mathrm{K}_{\mathrm{V}} 10.1$-BBS system, a novel tool for quantitative analysis of surface $\mathrm{K}_{\mathrm{V}} 10.1$ (Kohl et al., 2011; Herrmann et al., 2012). In this part of work, we aimed to quantify the surface amount of $\mathrm{K}_{\mathrm{V}} 10.1$ channels utilizing the $\mathrm{K}_{\mathrm{V}} 10.1$-BBS cells system. Bungarotoxin-biotin labeled $\mathrm{K}_{\mathrm{V}} 10.1$ channels contained in the cell lysates were immobilized on streptavidin-coated plates, and a sandwich ELISA was performed. The results of five independent experiments are summarized in Fig. 20. Data represent the amount of surface $K_{V} 10.1$ in HEK-K $\mathrm{V}_{\mathrm{V}} 10.1$-BBS cells transfected with $\mathrm{K}_{\mathrm{V}} 10.1^{\Delta 4-9}, \mathrm{~K}_{\mathrm{V}} 10.1^{\Delta 4-7}$ or pCDNA3-mVenus 
alone (transfected control), normalized against values of untrasfected cells. No relevant difference $(\mathrm{p}=0.618)$ was detected between $\mathrm{K}_{\mathrm{V}} 10.1^{\Delta 4-7}(0.96 \pm 0.07)$ and the control samples $(0.91 \pm 0.06)$; conversely the amount of membrane-bound $\mathrm{K}_{\mathrm{V}} 10.1$-BBS resulted significantly increased $(\mathrm{p}=0.015)$ in case $\mathrm{K}_{\mathrm{V}} 10.1^{\Delta 4-9}$ was co-expressed with the fulllength channel $(1.22 \pm 0.09)$. Cells containing the BBS without $\alpha$-bungarotoxin treatments as well as cells not containing the BBS were used as negative controls.

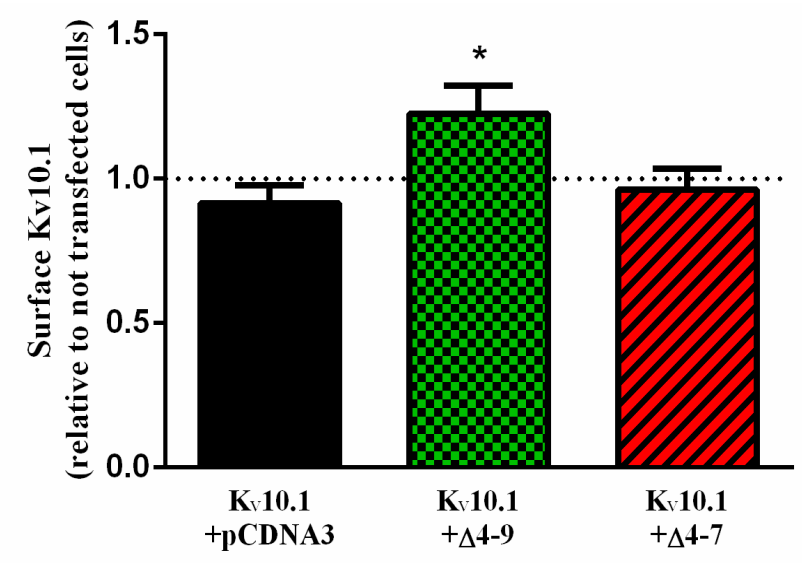

Figure $20 K_{V} 10.1$ surface amount increases in presence of $K_{V} 10.1^{\Delta 4-9}$ but not with $K_{V} 10.1^{\Delta 4-7}$. ELISA experiments: surface $\mathrm{K}_{\mathrm{V}} 10.1$-BBS amount was quantified for HEK- $\mathrm{K}_{\mathrm{v}} 10.1$-BBS transfected either with pCDNA3 (depicted in black, control group), $\mathrm{K}_{\mathrm{V}} 10.1^{\Delta 4-9}$ (in green), or $\mathrm{K}_{\mathrm{V}} 10.1^{\Delta 4-7}$ (in red). The presented data are normalized against HEK-K $\mathrm{V}_{\mathrm{V}} 10.1$-BBS untransfected cells values, and are derived from five independent experiments.

These results, contrary to what had been hypothesized after noise analysis recordings, point against the possibility that $K_{V} 10.1^{\Delta 4-7}$ reduce the amount of surface $K_{V} 10.1$ channels. However, if we consider that noise analysis takes in account only active channels, whereas the bungarotoxin used for our surface $K_{V} 10.1$ quantifications tags all the $\mathrm{K}_{\mathrm{V}} 10.1$ subunits located at the membrane surface, we propose that the factor underlying the $\mathrm{K}_{\mathrm{V}} 10.1^{\Delta 4-7}$-mediated $\mathrm{K}_{\mathrm{V}} 10.1$ current down-regulation is a reduction in the number of active channels situated at the membrane surface. For the same reason, the observed increase of $K_{V} 10.1$ surface amount in $K_{V} 10.1-K_{V} 10.1^{\Delta 4-9}$ samples could be due to functionally defective $K_{V} 10.1$ channels in the cell membrane. 


\section{8 $K_{V} 10.1, K_{V} 10.1^{\Delta 4-9}$ and $K_{V} 10.1^{\Delta 4-7}$ organization in native conditions}

In order to study the oligomeric state of $K_{V} 10.1, K_{V} 10.1^{\Delta 4-9}$ and $K_{V} 10.1^{\Delta 4-7}$ in native conditions, and to address the question whether $K_{V} 10.1^{\Delta 4-9}$ and/or $K_{V} 10.1^{\Delta 4-7}$ form heteromeric complexes with the full-length $\mathrm{K}_{\mathrm{V}} 10.1$, we performed biochemical assays maintaining native conditions, preserving the quaternary structure of the protein complexes. Blue Native PAGE (BN-PAGE) experiments were therefore carried out: membrane-enriched lysates from HEK-K $\mathrm{K}_{\mathrm{V}} 10.1$ cells transfected either with mVenus, $\mathrm{K}_{\mathrm{V}} 10.1^{\Delta 4-9} \mathrm{mVenus}$ or $\mathrm{K}_{\mathrm{V}} 10.1^{\Delta 4-7} \mathrm{mVenus}$ were subjected to electrophoretic separation on native polyacrylamide gel, then blotted on PVDF membrane. Membranes were decorated with an anti $\mathrm{K}_{\mathrm{V}} 10.1$ antibody targeting the C-terminal part of the full-length sequence and therefore recognizing also $K_{V} 10.1^{\Delta 4-9}$ and $K_{V} 10.1^{\Delta 4-7}$ epitopes. Under these conditions, broad bands of apparent molecular weight of approximately $900 \mathrm{kDa}$ were detected in all the $K_{V} 10.1$ positive cells; the same was observed for the $K_{V} 10.1^{\Delta 4-9}$ and $\mathrm{K}_{\mathrm{V}} 10.1^{\Delta 4-7}$ samples not containing $\mathrm{K}_{\mathrm{V}} 10.1$, indicating that also the short isoforms are arranged in macrocomplexes of apparent molecular weight of $\sim 900 \mathrm{kDa}$ (Fig. $21 \mathrm{~A}$ ).

To determine whether the macro-complexes detected here contained both short and fulllength isoforms, rather than only one of these components, two-dimensional SDSPAGE were carried out. With these experiments we could dissociate the components of the macro-complexes and separate them according to their molecular weight. In both $\mathrm{K}_{\mathrm{V}} 10.1+\mathrm{K}_{\mathrm{V}} 10.1^{\Delta 4-9}$ and $\mathrm{K}_{\mathrm{V}} 10.1+\mathrm{K}_{\mathrm{V}} 10.1^{\Delta 4-7}$ samples, the $900 \mathrm{kDa}$ complex contained full-length monomers of respectively $\sim 140 \mathrm{kDa}$ together with short isoform monomers of apparent molecular weight respectively $\sim 90 \mathrm{kDa}$ and $\sim 105 \mathrm{kDa}$ (Fig. $21 \mathrm{~B}$ ).

Based on their electrophoretic mobility we propose that in native conditions, full-length channel and short isoforms are likely to be assembled in supramolecular complexes, probably together with additional proteins. Yet, we are not able to tell whether they are organized in homo- or heterotetramers. However, despite our effort to refine the experimental conditions, in our experiments we still noticed a consistent amount of protein retained into the wells, which could be a sign of incomplete protein solubilization (Reisinger and Eichacker, 2007). Improvement in solubilization could change the electrophoretic behavior of our protein complexes, helping us to 
discriminate between the presence of $\mathrm{K}_{\mathrm{V}} 10.1$ homo- or heterotetramers in our preparations.
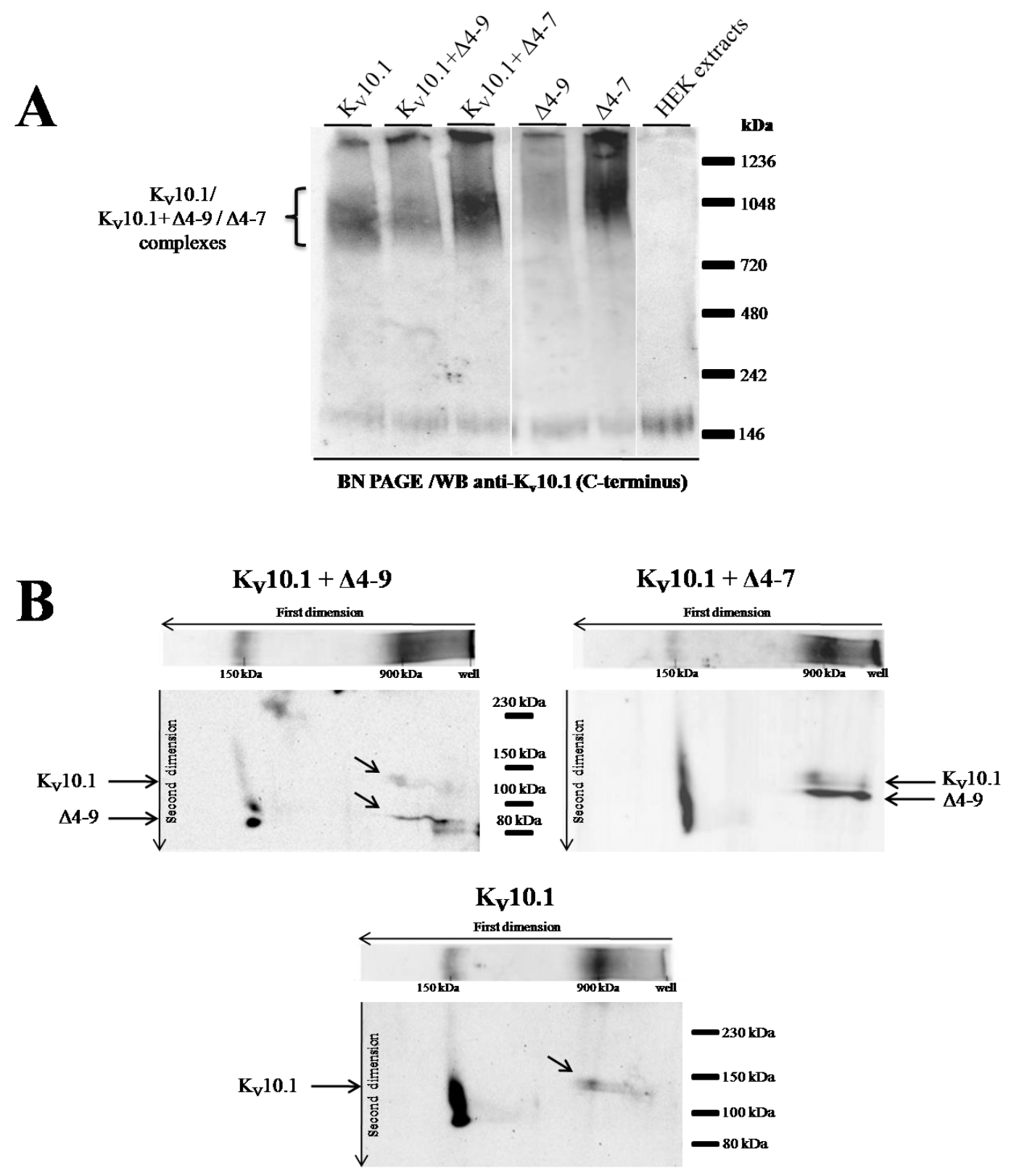

Figure $21 K_{\mathbf{v}} 10.1^{\Delta 4-9}$ and $K_{v} 10.1^{\Delta 4-7}$ interact with $K_{v} 10.1$ in native conditions. (A) BN-PAGE: $\sim 900$ $\mathrm{kDa}$ macromolecular complexes were detected in all the $\mathrm{K}_{\mathrm{V}} 10.1$ positive and $\mathrm{K}_{\mathrm{V}} 10.1^{\Delta 4-9} / \mathrm{K}_{\mathrm{V}} 10.1^{\Delta 4-7}$ $\mathrm{K}_{\mathrm{V}} 10.1$ negative samples; the band at $\sim 150 \mathrm{kDa}$ was unspecific because revealed also in $\mathrm{K}_{\mathrm{V}} 10.1$ negative samples. (B) Two-dimensional SDS-PAGE: the macromolecular complex contained both the full-length channel and the short isoforms. 


\subsection{Structural determinants of the interaction between $K_{V} 10.1^{\Delta 4-9}$ and $K_{V} 10.1^{\Delta 4-7}$ and full-length $K_{V} 10.1$}

The tetramerizing coiled coil (TCC) is a 41 amino acid sequence in $\mathrm{K}_{\mathrm{V}} 10.1 \mathrm{C}$-terminus region, responsible for its correct assembling in the tetrameric structure characteristic of the functional channel. A leucine to tyrosine mutation at position 20 within this sequence (L20Y) has been described to impair the ability of the channel to tetramerize and to preclude formation of functional ion channels (Jenke et al., 2003). Here, the L20Y mutation was used to check whether TCC is critical for the interaction between short isoforms $K_{V} 10.1^{\Delta 4-9}$ and $K_{V} 10.1^{\Delta 4-7}$, and the full length $K_{V} 10.1$. TCC sequence was mutated in both splice variants $K_{V} 10.1^{\Delta 4-9}$ and $K_{V} 10.1^{\Delta 4-7}$ sequences by site directed mutagenesis, and the existence of interaction was investigated by means of coIP experiments: immunoprecipitation of mVenus protein fused to $\mathrm{K}_{\mathrm{V}} 10.1^{\Delta 4-9} \mathrm{~L} 20 \mathrm{Y}$ and $\mathrm{K}_{\mathrm{V}} 10.1^{\Delta 4-7} \mathrm{~L} 20 \mathrm{Y}$ samples was followed by blotting the membrane with an antibody against $K_{V} 10.1$ (C-terminus): both mutated $K_{V} 10.1^{\Delta 4-9}$ and $K_{V} 10.1^{\Delta 4-7}$ coprecipitated with $\mathrm{K}_{\mathrm{V}} 10.1$ (protein size $\sim 130 \mathrm{kDa}$ ), although in $\mathrm{K}_{\mathrm{V}} 10.1^{\Delta 4-9}$ immunoprecipitation resulted quantitatively less efficient than in $\mathrm{K}_{\mathrm{V}} 10.1^{\Delta 4-7}$ L20Y samples (Fig. 22).

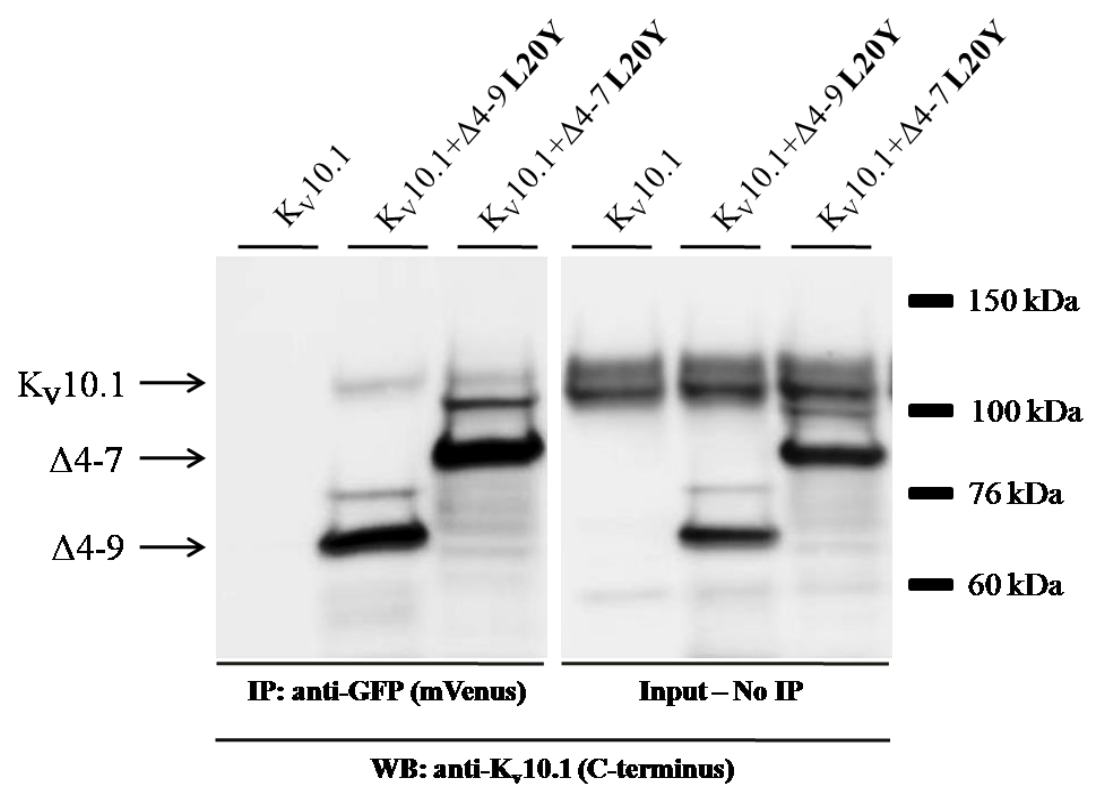

Figure $22 K_{v} 10.1$ short isoforms expressing a defective TCC domain coprecipitate with the fulllength channel. Co-IP experiments: immunoprecipitation of mVenus in $\mathrm{K}_{\mathrm{V}} 10.1+\mathrm{K}_{\mathrm{V}} 10.1^{\Delta 4-9} \mathrm{~L} 20 \mathrm{Y}$ and $\mathrm{K}_{\mathrm{V}} 10.1+\mathrm{K}_{\mathrm{V}} 10.1^{\Delta 4-7} \mathrm{~L} 20 \mathrm{Y}$ co-precipitated $\mathrm{K}_{\mathrm{V}} 10.1$ protein $(\sim 130 \mathrm{kDa})$. Input samples consist of $10 \%$ (20 $\mu \mathrm{g})$ cell extracts. 


\subsubsection{Impact of TCC inactivation on the $K_{V} 10.1$ current modulation exerted by $K_{V} 10.1^{\Delta 4-9}$ and $K_{V} 10.1^{\Delta 4-7}$}

Provided that $\mathrm{K}_{\mathrm{V}} 10.1$ and short isoforms having altered TCC domain still coimmunoprecipitate, the $\mathrm{K}_{\mathrm{V}} 10.1$ electrophysiological properties under co-expression with the L20Y splice variants constructs were analyzed with patch clamp recordings in the whole cell configuration (Fig. 23 A). Using as reference $K_{V} 10.1$-expressing cells, at $80 \mathrm{mV}$ voltage, $\mathrm{K}_{\mathrm{V}} 10.1$ current density was down-regulated by $45.3 \pm 20.3 \%$ (p=0.03) in $\mathrm{K}_{\mathrm{V}} 10.1+\mathrm{K}_{\mathrm{V}} 10.1^{\Delta 4-7}$ L20Y samples (Fig. $23 \mathrm{~B}$ and C), similarly to prior recordings with $\mathrm{K}_{\mathrm{V}} 10.1+\mathrm{K}_{\mathrm{V}} 10.1^{\Delta 4-7} \mathrm{WT}$.

Conversely, in $\mathrm{K}_{\mathrm{V}} 10.1+\mathrm{K}_{\mathrm{V}} 10.1^{\Delta 4-9} \mathrm{~L} 20 \mathrm{Y}$ samples the mild current reduction recorded (20.8 $\pm 21.9 \%)$ was not statistically significant compared to the reference group ( $p=0.34$, Fig. 23 B and C), in contrast with the outcome of previous electrophysiological analysis performed with $\mathrm{K}_{\mathrm{V}} 10.1+\mathrm{K}_{\mathrm{V}} 10.1^{\Delta 4-9}$. This result strongly indicates that current reduction of $\mathrm{K}_{\mathrm{V}} 10.1$ requires an intact TCC, therefore suggesting that the TCC sequence plays a critical role in the $\mathrm{K}_{\mathrm{V}} 10.1^{\Delta 4-9}$-induced $\mathrm{K}_{\mathrm{V}} 10.1$ current decrease.
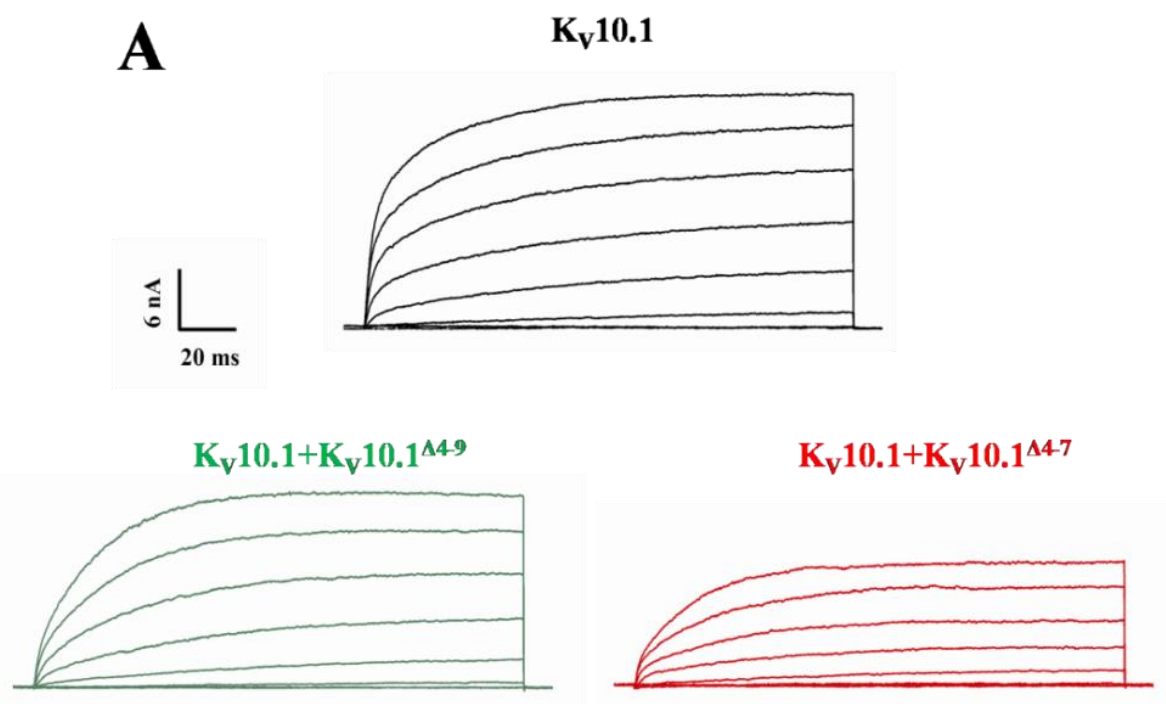


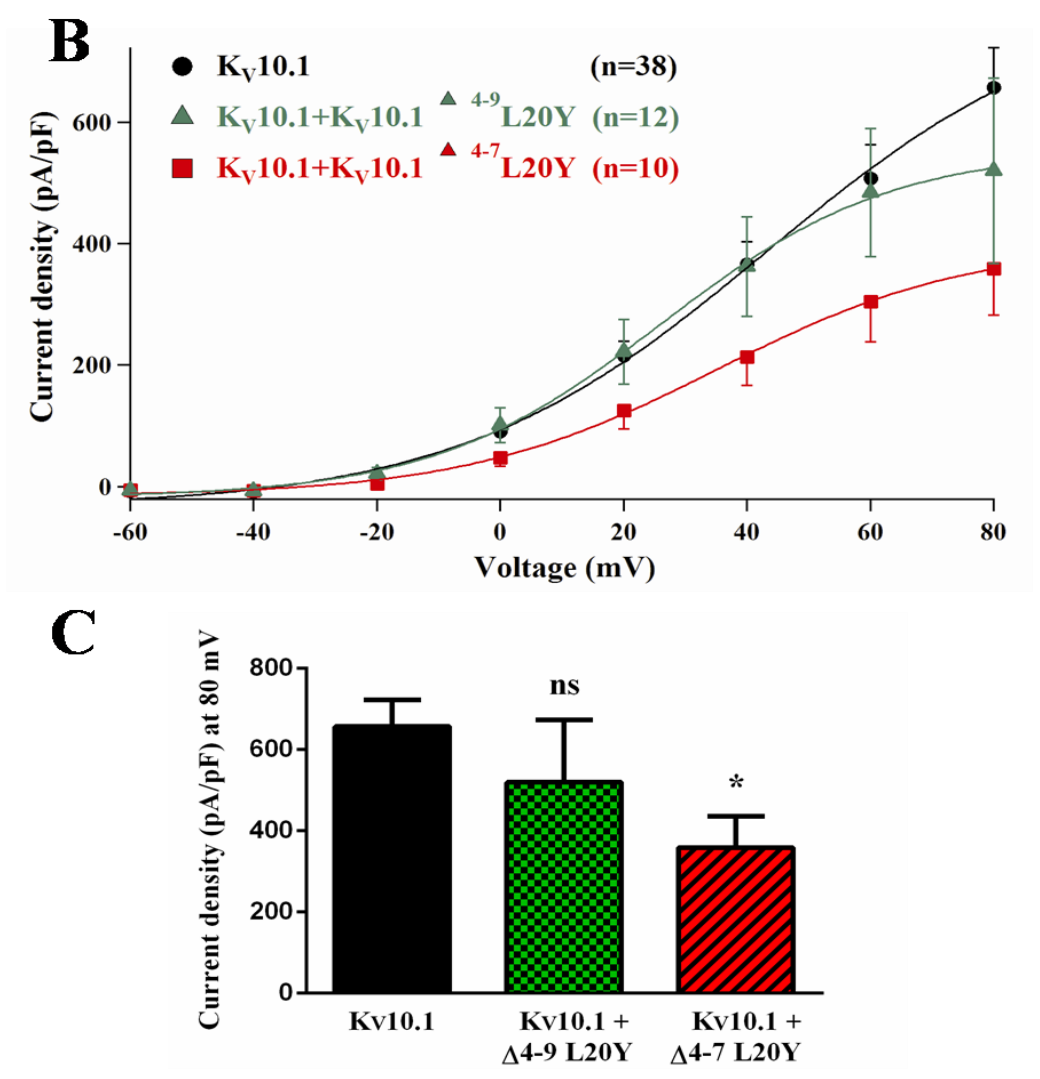

Figure $23 K_{v} 10.1$ current amplitude is unaffected by co-expression with $K_{v} 10.1^{\Delta 4-9}-\mathrm{L} 20 \mathrm{Y}$, whereas diminished with $\mathbf{K}_{\mathbf{V}} \mathbf{1 0 . 1}^{\Delta 4-7}$-L20Y. Patch clamp recordings of HEK cells: cells expressing $K_{\mathrm{V}} 10.1$ coexpressing either mVenus are depicted in black, $\mathrm{K}_{\mathrm{V}} 10.1^{\Delta 4-9}$-L20Y-mVenus (in green) or $\mathrm{K}_{\mathrm{V}} 10.1^{\Delta 4-7}$ L20Y-mVenus (in red). Only green fluorescent cells visualized under epifluorescence microscope were used for recordings. (A) Typical $\mathrm{K}_{\mathrm{V}} 10.1$ current traces. (B) I-V graph representing the mean of $\mathrm{K}_{\mathrm{V}} 10.1$ current density at each voltage step. (C) Bar graph resuming the $\mathrm{K}_{\mathrm{V}} 10.1$ current density values at +80 $\mathrm{mV}$.

\subsubsection{Effects on $K_{V} 10.1$ glycosylation pattern mediated by $K_{V} 10.1^{\Delta 4-7}$ interaction with the full-length channel}

$\mathrm{N}$-Linked glycosylation is a common post-translational modification of membrane proteins. Proper glycosylation is required for correct trafficking of $\mathrm{K}_{\mathrm{V}} 10.1$ protein to the membrane and important for the regular function of the channel already inserted in the membrane (Napp et al., 2005). $\mathrm{K}_{\mathrm{V}} 10.1$ glycosylation pattern (after immunobloting using a specific antibody) consists of two distinct bands, with electrophoretic mobilities corresponding to $\sim 110$ and $\sim 130 \mathrm{kDa}$ (termed E110 and E130). E110 corresponds to core glycosylated $\mathrm{K}_{\mathrm{V}} 10.1$ located in the ER and Golgi, while E130 is a post ER, complex glycosylated isoform (Napp et al., 2005). Results from co-IP experiments 
previously performed showed that under co-expression with $\mathrm{K}_{\mathrm{V}} 10.1^{\Delta 4-7}, \mathrm{~K}_{\mathrm{V}} 10.1$ protein presented an altered electrophoretic pattern, compared with $\mathrm{K}_{\mathrm{V}} 10.1^{\Delta 4-9}$ co-expression (Fig. 12 A). We wanted now to determine whether this phenomenon was a result of modified glycosylation occurring to $K_{V} 10.1$ under co-expression with $K_{V} 10.1^{\Delta 4-7}$. To this aim, we performed an immunoprecipitation with an antibody targeting mVenus, then we digested the samples with the enzymes Endo $\mathrm{H}$ (removing only core oligosaccharides) and PNGase F, (which fully deglycosylates proteins). $\mathrm{K}_{\mathrm{V}} 10.1$ glycosylation pattern resulted indistinguishable in both the cases $\mathrm{K}_{\mathrm{V}} 10.1$ is expressed alone or in combination with $\mathrm{K}_{\mathrm{V}} 10.1^{\Delta 4-9}$. Unlike the previous cases, $\mathrm{K}_{\mathrm{V}} 10.1$ glycosylation pattern was changed under co-expression with $\mathrm{K}_{\mathrm{V}} 10.1^{\Delta 4-7}$ : E130 band was very faint (Fig. 24 A) in the control lane, and virtually absent in the PNGase Ftreated samples. This would suggest that interaction between the full-length and $\mathrm{K}_{\mathrm{V}} 10.1^{\Delta 4-7}$ occurs when the $\mathrm{K}_{\mathrm{V}} 10.1$ protein is at immature state and that under these conditions its further glycosylation is impaired. The result of this phenomenon is a progressive reduction of $K_{V} 10.1$ complex glycosylated fraction in a $K_{V} 10.1^{\Delta 4-7}$ dosedependent manner. This is accompanied by a parallel increase of E110 $\mathrm{K}_{\mathrm{V}} 10.1$ form, as resulting from this IP experiment using oocytes injected with different ratios $\mathrm{K}_{\mathrm{V}} 10.1 / \mathrm{K}_{\mathrm{V}} 10.1^{\Delta 4-7}$ (Fig. $24 \mathrm{~B}$ and C). 


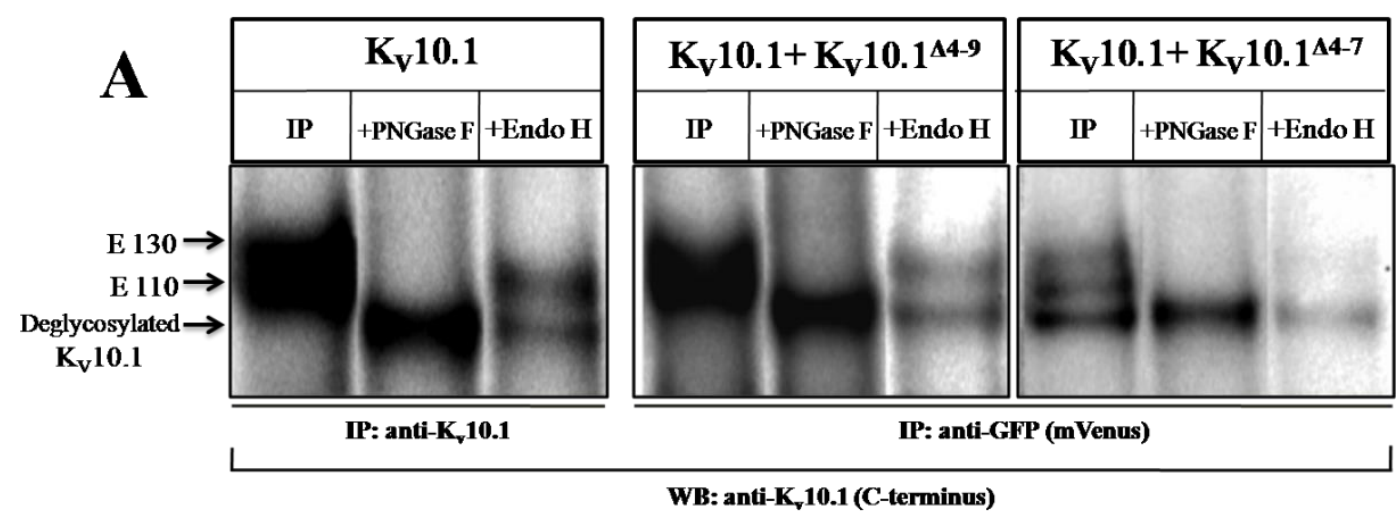

B

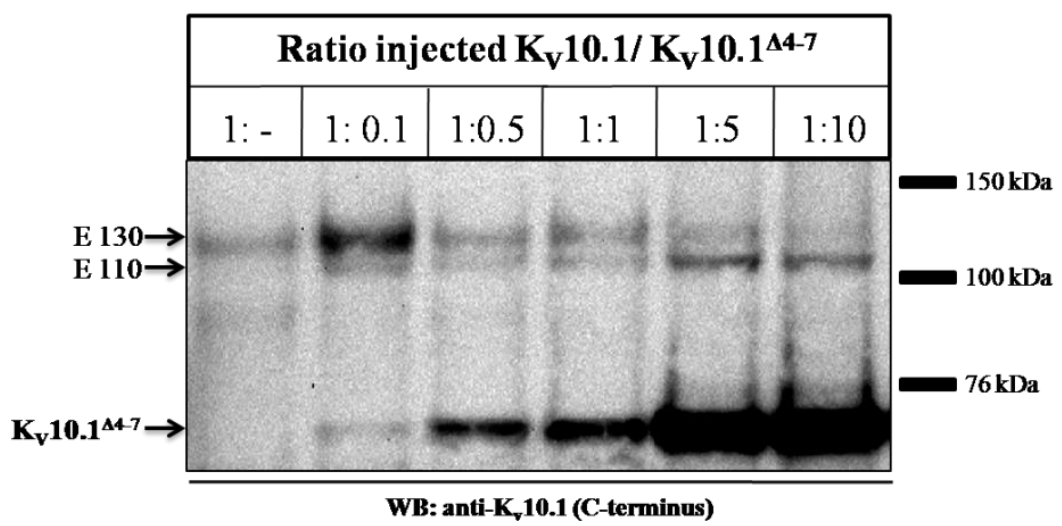

C

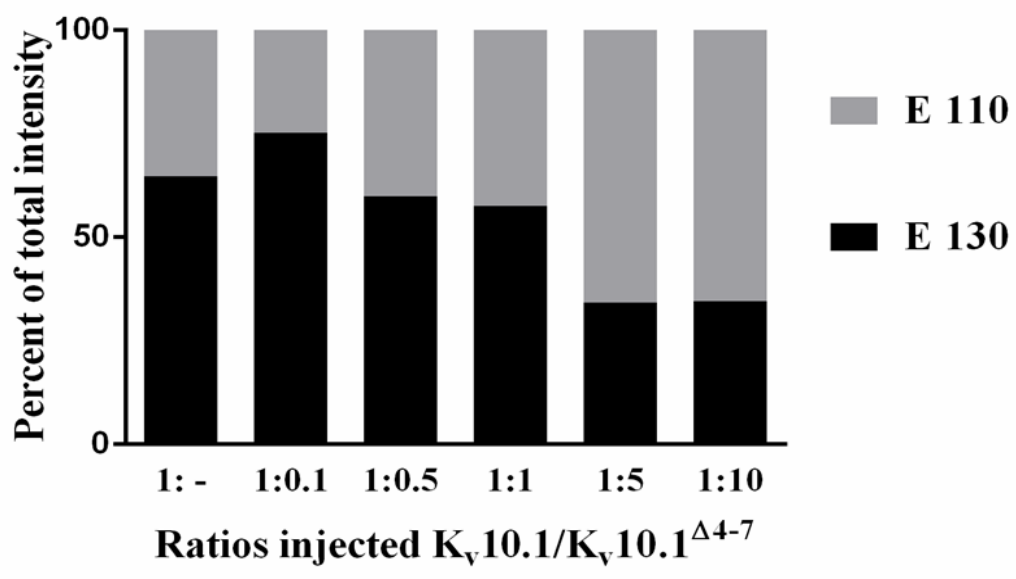

Figure 24 Analyses of $K_{V} 10.1$ glycosylation under co-expression with $K_{V} 10.1^{\Delta 4-7}$ and $K_{V} 10.1^{\Delta 4-9}$. (A) Co-immunoprecipitation of $K_{V} 10.1$ with the short isoforms $K_{V} 10.1^{\Delta 4-9}$ and $K_{V} 10.1^{\Delta 4-7}$ performed using Endo $\mathrm{H}$ and PNGase $\mathrm{F}$ to highlight the $\mathrm{K}_{\mathrm{V}} 10.1$ glycosylation pattern. Notice that $\mathrm{E} 130$ is virtually absent under co-interaction $\mathrm{K}_{\mathrm{V}} 10.1-\mathrm{K}_{\mathrm{V}} 10.1^{\Delta 4-7}$. (B) Immunoprecipitation of $\mathrm{K}_{\mathrm{V}} 10.1$ and $\mathrm{K}_{\mathrm{V}} 10.1^{\Delta 4-7}$ proteins in oocytes injected with increasing ratios $\mathrm{K}_{\mathrm{V}} 10.1^{\Delta 4-7}-\mathrm{K}_{\mathrm{V}} 10.1$. E110/E130 ratio increases together with increasing ratios of $K_{V} 10.1^{\Delta 4-7} / K_{V} 10.1 c R N A$ injected. (C) Densitometric analysis of Fig. 4.16 B: for each injected group, single E110 and E130 densitometry values were normalized against the sum of E110 + E130. 


\subsection{Analyses of the possible impact of $K_{V} 10.1^{\Delta 4-9}$ and $K_{V} 10.1^{\Delta 4-7}$ on the proliferation and cell cycle progression of $K_{\mathrm{V}} 10.1$-expressing cells}

$\mathrm{K}_{\mathrm{V}} 10.1$ channels expression and function has been related to cell proliferation (Pardo et al., 1999; Weber et al., 2006). Moreover, $\mathrm{K}_{\mathrm{V}} 10.1$ channel activity is thought to be dependent on the cell cycle phase (Meyer and Heinemann, 1998; Camacho et al., 2000). Here we investigated whether the $K_{V} 10.1$ interaction with $K_{V} 10.1^{\Delta 4-9}$ and $K_{V} 10.1^{\Delta 4-7}$ and the underlying channel functional reduction lead to consequences in terms of cell proliferation and variations in cell cycle distribution. We performed live cell imaging with an IncuCyte Zoom device on cells transiently transfected with either $K_{V} 10.1^{\Delta 4-9}$ or $\mathrm{K}_{\mathrm{V}} 10.1^{\Delta 4-7}$. pCDNA3-mVenus was the construct transfected in the cells of the control group. A cell confluency mask was created, and the confluency percentage was plotted versus the time of culture (analyses always started 5 hours after transfections) (Fig. 25). In HEK-K $\mathrm{V}_{\mathrm{V}} 10.1$ cells, the proliferation rate was virtually indistinguishable between short isoforms-transfected cells and the control group (data not shown). In SH-SY5Y, $\mathrm{K}_{\mathrm{V}} 10.1^{\Delta 4-9}$ transfected cells showed a mild reduction in proliferation, which peaked ($8.37 \%$ ) at about 50 hour after the analysis started, albeit not statistically significant ( $\mathrm{p} \geq 0.608$ ). Similarly, the proliferation rate of the $\mathrm{K}_{\mathrm{V}} 10.1^{\Delta 4-7}$-transfected cells was reduced. The difference was the most prominent at $\sim 60$ hour after analysis start ($18.1 \%)$; however this difference was also not statistically significant $(\mathrm{p} \geq 0.145)$. Overall, no significant changes in $\mathrm{K}_{\mathrm{V}} 10.1$ expressing cell proliferation were observed under coexpression with $\mathrm{K}_{\mathrm{V}} 10.1^{\Delta 4-9}$ or $\mathrm{K}_{\mathrm{V}} 10.1^{\Delta 4-7}$. 


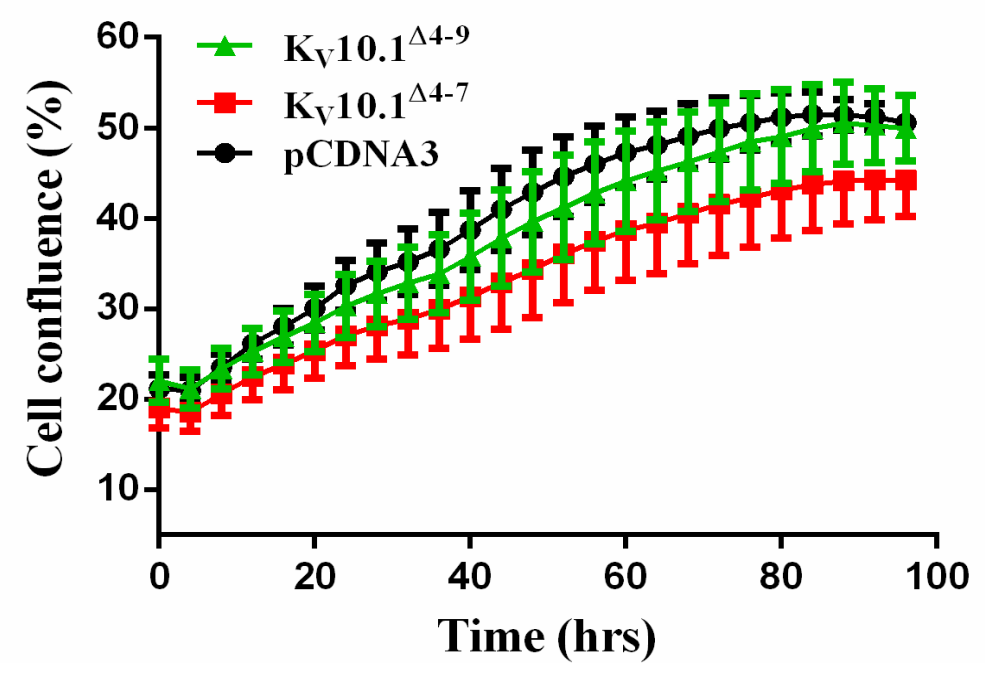

Figure $25 K_{V} 10.1^{\Delta 4-9}$ and $K_{V} 10.1^{\Delta 4-7}$ overexpression does not significantly affect the growth rate of SH-SY5Y cells. In the graph are depicted the growth kinetics of SH-SY5Y cells transiently transfected with either $\mathrm{K}_{\mathrm{V}} 10.1^{\Delta 4-9}$ (green line), $\mathrm{K}_{\mathrm{V}} 10.1^{\Delta 4-7}$ (red line), or a pCDNA3 empty vector (black line; control group). The time interval between each measurement is 4 hours.

We also evaluated the cell cycle distribution of $\mathrm{K}_{\mathrm{V}} 10.1$ expressing cells, under coexpression with either pCDNA3 empty vector, $K_{V} 10.1^{\Delta 4-9}$ or $K_{V} 10.1^{\Delta 4-7}$. To this aim we stained the cells' DNA with Pi and performed flow cytometry experiments. Both cells natively expressing splice variants (SH-SY5Y) as well as non-expressing $\mathrm{K}_{\mathrm{V}} 10.1^{\Delta 4-9}$ and $\mathrm{K}_{\mathrm{V}} 10.1^{\Delta 4-7}$ cells $\left(\mathrm{CHO}-\mathrm{K}_{\mathrm{V}} 10.1\right.$ cells) were used in these experiments (Fig. 26). No evident changes in the fraction of cells retained in different cell cycle phases were observed in any of the cell lines investigated.

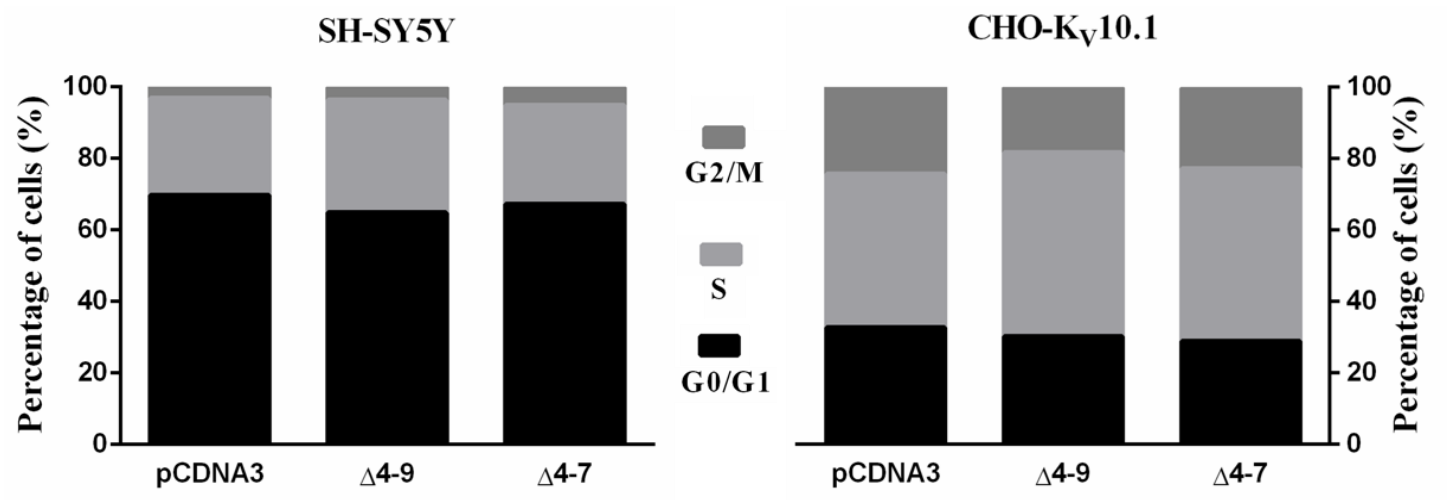

Figure 26 Expression of $K_{V} 10.1^{\Delta 4-9}$ and $K_{V} 10.1^{\Delta 4-7}$ does not alter the cell cycle profile of CHO$\mathrm{K}_{\mathrm{V}} 10.1$ and SH-SY5Y cells. The fraction of cells in G0/G1 is depicted in black; cells in S phase are in grey; and G2/M cells represent the dark grey fraction. 


\section{Discussion}

The general aim of the present thesis work has been to study the impact of alternative splicing on $\mathrm{K}_{\mathrm{V}} 10.1$ biological properties, by first confirming the expression of $\mathrm{K}_{\mathrm{V}} 10.1$ short isoforms in native system, and then studying the mechanisms and consequences of interaction in detail. We started providing direct evidence of E65 and E70 expression in native systems. Both of the short isoforms coprecipitated and colocalized with $\mathrm{K}_{\mathrm{V}} 10.1$ full-length channel in a reconstituted system. Remarkably, E65 and E70 also occurred together with the full-length channel in the same supramolecular complex in native conditions. A robust down-regulation of ion currents through $\mathrm{K}_{\mathrm{V}} 10.1$ channels was observed when $\mathrm{K}_{\mathrm{V}} 10.1$ was co-expressed with E65 and E70. The modulation is dosedependent and most likely specific to $\mathrm{K}_{\mathrm{V}} 10.1$ channels, since there was generally no effect on $\mathrm{K}_{\mathrm{V}} 1.4$ current properties. Possible mechanisms underlying E65- and E70induced current down-regulation were also investigated. The two short isoforms seem to affect $\mathrm{K}_{\mathrm{V}} 10.1$ function through different mechanisms. In the case of E65 the TCC, although not required for the interaction between the two proteins, seems to play a critical role in the modulation of $\mathrm{K}_{\mathrm{V}} 10.1$ current amount. On the other hand E70 expression impaired the glycosylation of $\mathrm{K}_{\mathrm{V}} 10.1$ channels and was independent of TCC; this would probably result in the production of 'immature' ion channels which, although capable of reaching the membrane, would be defective in terms of function.

\section{$5.1 \mathrm{~K}_{\mathrm{V}} 10.1$ short isoforms are expressed in normal brain and cell lines from diverse origins}

E65 and E70 are non-channel proteins recently identified in our laboratory that are derived from alternative spliced $\mathrm{K}_{\mathrm{V}} 10.1$ voltage-gated potassium channels. By PCR analysis, E70 was found in human brain (Pardo LA, unpublished data) and in the 
melanoma cell line IPC 298 (Ramos Gomes PhD thesis, 2010), while E65 was isolated IGR 39, another melanoma cell lines.

It was crucial to confirm that the expression of the splice variants was not due to artifacts derived from DNA amplification. This was achieved using the nuclease protection assay (Cocquet et al., 2006; Roy and Irimia, 2008). E65 expression was found in IGR 39 melanoma cell lines (experiments performed by Dr. Ramos Gomes) whereas E70 was detected in the neuroblastoma cell lines IMR 32 and SH-SY5Y (Fig. 11). Nuclease protection assay (RPA) did not confirm the expression of E70 previously detected with nested PCR in IPC 298 cells

Nested PCR experiments were also carried out in a panel of cancer as well as noncancer cell lines (see table 6). The outcome matched with the result of RPA experiments, and moreover suggested that expression of short isoforms is not limited to cancer cells, since E65 was detected in the prostate epithelium cells and E70 was found in human brain. Presumably, E65 and E70 expression does not derive from cancerspecific events driving alternative splicing. E65 and E70 production would rather be the result of a conserved splicing mechanism occurring in both physiological and pathological scenarios.

Unfortunately, expression of E65 and E70 could not be quantitatively measured by realtime PCR analysis. Specifically designed E65/E70 primers and TaqMan probes showed high sensitivity towards plasmid DNA as a template (Fig. 10), but could not detect the splice variants in cells natively expressing the short isoforms. PCR in general is a very sensitive technique (10-50 copies mRNA target represent a realistic detection limit (Piatak et al., 1993)), but the relative sensitivities of nested and real-time PCR are under dispute. Some reports claim that real-time PCR sensitivity is equivalent or even superior to nested PCR (Drago et al., 2004; Kawada et al., 2004; Kim et al., 2008), but others conclude the opposite (Elmaagacliet al., 2000; Guo et al., 2002; Takenokuchi et al., 2004). In agreement with the latter reports, in this work we could successfully amplify E65 and E70 with nested PCR, but not with real-time PCR.

We successfully detected both isoforms in RPA assays, which have a detection limit of $\sim 10^{5}$ transcript copies (Foley et al., 1993), much less sensitive than PCR techniques. 
However, the amount of template used for RPA was $\sim 400$ times higher $(80 \mu \mathrm{g})$ that for PCR ( 200 ng), and therefore sensitivities cannot be compared.

In accordance with the scarce E65 and E70 transcripts expression, we did not detect the presence of bands of molecular weight compatible with the predicted 65 and $70 \mathrm{kDa}$ by western blot in natively expressing systems, although they were detected in lysates from cells overexpressing constructs encoding both the $\mathrm{K}_{\mathrm{V}} 10.1$ short isoforms.

The scant E65 and E70 expression levels in the heterogeneous cell population can be due to low expression levels in a majority of cells, but also to a higher level in a restricted subpopulation. In this regard, AS regulation driving E65 and E70 expression could be a time-selective process, depending on a particular phase of cell cycle, or triggered by defined transcription factors or protein modifications. Interestingly, fulllength $\mathrm{K}_{\mathrm{V}} 10.1$ channel expression is selectively regulated along the cell cycle, as initially described (Meyer and Heinemann, 1998; Pardo et al., 1998; Camacho et al., 2000), and more recently by Urrego Blanco from our research group (Urrego Blanco $\mathrm{PhD}$ thesis, 2014)). Therefore it is conceivable that E65 and E70 expression could also be cell cycle-dependent. This would not be unique for $\mathrm{K}_{\mathrm{V}} 10.1$, because the AS pattern of $\mathrm{Ca}_{\mathrm{v}} 3.1$ and $\mathrm{K}_{\mathrm{V}} 11.1$ (which belongs to the eag family) channels changes during differentiation of neuroblastoma cells (Crociani et al., 2003; Bertolesi et al., 2006). We tested this hypothesis by synchronizing cells natively expressing $\mathrm{K}_{\mathrm{V}} 10.1$ at the G1/S boundary of the cell cycle using the double thymidine block strategy (Prescott et al., 1971): we noticed changes in E65 and E70 expression pattern along the cell cycle (data not shown). However, since we were forced to use the nested PCR technique (see above), the quantification was arduous and we could draw no conclusive statement regarding this assumption.

In a recent publication, Sun and coworkers reported that calcium influx (mediated by ionomycin) or activation by either PKA or PKC (Sun et al., 2009) stimulate the production of a short isoform of D-Eag1, the $\mathrm{K}_{\mathrm{V}} 10.1$ ortholog in Drosophila. Importantly, this truncated splicing isoform was generated from cDNA of the fulllength channel transfected in mammalian cells, not from genomic DNA in a native system. We tested if a similar mechanism takes place in mammalian cells transfected with full-length $\mathrm{K}_{\mathrm{V}} 10.1$ and in cells natively expressing E65 and E70. Ionomycin treatment or stimulation of protein kinase $\mathrm{A}$ and $\mathrm{C}$ failed to increase transcript 
expression, and no E65 or E70 proteins were observed (data not shown). However, it has to be kept in mind that for E65 and E70 transcripts analysis we have to deal with the limitation of nested PCR technique, which is not meant to be a quantitative assay and therefore we may have missed subtle expression changes.

Further investigation will be required to elucidate the factor(s) triggering $\mathrm{K}_{\mathrm{V}} 10.1$ short isoforms expression. This would certain benefit from the comprehension of E65 and E70 physiological and pathophysiological functions.

\subsection{E65 and E70 interact with $K_{V} 10.1$ channel and modulate its function}

AS is emerging as a mechanism for the modulation of ion channel function. There are several cases where interaction occurs between functionally inactive splice isoforms and the correspondent full-length ion channel. This is usually associated with modulation of current flow, leading to a dominant negative-effect on current amplitude (Kupershmidt et al., 1998; Chu et al., 2005; Guasti et al., 2008; Veale et al., 2010; Wagner et al., 2010; Ohya et al., 2011; Bidaux et al., 2012).

Here we show for the first time that both non-conducting E65 and E70 splice isoforms interact with full-length $K_{V} 10.1$ channels (Fig. 12 and 13) and modulate $K_{V} 10.1$ current amplitude (Fig. 14 and 17), in a dose-dependent manner (Fig. 14). KV10.1 current undergoes a mild voltage dependent inward rectification in all our recordings. Such a phenomenon appears to be exacerbated upon co-expression with splice variants. This is yet another consequence of the functional modulation mediated by the short isoforms on the full-length channel. Rectification can be caused by at least two different processes (Hille, 2001). In some channels, it is caused by soluble factors blocking the pore, such as $\mathrm{Mg}^{2+}$ or polyamines. In others, the rectification is directly caused by voltage- and/or state-dependent conformational changes of the channel. A member of the eag family, $K_{V} 11.1$, undergoes the latter rectification mechanism (Schönherr and Heinemann, 1996; Smith et al., 1996; Spector et al., 1996). $K_{V} 10.1$ channels expressed in Xenopus laevis oocytes can exhibit a dramatic voltage-dependent inward rectification (due to 
intracellular $\mathrm{Na}^{+}$ions), although this phenomenon is restricted upon onset of maturation (Pardo et al., 1998).

The current modulation by E65 and E70 seems restricted to $\mathrm{K}_{\mathrm{V}} 10.1$ channel since the expression of either short isoform did not affect the activity of $\mathrm{K}_{\mathrm{V}} 1.4$ voltage-gated potassium channels, albeit $\mathrm{E} 65 / \mathrm{K}_{\mathrm{V}} 1.4$ injected oocytes (at 10:1 ratio) significantly decreased the current through $\mathrm{K}_{\mathrm{V}} 1.4$ (Fig. 16). However, E65 is capable of inducing maturation of Xenopus laevis oocytes (Ramos Gomes, PhD thesis, 2010). Moreover, current flowing through potassium channels can be altered depending on the cell cycle phase: apart from the already mentioned case of $\mathrm{K}_{\mathrm{V}} 10.1$, this phenomenon has been observed in $K_{V} 11.1$ and $K_{V} 1.3$ channels (Arcangeli et al., 1995; Chittajallu et al., 2002). It is therefore conceivable that the maturation triggered by E65 may account for the effect on $K_{V} 1.4$ current, without the need of a direct interaction between E65 and $K_{V} 1.4$. Nonetheless, it has been reported that the $\mathrm{K}_{\mathrm{V}} 1.4$ current amplitude does not dramatically change upon oocyte maturation (Brüggemann et al., 1997).

$\mathrm{K}_{\mathrm{V}} 10.1$ activation kinetics were slowed down by an excess (10:1) of either isoform (Fig. 15). Mutations induced in both intracytoplasmic PAS and cNBD domain sequences of $\mathrm{K}_{\mathrm{V}} 10.1$ channel also result in decelerated activation kinetics (Stevens et al., 2009). Furthermore, it has been recently described that in the $K_{V} 10.1$ crystal structures the cNBD and PAS domains interact extensively. Destabilizing the molecular bridge connecting these two regions also affects gating of the channel, resulting in slower activation kinetics (Haitin et al., 2013). Thus, one possibility would be that E65 and E70 expression at high concentration affect the canonical $\mathrm{K}_{\mathrm{V}} 10.1$ channel intracytoplasmic folding, modifying the cNBD/PAS domain interaction and affecting the channel activation kinetics.

Further electrophysiological analyses have been carried out to understand the determinant(s) underlying the reduction in $\mathrm{K}_{\mathrm{V}} 10.1$ current amplitude induced by the splice variants. Changes in voltage dependence have been excluded (Fig. 18). Total current $I$ flowing through ion channels in a membrane is the product of the number of channels expressed on the plasma membrane $N$, the channel unitary conductance $i$, and open probability $P_{o}$ (see equation 3 ). Noise analysis revealed that $P_{o}$ was not significantly affected upon co-expression of $\mathrm{K}_{\mathrm{V}} 10.1$ with E65, whereas single channel current $i$ was reduced by $\sim 40 \%$ (Fig. 19). This would explain the $\sim 42 \%$ reduction in 
total current amplitude $I$ that this short isoform exerts on $\mathrm{K}_{V} 10.1$ current, albeit surface $\mathrm{K}_{\mathrm{V}} 10.1$ was significantly increased upon co-expression $\mathrm{K}_{\mathrm{V}} 10.1$-E65 (Fig. 20). $i$ and $P_{o}$ values were unaltered by co-expression of E70, indicating a reduced amount of surface $\mathrm{K}_{\mathrm{V}}$ 10.1. Biochemical binding assays did not corroborate with the assumption of a reduced $\mathrm{K}_{\mathrm{V}} 10.1$ surface expression in E70 expressing samples.

However, regarding the method used to measure the surface $K_{V} 10.1$, although we know that the stoichiometry of bungarotoxin binding to the BBS of each $\mathrm{K}_{\mathrm{V}} 10.1$ monomer is $1: 1$, we cannot exclude the possibility that steric hindrance would allow only one bungarotoxin-biotin molecule binding to the $\mathrm{K}_{\mathrm{V}} 10.1$ tetramer. Therefore, since the BBS is only present in $\mathrm{K}_{\mathrm{V}} 10.1$, and not in $\mathrm{E} 65$ or E70, if the latter two form heteromultimers with the full-length channel, we could still quantify them with the $\alpha$-bungarotoxin approach, being unable to distinguish between homotetramers of full-length channel and heteromers with short isoforms. The heteromers are most likely functionally inactive, and not measured by noise analysis recordings. Functionally defective channels arising from a scenario where E65 and E70 would lock the membrane surface $K_{V} 10.1$ in a functionally inactive state without necessarily heterotetramerize would also be measured by our biochemical binding assay, whereas not counted by noise analysis recordings. Ultimately, if we consider that noise analysis takes in account only active channels, whereas the bungarotoxin used for our surface $\mathrm{K}_{\mathrm{V}} 10.1$ quantifications tags all $\mathrm{K}_{\mathrm{V}} 10.1$ surface channel subunits, we infer that the reduction in the number of active channels situated at the membrane surface is the factor underlying the E70-mediated $\mathrm{K}_{\mathrm{V}} 10.1$ current down-regulation.

Unlike what observed with E70, E65 co-expression with $\mathrm{K}_{\mathrm{V}} 10.1$ results in diminished single channel current $i$. Moreover, the detected increase in surface expression of $\mathrm{K}_{\mathrm{V}} 10.1$ subunits could be due to simultaneous effect of this splice variant on trafficking and/or turnover rate of the full-length.

Recapitulating, each of the two short isoforms would achieve the same effect (reducing the Kv10.1 current amplitude) through a different mechanism of action: E65 expression would mainly diminish the $\mathrm{K}_{\mathrm{V}} 10.1$ single channel current, while E70 may render a fraction of channels locked in a non-conducting state. 
Both E65 and E70 isoforms occur in the same supramolecular complex together $\mathrm{K}_{\mathrm{V}} 10.1$ full-length, as deduced from membrane-enriched extracts in native conditions (Fig. 21). This supports our assumption that each of the short isoforms interacts with the fulllength at the plasma membrane. Moreover it suggests that $E 65 / K_{V} 10.1$ and $E 70 / K_{V} 10.1$ could be components of a bigger macromolecular complex in native conditions. Additional $\mathrm{K}_{\mathrm{V}} 10.1$ interaction partners have been identified. The $\mathrm{K}^{+}$channel regulator 1 (KCR1) is a plasma membrane-associated protein binding to the $\mathrm{C}$-terminal region of the rat $K_{V} 10.1$, modulating its electrophysiological properties (Hoshi et al.,1998). Rabaptin-5 is a binding partner $K_{V} 10.1$, crucial for trafficking (Ninkovic et al., 2012). Cortactin is an actin-interacting protein implicated in cytoskeletal architecture, binding the $\mathrm{K}_{\mathrm{V}} 10.1 \mathrm{C}$-terminus and modulating the channel's surface expression (Herrmann et al., 2012). Moreover, Hsu and co-workers reported that 14-3-30, which belongs to a family of proteins abundantly expressed in the brain and implicated in the modulation of several neuronal processes, is a binding partner of the rat $\mathrm{K}_{\mathrm{V}} 10.1$ channel. Both the $\mathrm{N}$ and C-termini of the channel are required for association with 14-3-30. Co-expression of 14-3-30 with $\mathrm{K}_{\mathrm{V}} 10.1$ reduces current amplitude. Interestingly, no apparent alteration of the steady-state voltage dependence, gating kinetics, single channel conductance or changes in surface protein level or membrane trafficking were detected (Hsu et al., 2012). This scenario strongly resembles what we observed for E70.

Speculating about the molecular association between full-length and short isoforms, one of the possibilities would imply heterotetramerization between full-length and short isoforms. Heterotetramerization is a rather common phenomenon among ion channels, also involving voltage-gated potassium channels (Pongs, 1992). Furthermore, both E65 and E70 retain the TCC domain (situated within the C-terminal sequence), critical for channel tetramerization (Jenke et al., 2003; Ludwig et al., 1997). However, despite the presence of these elements, we tend to exclude that heterotetramerization between fulllength and short isoforms is taking place for the following reasons. Coiled coils (whose formation underlies tetramerization) are protein-protein interaction domains having a helical arrangement consisting in repetition of a heptad structural motif (abcdefg), where the positions $a$ and $d$ are preferably occupied by hydrophobic amino acids (Lupas, 1996). The lack of hydrophobic region within the splice variants sequences would make the heterotetramer formation energetically unfavorable, as well as result in 
functionally inactive channels, because all four subunits must contribute to form the pore, and therefore mutations in the pore are dominant-negative (Kuzhikandathil and Oxford, 2000). Furthermore, TCC-defective E65 and E70 short isoforms conserve the interaction with $\mathrm{K}_{\mathrm{V}} 10.1$ (Fig. 22), ruling out the occurrence of heterotetramerization between short isoforms and full-length channel. Consequently, the interaction between short isoforms and $\mathrm{K}_{\mathrm{V}} 10.1$ would occur by means of interaction site(s) across the $\mathrm{N}$ and/or C-termini regions, which are mostly conserved in the splice variants and fulllength channels.

\subsection{Involvement of the TCC domain in the modulation of $\mathrm{K}_{\mathrm{V}} 10.1$ channels by $\mathrm{E} 65$}

We suppose that co-expression of E65 with $\mathrm{K}_{\mathrm{V}} 10.1$ causes a reduction of single channel conductance leading to a current amplitude reduction. Additionally, results from the measurement of the surface $K_{V} 10.1$ subunits, together with the ones from the analysis of further $\mathrm{K}_{\mathrm{V}} 10.1$ biophysical properties, suggest that under E65 co-expression a fraction of functionally inactive $K_{V} 10.1$ channels could be produced (as also observed in the context of E70 co-expression with $\mathrm{K}_{\mathrm{V}} 10.1$ ).

Moreover, we have evidence strongly suggesting that TCC domain is accounting for the observed functional modulation: E65 bearing a TCC domain defective in its ability to tetramerize (mutation L20Y) (Jenke et al., 2003) fails to diminish $\mathrm{K}_{\mathrm{V}} 10.1$ current amplitude (Fig. 23), in contrast to co-expression with the E65 WT. To our knowledge, this is the first case in which a channel function alteration mediated by a non-conductive splicing isoform is associated to a specific domain.

E65 L20Y co-precipitates with the full-length $\mathrm{K}_{\mathrm{V}} 10.1$ (Fig. 22). This implies that occurrence of physical interaction per se is not sufficient to trigger E65-mediated functional modulation of $\mathrm{K}_{\mathrm{V}} 10.1$ current. As previously mentioned, $\mathrm{K}_{\mathrm{V}} 10.1$ voltage dependent inward rectification in all our recordings was augmented when $K_{V} 10.1$ was expressed together with the short isoforms. However, this phenomenon was conserved upon co-expression of L20Y splice variants (also in E65 L20Y, where $\mathrm{K}_{\mathrm{V}} 10.1$ current down-regulation is virtually absent). This suggests that the voltage-dependent 
rectification may be linked to the physical interaction between splice variants and fulllength channel rather than to the functional modulation of the channel exerted by E65 and E70.

\subsection{Altered $K_{V} 10.1$ glycosylation could explain the modulation of $K_{V} 10.1$ channels by E70}

Based on experiments, we propose that E70 modulates $\mathrm{K}_{\mathrm{V}} 10.1$ by rendering a fraction of $\mathrm{K}_{\mathrm{V}} 10.1$ channels non-conductive (this may occur also for E65). How could E70 exert this action? Our data provides a possible answer: E70 coprecipitates prevalently with an immature glycosylated form of $\mathrm{K}_{\mathrm{V}} 10.1$ (Fig. 24 A) and its expression diminishes the ratio of complex glycosylated to core glycosylated $\mathrm{K}_{\mathrm{V}} 10.1$ in a dose-dependent manner (Fig. $24 \mathrm{~B}$ and C). The relevance of glycosylation of $\mathrm{K}_{\mathrm{V}} 10.1$ channels has been exhaustively investigated in a previous report from our lab. Interestingly, a $\mathrm{K}_{\mathrm{V}} 10.1$ mutant unable to undergo complex glycosylation (N406Q) showed dramatically reduced current amplitude and decelerated activation kinetics (Napp et al., 2005). This resembles the electrophysiological behavior of $\mathrm{K}_{\mathrm{V}} 10.1$ channels co-expressed with E70. However, unlike what we observe in $\mathrm{K}_{\mathrm{V}} 10.1 / \mathrm{E} 70$ cells, N406Q also exhibits a dramatically reduced surface expression. The latter does not appear to be a general rule: complex $\mathrm{N}$-glycosylation is not required for surface expression of Trpm $4 \mathrm{~b}$ channel (Woo et al., 2013), $K_{\mathrm{Ca}} 1.1$ (Pabon et al., 2000), $\mathrm{K}_{\mathrm{V}} 1.1$ (Deal et al., 1994) and $\mathrm{K}_{\mathrm{V}} 11.1$ (Gong et al., 2002). Altered glycosylation may also reduce the stability of $K_{V} 10.1$ and $\mathrm{K}_{\mathrm{V}} 11.1$ channels, increasing their turnover rate (Napp et al., 2005; Gong et al., 2002). Based on our data, we cannot exclude the occurrence of the latter phenomenon upon coexpression of $\mathrm{K}_{\mathrm{V}} 10.1$ with $\mathrm{E} 70$.

Endogenous $\mathrm{K}_{\mathrm{V}} 10.1$ channels enter the synapses of hippocampal neurons by lateral diffusion (Gómez-Varela et al., 2010). Moreover $\mathrm{K}_{\mathrm{V}} 10.1$ channels partition to different membrane subdomains, and this affects current amplitude (without any noticeable effects on other biophysical parameters) (Jiménez-Garduño et al., 2014). In this scenario, E70 expression could modulate $\mathrm{K}_{\mathrm{V}} 10.1$ function by influencing membrane 
subdomain localization without the need to alter the overall surface expression of channels.

\subsection{Possible physiological role of $K_{V} 10.1$ splice variants}

Potassium channels are implicated in diverse physiological and pathophysiological processes. Cell cycle and proliferation, cell migration, invasion and apoptosis are all processes that can be modified by the expression of potassium channels (Pardo and Stühmer, 2014). $\mathrm{K}_{\mathrm{V}} 10.1$ has been extensively studied in this context since it displays oncogenic properties: cells expressing $\mathrm{K}_{\mathrm{V}} 10.1$ have in general increased proliferation rate and its down-regulation reduces proliferation. Indeed, $\mathrm{K}_{\mathrm{V}} 10.1$ blockade mediated by astemizole and siRNA reduces tumor cell proliferation both in vitro (OuadidAhidouch et al., 2001; Gavrilova-Ruch et al., 2002; Weber et al., 2006) and in vivo (Downie et al., 2008).

RNA interference represents a potent tool to disclose the function of a specific gene. For this reason, siRNA sequences specifically targeting E65 and E70 have been designed to down-regulate the short isoforms. The only primary sequence differences between fulllength and splice variants lie in the boundary between exon three and ten (for E65) and exon three and eight (for E70). This limitation adds to the notorious difficulties for the design of an optimal siRNA. Nevertheless, we failed to successfully knock-down the splice variants transcript levels (real-time PCR using overexpressing models, data not shown).

Given these issues with RNA interference methods, we set to gain insights into the E65 and E70 function investigating the effects of their overexpression. In particular, since reduction in $\mathrm{K}_{\mathrm{V}} 10.1$ channel activity decreases cell proliferation, it is conceivable that also short isoforms could reduce cell proliferation by diminishing currents through $\mathrm{K}_{\mathrm{V}} 10.1$ channels. We tested this hypothesis using $\mathrm{K}_{\mathrm{V}} 10.1$ expressing cells that simultaneously overexpress the short isoforms. We did not observe any statistically significant reduction of cell proliferation in E65- nor in E70- transfected cells (Fig. 25). However, low transfection efficiency of the E65 and E70 constructs could account for 
the lack of effect on cell proliferation. In this regard, generation of stable cell lines coexpressing short isoforms and full-length channels will help to clarify this issue. Remarkably, it has been recently found that E65 directly activates the maturation of Xenopus laevis oocytes, suggesting a role in cell cycle regulation for this splicing isoform (Ramos Gomes Ph.D. thesis, 2010). However, we did not detect obvious changes in cell cycle profile of cells transfected with either E65 or E70 (Fig. 26).

In conclusion, in this study we undoubtedly confirmed the concomitant expression of E65 and E70 with $\mathrm{K}_{\mathrm{V}} 10.1$, and we further identified mechanism involved in their modulation of $\mathrm{K}_{\mathrm{V}} 10.1$ function. However, more studies will be required in order to unravel the physiological and pathophysiological significance of the E65 and E70 splice variants. So far, the lack of specific knock-downs and pharmacological tools restricted our 'arsenal' of methods. Future improvement of the techniques available to manipulate and quantitatively detect the splice variants expression will certainly help to further advance this complex but promising field. 


\section{Summary}

In the past few years, several publications highlighted the role of alternative splicing as additional source of modulation of ion channels activity. E65 and E70 (also termed as $\mathrm{K}_{\mathrm{V}} 10.1^{\Delta 4-7}$ and $\mathrm{K}_{\mathrm{V}} 10.1^{\Delta 4-9}$ ) represent two recently identified non-channel proteins derived from alternative splicing of $\mathrm{K}_{\mathrm{V}} 10.1$ voltage-gated potassium channels. The two short isoforms were identified with PCR techniques and their physiological significance was largely obscure.

This thesis work primarily aimed at studying the impact of E65 and E70 on $\mathrm{K}_{\mathrm{V}} 10.1$ properties.

Firstly, the expression of $\mathrm{K}_{\mathrm{V}} 10.1$ short isoforms in native system was definitely demonstrated by means of nuclease protection assays. Afterwards, occurrence of interaction between both E65 and E70 with $\mathrm{K}_{\mathrm{V}} 10.1$ was investigated: the two splice isoforms coprecipitated and colocalized with the $K_{V} 10.1$ full-length channel in a reconstituted system. Remarkably, E65 and E70 also occurred together with the fulllength channel in the same supramolecular complex in native conditions. A robust down-regulation of ion currents through $\mathrm{K}_{\mathrm{V}} 10.1$ channels was observed when $\mathrm{K}_{\mathrm{V}} 10.1$ was co-expressed with E65 and E70. The modulation was dose-dependent and most likely specific to $\mathrm{K}_{\mathrm{V}} 10.1$ channels, since there were generally no effects on $\mathrm{K}_{\mathrm{V}} 1.4$ current. The two short isoforms affect the $\mathrm{K}_{\mathrm{V}} 10.1$ function through different mechanisms. In the case of E65, the TCC domain, although not required for the interaction between the two proteins, seems to play a critical role in the modulation of $\mathrm{K}_{\mathrm{V}} 10.1$ current. On the other hand E70 co-expression with the full-length channel impairs glycosylation of $\mathrm{K}_{\mathrm{V}} 10.1$; this would probably result in the production of 'immature' ion channels that, although capable of reaching the membrane, would be defective in terms of function.

$\mathrm{K}_{\mathrm{V}}$ 10.1 channels expression has been implicated in physiological and pathophysiological processes like cell proliferation, cell cycle and cancerogenesis. It was finally investigated whether E65 and E70 could also be involved in cell proliferation and cell cycle modulation. No obvious alterations of cell cycle profile and 
growth rate of $\mathrm{K}_{\mathrm{V}} 10.1$-expressing cells were observed under overexpression of E65 or E70.

In conclusion, this study unequivocally demonstrated the expression of E65 and E70 in natively expressing systems and provided mechanistic insights into their modulation of $\mathrm{K}_{\mathrm{V}} 10.1$ channel function; yet further studies will be required in order to unravel the overall E65 and E70 physiological (and eventually pathophysiological) significance. 


\section{References}

Adler, J., and Parmryd, I. (2010). Quantifying colocalization by correlation: the Pearson correlation coefficient is superior to the Mander's overlap coefficient. Cytometry. Part A : The Journal of the International Society for Analytical Cytology, 77(8), 733-42. doi:10.1002/cyto.a.20896

Alberts, B., Johnson, A., Lewis, J., Raff, M., Roberts, K., and Walter, P. New York: Garland Science; 2002.

Arcangeli, A., Bianchi, L., Becchetti, A., Faravelli, L., Coronnello, M., Mini, E., ... Wanke, E. (1995). A novel inward-rectifying $\mathrm{K}+$ current with a cell-cycle dependence governs the resting potential of mammalian neuroblastoma cells. The Journal of Physiology, 489 ( Pt 2, 455-71.

Ars, E., Serra, E., García, J., Kruyer, H., Gaona, A, Lázaro, C., and Estivill, X. (2000). Mutations affecting mRNA splicing are the most common molecular defects in patients with neurofibromatosis type 1. Human Molecular Genetics, 9(2), 237-47.

Ashcroft, F. M. (2006). From molecule to malady. Nature, 440(7083), 440-7. doi:10.1038/nature04707

Barajas Farias, M. L., Bermúdez Ocaña, D., Díaz, L., Marı, L., Diaz, L., Cadena, A., ... Camacho, J. (2004). Ether à go-go Potassium Channels as Human Cervical Cancer Markers Ether a ' go-go Potassium Channels as Human Cervical Cancer Markers. Cancer Research, 64, 6996-7001.

Barash, Y., Calarco, J. A, Gao, W., Pan, Q., Wang, X., Shai, O., ... Frey, B. J. (2010). Deciphering the splicing code. Nature, 465(7294), 53-9. doi:10.1038/nature09000

Bartel, F., Taubert, H., and Harris, L. C. (2002). Alternative and aberrant splicing of MDM2 mRNA in human cancer. Cancer Cell, 2(1), 9-15.

Beeton, C., Pennington, M. W., Wulff, H., Singh, S., Nugent, D., Crossley, G., ... Chandy, K. G. (2005). Targeting Effector Memory T Cells with a Selective Peptide Inhibitor of Kv1 . 3 Channels for Therapy of Autoimmune Diseases, 67(4), 1369-1381. doi:10.1124/mol.104.008193.

Bertolesi, G. E., Walia Da Silva, R., Jollimore, C. A. B., Shi, C., Barnes, S., and Kelly, M. E. M. (2006). Ca(v)3.1 splice variant expression during neuronal differentiation of Y-79 retinoblastoma cells. Neuroscience, 141(1), 259-268. doi:10.1016/j.neuroscience.2006.03.067 
Bett, G. C. L., and Rasmusson, R. L. (2004). Inactivation and recovery in Kv1.4 K+ channels: lipophilic interactions at the intracellular mouth of the pore. The Journal of Physiology, 556(Pt 1), 109-20. doi:10.1113/jphysiol.2003.055012

Bezanilla, F. (2005). Voltage-gated ion channels. IEEE Transactions on Nanobioscience, 4(1), 34-48.

Bidaux, G., Beck, B., Zholos, A., Gordienko, D., Lemonnier, L., Flourakis, M., ... Prevarskaya, N. (2012). Regulation of Activity of Transient Receptor Potential Melastatin 8 (TRPM8) Channel by Its Short Isoforms. Journal of Biological Chemistry, 287(5), 2948-2962. doi:10.1074/jbc.M111.270256

Bijlenga, P., Occhiodoro, T., Liu, J., Bader, C. R., Bernheim, L., and Fischer-lougheed, J. (1998). An ether-a-go-go K+ current, Ih-eag contributes to the hyperpolarizartion of human fusion-competent myoblasts. Journal of Physiology, 512.2, 317-323.

Binder, G., Brown, M., and Parks, J. S. (1996). Mechanisms responsible for dominant expression of human growth hormone gene mutations. The Journal of Clinical Endocrinology and Metabolism, 81(11), 4047-50. doi:10.1210/jcem.81.11.8923859

Bolte, S., and Cordelières, F. P. (2006). A guided tour into subcellular colocalization analysis in light microscopy. Journal of Microscopy, 224 ( $\mathrm{Pt}$ 3), 213-32. doi:10.1111/j.1365-2818.2006.01706.

Brüggemann, A., Pardo, L. A., Stühmer, W., and Pongs, O. (1993). Ether-à-go-go encodes a voltage-gated channel permeable to $\mathrm{K}+$ and $\mathrm{Ca} 2+$ and modulated by cAMP. Nature, 365(6445), 445-8.

Brüggemann, A., Stühmer, W., and Pardo, L. A. (1997). Mitosis-promoting factormediated suppression of a cloned delayed rectifier potassium channel expressed in Xenopus oocytes. Proceedings of the National Academy of Sciences of the United States of America, 94(2), 537-42.

Camacho, J., Sánchez, A., Stühmer, W., and Pardo, L. A. (2000). Cytoskeletal interactions determine the electrophysiological properties of human EAG potassium channels. Pflugers Archiv European Journal of Physiology, 441(2-3), 167-174. doi:10.1007/s004240000420

Catterall, W. A. (1995). Structure and function of voltage-gated ion channels. Annual Review of Biochemistry, 64, 493-531. doi:10.1146/annurev.bi.64.070195.002425

Catterall, W. A. (2000a). From ionic currents to molecular mechanisms: the structure and function of voltage-gated sodium channels. Neuron, 26(1), 13-25.

Catterall, W. A. (2000b). Structure and regulation of voltage-gated $\mathrm{Ca} 2+$ channels. Annual Review of Cell and Developmental Biology, 16, 521-55. doi:10.1146/annurev.cellbio.16.1.521

Chandy, K. (1991). Simplified gene nomenclature. Nature, 352(6330), 26. 
Changeux, J. P., Kasai, M., and Lee, C. Y. (1970). Use of a snake venom toxin to characterize the cholinergic receptor protein. Proceedings of the National Academy of Sciences of the United States of America, 67(3), 1241-7.

Chen, L., Tian, L., MacDonald, S. H.-F., McClafferty, H., Hammond, M. S. L., Huibant, J.-M., ... Shipston, M. J. (2005). Functionally diverse complement of large conductance calcium- and voltage-activated potassium channel (BK) alpha-subunits generated from a single site of splicing. The Journal of Biological Chemistry, 280(39), 33599-609. doi:10.1074/jbc.M505383200

Chen, Y., Sánchez, A., Rubio, M. E., Kohl, T., Pardo, L. A., and Stühmer, W. (2011). Functional K(v)10.1 channels localize to the inner nuclear membrane. PloS One, 6(5), e19257. doi:10.1371/journal.pone.0019257

Chittajallu, R., Chen, Y., Wang, H., Yuan, X., Ghiani, C. a, Heckman, T., ... Gallo, V. (2002). Regulation of Kv1 subunit expression in oligodendrocyte progenitor cells and their role in G1/S phase progression of the cell cycle. Proceedings of the National Academy of Sciences of the United States of America, 99(4), 2350-5. doi:10.1073/pnas.042698399

Chiu, Y.-H., Alvarez-Baron, C., Kim, E. Y., and Dryer, S. E. (2010). Dominantnegative regulation of cell surface expression by a pentapeptide motif at the extreme $\mathrm{COOH}$ terminus of an Slo1 calcium-activated potassium channel splice variant. Molecular Pharmacology, 77(4), 497-507. doi:10.1124/mol.109.061929.

Chu, X., Tong, Q., Wozney, J., Zhang, W., Cheung, J. Y., Conrad, K., ... Miller, B. A. (2005). Identification of an N-terminal TRPC2 splice variant which inhibits calcium influx. Cell Calcium, 37(2), 173-182. doi:10.1016/j.ceca.2004.08.005

Claes, K., Poppe, B., Machackova, E., Coene, I., Foretova, L., De Paepe, A., and Messiaen, L. (2003). Differentiating pathogenic mutations from polymorphic alterations in the splice sites of BRCA1 and BRCA2. Genes, Chromosomes \& Cancer, 37(3), 31420. doi:10.1002/gcc.10221

Cocquet, J., Chong, A., Zhang, G., and Veitia, R. A. (2006). Reverse transcriptase template switching and false alternative transcripts. Genomics, 88(1), 127-131. doi:10.1016/j.ygeno.2005.12.013

Cole, S. (1978). Cole-Moore effect in the frog node. Proceedings of the National Academy of Sciences, 75(7), 3254-3257.

Crociani, O., Guasti, L., Balzi, M., Becchetti, A., Wanke, E., Olivotto, M., ... Arcangeli, A. (2003). Cell cycle-dependent expression of HERG1 and HERG1B isoforms in tumor cells. The Journal of Biological Chemistry, 278(5), 2947-55. doi:10.1074/jbc.M210789200

Deal, K. K., Lovinger, D. M., and Tamkun, M. M. (1994). The brain Kv1.1 potassium channel: in vitro and in vivo studies on subunit assembly and posttranslational 
processing. The Journal of Neuroscience: The Official Journal of the Society for Neuroscience, 14(3 Pt 2), 1666-76.

Downie, B. R., Sánchez, A., Knötgen, H., Contreras-Jurado, C., Gymnopoulos, M., Weber, C., ... Pardo, L. A. (2008). Eag1 expression interferes with hypoxia homeostasis and induces angiogenesis in tumors. The Journal of Biological Chemistry, 283(52), 36234-40. doi:10.1074/jbc.M801830200

Doyle, D. A. (1998). The Structure of the Potassium Channel: Molecular Basis of K+ Conduction and Selectivity. Science, 280(5360), 69-77. doi:10.1126/science.280.5360.69

Drago, L., Lombardi, A., De Vecchi, E., Giuliani, G., Bartolone, R., and Gismondo, M. R. (2004). Comparison of nested PCR and real time PCR of Herpesvirus infections of central nervous system in HIV patients. BMC Infectious Diseases, 4(1), 55. doi:10.1186/1471-2334-4-55

Ellgaard, L., and Helenius, A. (2001). ER quality control: towards an understanding at the molecular level. Current Opinion in Cell Biology, 13(4), 431-7.

Elmaagacli, A. H., Beelen, D. W., Opalka, B., Seeber, S., and Schaefer, U. W. (2000). The amount of BCR-ABL fusion transcripts detected by the real-time quantitative polymerase chain reaction method in patients with Philadelphia chromosome positive chronic myeloid leukemia correlates with the disease stage. Annals of Hematology, 79(8), 424-31.

Ertel, E. A. Campbell, K. P. Harpold, M. M. Hofmann, F. Mori, Y. Perez-Reyes, E. Schwartz, A. Snutch, TP. Tanabe, T. Birnbaumer, L. Tsien, RW. Catterall, W. (2000). Nomenclaure of voltage-gated calcium channels. Neuron, 25(3), 533-35. doi:10.1016/j.mjafi.2013.10.004

Erxleben, C., Everhart, A. L., Romeo, C., Florance, H., Bauer, M. B., Alcorta, D. A, ... Armstrong, D. L. (2002). Interacting effects of N-terminal variation and strex exon splicing on slo potassium channel regulation by calcium, phosphorylation, and oxidation. The Journal of Biological Chemistry, 277(30), 27045-52. doi:10.1074/jbc.M203087200

Fan, Z., Zhang, Z., Fu, M., Qi, Z., and Xiao, Z. (2013). Effect of inserting charged peptide at $\mathrm{NH}(2)$-terminal on N-type inactivation of Kv1.4 channel. Biochimica et Biophysica Acta, 1828(3), 990-6. doi:10.1016/j.bbamem.2012.11.016

Faustino, N. A., and Cooper, T. A. (2003). Pre-mRNA splicing and human disease. Genes \& Development, 17(4), 419-37. doi:10.1101/gad.1048803

Ficker, E., Dennis, A. T., Wang, L., and Brown, A. M. (2003). Role of the cytosolic chaperones Hsp70 and Hsp90 in maturation of the cardiac potassium channel HERG. Circulation Research, 92(12), e87-100. doi:10.1161/01.RES.0000079028.31393.15 
Ficker, E., Jarolimek, W., and Brown, A M. (2001). Molecular determinants of inactivation and dofetilide block in ether a-go-go (EAG) channels and EAG-related $\mathrm{K}(+)$ channels. Molecular Pharmacology, 60(6), 1343-8.

Fletcher, E. V, Kullmann, D. M., and Schorge, S. (2011). Alternative splicing modulates inactivation of type 1 voltage-gated sodium channels by toggling an amino acid in the first S3-S4 linker. The Journal of Biological Chemistry, 286(42), 36700-8. doi:10.1074/jbc.M111.250225

Foley, K. P., Leonard, M. W., and Douglas Engel, J. (1993). Quantitation of RNA using the polymerase chain reaction. Trends in Genetics : TIG, 9(11), 380-84.

Forte, A, Cipollaro, M., Cascino, A, and Galderisi, U. (2005). Small interfering RNAs and antisense oligonucleotides for treatment of neurological diseases. Current Drug Targets, 6(1), 21-9.

Frings, S., Brüll, N., Dzeja, C., Angele, A, Hagen, V., Kaupp, U. B., and Baumann, A. (1998). Characterization of ether-à-go-go channels present in photoreceptors reveals similarity to $\mathrm{IKx}$, a $\mathrm{K}+$ current in rod inner segments. The Journal of General Physiology, 111(4), 583-99.

Gabashvili, I., Sokolowski, B., Morton, C., and Giersch, A. (2007). Ion Channel Gene Expression in the Inner Ear. Journal of the Association for Research in Otolaryngology, 8, 305-328. doi:10.1007/s10162-007-0082-y

García-Ferreiro, R. E., Kerschensteiner, D., Major, F., Monje, F., Stühmer, W., and Pardo, L. A. (2004). Mechanism of block of hEag1 K+ channels by imipramine and astemizole. The Journal of General Physiology, 124(4), 301-17. doi:10.1085/jgp.200409041

Gavrilova-Ruch, O., Schönherr, K., Gessner, G., Schönherr, R., Klapperstück, T., Wohlrab, W., and Heinemann, S. H. (2002). Effects of imipramine on ion channels and proliferation of IGR1 melanoma cells. The Journal of Membrane Biology, 188(2), 13749. doi:10.1007/s00232-001-0181-3

Goldin, A. L. (2002). Evolution of voltage-gated Na + channels. The Journal of Experimental Biology, (205), 575-584.

Gomes, F. R. (2010). Analysis of ether-à-go-go potassium channel ( Eag1 ) splice variants in melanoma cells.

Gómez-Varela, D., Zwick-Wallasch, E., Knötgen, H., Sánchez, A., Hettmann, T., Ossipov, D., ... Pardo, L. A. (2007). Monoclonal antibody blockade of the human Eag1 potassium channel function exerts antitumor activity. Cancer Research, 67(15), 7343-9. doi:10.1158/0008-5472.CAN-07-0107

Gonçalves, J., and Stühmer, W. (2010). Calmodulin Interaction with hEAG1 Visualized by FRET Microscopy. PloS One, 5(5), 1-8. doi:10.1371/Citation 
Gong, Q., Anderson, C. L., January, C. T., and Zhou, Z. (2002). Role of glycosylation in cell surface expression and stability of HERG potassium channels. American Journal of Physiology. Heart and Circulatory Physiology, 283(1), H77-84. doi:10.1152/ajpheart.00008.2002

Guasti, L., Crociani, O., Redaelli, E., Pillozzi, S., Polvani, S., Masselli, M., ... Arcangeli, A. (2008). Identification of a posttranslational mechanism for the regulation of hERG1 K+ channel expression and hERG1 current density in tumor cells. Molecular and Cellular Biology, 28(16), 5043-60. doi:10.1128/MCB.00304-08

Guo, J. Q., Lin, H., Kantarjian, H., Talpaz, M., Champlin, R., Andreeff, M., ... Arlinghaus, R. B. (2002). Comparison of competitive-nested PCR and real-time PCR in detecting BCR-ABL fusion transcripts in chronic myeloid leukemia patients. Leukemia, 16(12), 2447-53. doi:10.1038/sj.leu.2402730

Günthert, U., Hofmann, M., Rudy, W., Reber, S., Zöller, M., Haussmann, I., ... Herrlich, P. (1991). A new variant of glycoprotein CD44 confers metastatic potential to rat carcinoma cells. Cell, 65(1), 13-24.

Haitin, Y., Carlson, A. E., and Zagotta, W. N. (2013). The structural mechanism of KCNH-channel regulation by the eag domain. Nature, 501(7467), 444-8. doi:10.1038/nature 12487

Hamill, O. P., Marty, A., Neher, E., Sakmann, B., and Sigworth, F. J. (1981). Improved patch-clamp techniques for high-resolution current recording from cells and cell-free membrane patches. Pflügers Archive: European Journal of Physiology, 391(2), 85-100.

Harel, M., Kasher, R., Nicolas, A, Guss, J. M., Balass, M., Fridkin, M., ... Fuchs, S. (2001). The binding site of acetylcholine receptor as visualized in the X-Ray structure of a complex between alpha-bungarotoxin and a mimotope peptide. Neuron, 32(2), $265-75$.

Hartung, F., Stühmer, W., and Pardo, L. A. (2011). Tumor cell-selective apoptosis induction through targeting of Kv10.1 via bifunctional TRAIL antibody. Molecular Cancer, 10(1), 109. doi:10.1186/1476-4598-10-109

Hattori, M. (2005). [Finishing the euchromatic sequence of the human genome]. Tanpakushitsu Kakusan Koso. Protein, Nucleic Acid, Enzyme, 50(2), 162-8.

Hegle, A. P., Marble, D. D., and Wilson, G. F. (2006). A voltage-driven switch for ionindependent signaling by ether-à-go-go $\mathrm{K}+$ channels. Proceedings of the National Academy of Sciences of the United States of America, 103(8), 2886-91. doi:10.1073/pnas.0505909103

Heinemann, S. H., and Conti, F. (1992). Nonstationary noise analysis and application to patch clamp recordings. Methods in Enzymology, 207, 131-48. 
Hemmerlein, B., Weseloh, R. M., Mello de Queiroz, F., Knötgen, H., Sánchez, A., Rubio, M. E., ... Pardo, L. A. (2006). Overexpression of Eag1 potassium channels in clinical tumours. Molecular Cancer, 5, 41. doi:10.1186/1476-4598-5-41

Herrmann, S., Ninkovic, M., Kohl, T., Lörinczi, É., and Pardo, L. A. (2012). Cortactin controls surface expression of the voltage-gated potassium channel Kv10.1. The Journal of Biological Chemistry, 287(53), 44151-63. doi:10.1074/jbc.M112.372540

Hille, B. (2001) Ion Channels of Excitable Membranes. Sunderland, MA, Sinauer Associates.

Hille, B. (2008), Scholarpedia, 3(10):6051. doi:10.4249/scholarpedia.6051

Hodgkin, A. L., and Huxley, F. (1952). A quantitative description of membrane current and its application to conduction and excitation in nerve. J. Physiol., (117), 500-544.

Hoshi, N., Takahashi, H., Shahidullah, M., Yokoyama, S., and Higashida, H. (1998). KCR1 , a Membrane Protein That Facilitates Functional Expression of Non-inactivating $\mathrm{K}+$ Currents Associates with Rat EAG Voltage-dependent K+ Channels. Journal of Biological Chemistry, 273, 23080-23085.

Hsu, P.-H., Miaw, S.-C., Chuang, C.-C., Chang, P.-Y., Fu, S.-J., Jow, G.-M., ... Jeng, C.-J. (2012). 14-3-30 is a binding partner of rat Eag1 potassium channels. PloS One, 7(7), e41203. doi:10.1371/journal.pone.0041203

Hui, J. (2009). Regulation of mammalian pre-mRNA splicing. Science in China. Series C, Life Sciences / Chinese Academy of Sciences, 52(3), 253-60. doi:10.1007/s11427009-0037-0

Jahn, R., and Scheller, R. H. (2006). SNAREs--engines for membrane fusion. Nature Reviews. Molecular Cell Biology, 7(9), 631-43. doi:10.1038/nrm2002

Jenke, M., Sánchez, A., Monje, F., Stühmer, W., Weseloh, R. M., and Pardo, L. A. (2003). C-terminal domains implicated in the functional surface expression of potassium channels. The EMBO Journal, 22(3), 395-403. doi:10.1093/emboj/cdg035

Jiménez-Garduño, A. M., Mitkovski, M., Alexopoulos, I. K., Sánchez, A., Stühmer, W., Pardo, L. A, and Ortega, A. (2013). Kv10.1 K(+)-channel plasma membrane discrete domain partitioning and its functional correlation in neurons. Biochimica et Biophysica Acta, 1838(3), 921-931. doi:10.1016/j.bbamem.2013.11.007

Kaida, D., Motoyoshi, H., Tashiro, E., Nojima, T., Hagiwara, M., Ishigami, K., ... Yoshida, M. (2007). Spliceostatin A targets SF3b and inhibits both splicing and nuclear retention of pre-mRNA. Nature Chemical Biology, 3(9), 576-83. doi:10.1038/nchembio.2007.18

Kandel E. R., Schwartz J. H. , Jessell T. M. (2000). Principles of Neural Science, 4th ed. McGraw-Hill, New York. ISBN 0-8385-7701-6 
Kaplan, H. A, Welply, J. K., and Lennarz, W. J. (1987). Oligosaccharyl transferase: the central enzyme in the pathway of glycoprotein assembly. Biochimica et Biophysica Acta, 906(2), 161-73.

Kaplan, W. D., and Trout, W. E. (1969). The behavior of four neurological mutants of Drosophila. Genetics, 61(2), 399-409.

Kawada, J., Kimura, H., Ito, Y., Hoshino, Y., Tanaka-Kitajima, N., Ando, Y., ... Morishima, T. (2004). Comparison of real-time and nested PCR assays for detection of herpes simplex virus DNA. Microbiology and Immunology, 48(5), 411-5.

Keren, H., Lev-Maor, G., and Ast, G. (2010). Alternative splicing and evolution: diversification, exon definition and function. Nature Reviews. Genetics, 11(5), 345-55. doi: $10.1038 / \mathrm{nrg} 2776$

Kim, H. S., Kim, D.-M., Neupane, G. P., Lee, Y., Yang, N.-W., Jang, S. J., ... Lee, S. H. (2008). Comparison of conventional, nested, and real-time PCR assays for rapid and accurate detection of Vibrio vulnificus. Journal of Clinical Microbiology, 46(9), 29928. doi:10.1128/JCM.00027-08

Kohl, T., Lorinczi, E., Pardo, L. A., and Stühmer W. (2011). Rapid Internalization of the Oncogenic K + Channel. PloS One, 6(10). doi:10.1371/Citation

Kolb, S. J., Battle, D. J., and Dreyfuss, G. (2007). Molecular functions of the SMN complex. Journal of Child Neurology, 22(8), 990-4. doi:10.1177/0883073807305666

Kornblihtt, A. R., Schor, I. E., Alló, M., Dujardin, G., Petrillo, E., and Muñoz, M. J. (2013). Alternative splicing: a pivotal step between eukaryotic transcription and translation. Nature Reviews. Molecular Cell Biology, 14(3), 153-65. doi: $10.1038 / \mathrm{nrm} 3525$

Kosolapov, A., and Deutsch, C. (2003). Folding of the voltage-gated K+ channel T1 recognition domain. The Journal of Biological Chemistry, 278(6), 4305-13. doi:10.1074/jbc.M209422200

Kotake, Y., Sagane, K., Owa, T., Mimori-Kiyosue, Y., Shimizu, H., Uesugi, M., ... Mizui, Y. (2007). Splicing factor SF3b as a target of the antitumor natural product pladienolide. Nature Chemical Biology, 3(9), 570-5. doi:10.1038/nchembio.2007.16

Kunzelmann, K. (2005). Ion channels and cancer. The Journal of Membrane Biology, 205(3), 159-73. doi:10.1007/s00232-005-0781-4

Kupershmidt, S., Snyders, D. J., Raes, A, and Roden, D. M. (1998). A K+ channel splice variant common in human heart lacks a $\mathrm{C}$-terminal domain required for expression of rapidly activating delayed rectifier current. The Journal of Biological Chemistry, 273(42), 27231-5. 
Kuzhikandathil, E. V, and Oxford, G. S. (2000). Dominant-negative mutants identify a role for GIRK channels in D3 dopamine receptor-mediated regulation of spontaneous secretory activity. The Journal of General Physiology, 115(6), 697-706.

Lang, F., Ritter, M., Gamper, N., Huber, S., Tanneur, V., Lepple-wienhues, A., ... Gulbins, E. (2000). Cell Volume in the Regulation of Cell Proliferation and Apoptotic Cell Death. Cellular Physiology and Biochemistry, (10), 417-428.

Lee, Y. S., Sayeed, M. M., and Wurster, R. D. (1993). Inhibition of cell growth by K+ channel modulators is due to interference with agonist-induced $\mathrm{Ca} 2+$ release. Cellular Signalling, 5(6), 803-9.

Li, M., Jan, Y. N., and Jan, L. Y. (1992). Specification of Subunit Assembly by the Hydrophilic Amino-Terminal Domain of the Shaker Potassium Channel. Science, 257(5074), 1225-30.

Li, Y., Um, S. Y., and Mcdonald, T. V. (2006). Voltage-Gated Potassium Channels: Regulation by Accessory Subunits. Neuroscientist doi:10.1177/1073858406287717

Lim, K. H., Ferraris, L., Filloux, M. E., Raphael, B. J., and Fairbrother, W. G. (2011). Using positional distribution to identify splicing elements and predict pre-mRNA processing defects in human genes. Proceedings of the National Academy of Sciences, 108(27), 11093-11098. doi:10.1073/pnas.1101135108

Liu, S., and Cheng, C. (2013). Alternative RNA splicing and cancer. Wiley Interdisciplinary Reviews. RNA, 4(5), 547-66. doi:10.1002/wrna.1178

Ludwig, J., Owen, D., and Pongs, O. (1997). Carboxy-terminal domain mediates assembly of the voltage-gated rat ether-à-go-go potassium channel. The EMBO Journal, 16(21), 6337-45. doi:10.1093/emboj/16.21.6337

Ludwig, J., Terlau, H., Wunder, F., Bruggemann, A., Pardo, L. A., and Marquardt, A. (1994). Functional expression of a rat homologue of the voltage gated ether a go-go potassium channel reveals differences in selectivity and activation kinetics between the Drosophila channel and its mammalian counterpart. The EMBO Journal, 13(19), 44514458.

Lupas, A. (1996). Coiled coils: new structures and new functions. Trends in Biochemical Sciences, 21(10), 375-82.

Matlin, A. J., Clark, F., and Smith, C. W. J. (2005). Understanding alternative splicing: towards a cellular code. Nature Reviews. Molecular Cell Biology, 6(5), 386-398. doi:10.1038/nrm1645

McCartney, C. E., McClafferty, H., Huibant, J.-M., Rowan, E. G., Shipston, M. J., \& Rowe, I. C. M. (2005). A cysteine-rich motif confers hypoxia sensitivity to mammalian large conductance voltage- and Ca-activated K (BK) channel alpha-subunits. Proceedings of the National Academy of Sciences of the United States of America, 102(49), 17870-6. doi:10.1073/pnas.0505270102 
Mello de Queiroz, F., Suarez-Kurtz, G., Stühmer, W., and Pardo, L. A. (2006). Ether à go-go potassium channel expression in soft tissue sarcoma patients. Molecular Cancer, 5, 42. doi:10.1186/1476-4598-5-42

Meyer, R., and Heinemann, S. H. (1998). Characterization of an eag-like potassium channel in human neuroblastoma cells. The Journal of Physiology, 508 ( Pt 1, 49-56.

Mortensen, L. S. (2012). Modulation of synaptic transmission by the voltage-gated potassium channel

Napp, J., Monje, F., Stühmer, W., and Pardo, L. A. (2005). Glycosylation of Eag1 (Kv10.1) potassium channels: intracellular trafficking and functional consequences. The Journal of Biological Chemistry, 280(33), 29506-12. doi:10.1074/jbc.M504228200

Neher, E., Sakmann, B., and Steinbach, J. H. (1978). The extracellular patch clamp: a method for resolving currents through individual open channels in biological membranes. Pflügers Archive: European Journal of Physiology, 375(2), 219-28.

Ninkovic, M., Mitkovski, M., Kohl, T., Stühmer, W., and Pardo, L. A. (2012). Physical and functional interaction of Kv10.1 with Rabaptin-5 impacts ion channel trafficking. FEBS Letters, 586(19), 3077-84. doi:10.1016/j.febslet.2012.07.055

Noda, M., Furutani, Y., Takahashi, H., Toyosato, M., Tanabe, T., Shimizu, S., ... Inayama, S. (1983). Cloning and sequence analysis of calf cDNA and human genomic DNA encoding alpha-subunit precursor of muscle acetylcholine receptor. Nature, 305(5937), 818-23.

Noda, M., Shimizu, S., Tanabe, T., Takai, T., Kayano, T., Ikeda, T., ... Minamino, N. (1984). Primary structure of Electrophorus electricus sodium channel deduced from cDNA sequence. Nature, 312(5990), 121-7.

Occhiodoro, T., Bernheim, L., Liu, J. H., Bijlenga, P., Sinnreich, M., Bader, C. R., and Fischer-Lougheed, J. (1998). Cloning of a human ether-a-go-go potassium channel expressed in myoblasts at the onset of fusion. FEBS Letters, 434(1-2), 177-82.

Ohya, S., Niwa, S., Yanagi, A., Fukuyo, Y., Yamamura, H., and Imaizumi, Y. (2011). Involvement of dominant-negative spliced variants of the intermediate conductance $\mathrm{Ca} 2+$-activated $\mathrm{K}+$ channel, $\mathrm{K}(\mathrm{Ca}) 3.1$, in immune function of lymphoid cells. The Journal of Biological Chemistry, 286(19), 16940-16952. doi:10.1074/jbc.M110.184192

Ouadid-Ahidouch, H., Le Bourhis, X., Roudbaraki, M., Toillon, R. A., Delcourt, P., and Prevarskaya, N. (2001). Changes in the K+ current-density of MCF-7 cells during progression through the cell cycle: possible involvement of a h-ether.a-gogo $\mathrm{K}+$ channel. Receptors \& Channels, 7(5), 345-56.

Overington, J. P., Al-Lazikani, B., and Hopkins, A. L. (2006). How many drug targets are there? Nature Reviews. Drug Discovery, 5(12), 993-6. doi:10.1038/nrd2199 
Owen, N., Zhou, H., Malygin, A. A, Sangha, J., Smith, L. D., Muntoni, F., and Eperon, I. C. (2011). Design principles for bifunctional targeted oligonucleotide enhancers of splicing. Nucleic Acids Research, 39(16), 7194-208. doi:10.1093/nar/gkr152

Pabon, A, Chan, K. W., Sui, J. L., Wu, X., Logothetis, D. E., and Thornhill, W. B. (2000). Glycosylation of GIRK1 at Asn119 and ROMK1 at Asn117 has different consequences in potassium channel function. The Journal of Biological Chemistry, 275(39), 30677-82. doi:10.1074/jbc.M005338200

Pardo, L. A. (2004). Voltage-gated potassium channels in cell proliferation. Physiology (Bethesda, Md.), 19, 285-92. doi:10.1152/physiol.00011.2004

Pardo, L. A, Brüggemann, A, Camacho, J., and Stühmer, W. (1998). Cell cycle-related changes in the conducting properties of r-eag $\mathrm{K}+$ channels. The Journal of Cell Biology, 143(3), 767-75.

Pardo, L. A, del Camino, D., Sánchez, A, Alves, F., Brüggemann, A, Beckh, S., and Stühmer, W. (1999). Oncogenic potential of EAG K(+) channels. The EMBO Journal, 18(20), 5540-7. doi:10.1093/emboj/18.20.5540

Pardo, L. A, and Stühmer, W. (2008). Eag1: an emerging oncological target. Cancer Research, 68(6), 1611-3. doi:10.1158/0008-5472.CAN-07-5710

Pardo, L. A, and Stühmer, W. (2014). The roles of $\mathrm{K}(+)$ channels in cancer. Nature Reviews. Cancer, 14(1), 39-48. doi:10.1038/nrc3635

Pedersen, S. F., and Stock, C. (2013). Ion channels and transporters in cancer: pathophysiology, regulation, and clinical potential. Cancer Research, 73(6), 1658-61. doi:10.1158/0008-5472.

Philips, A V, and Cooper, T. A. (2000). RNA processing and human disease. Cellular and Molecular Life Sciences: CMLS, 57(2), 235-49.

Piatak, M., Luk, K. C., Williams, B., and Lifson, J. D. (1993). Quantitative competitive polymerase chain reaction for accurate quantitation of HIV DNA and RNA species. BioTechniques, 14(1), 70-81.

Pilch, B., Allemand, E., Facompré, M., Facompre, M., Bailly, C., Riou, J., ... Tazi, J. (2001). Specific Inhibition of Serine- and Arginine-rich Splicing Factors Phosphorylation, Spliceosome Assembly, and Splicing by the Antitumor Drug NB-506 Specific Inhibition of Serine- and Arginine-rich Splicing Factors Phosphorylation, Spliceosome Assembly ,. Cancer Research, 61(18), 6876-6884.

Pongs, O. (1992). Molecular Biology of Voltage-Dependent. Physiological Reviews, 72(4).

Prescott, D. M., Kirkpatrick, J. B., and Bostock, C. J. (1971). An evaluation of the double thymidine block for synchronizing mammalian cells at the G1/S border. Experimental Cell Research, 68, 163-168. 
Reisinger, V., and Eichacker, L. A. (2007). How to analyze protein complexes by 2D blue native SDS-PAGE. Proteomics, 7 Suppl 1, 6-16. doi:10.1002/pmic.200700205

Rodríguez-Rasgado, J. A., Acuña-Macías, I., and Camacho, J. (2012). Eag1 channels as potential cancer biomarkers. Sensors (Basel, Switzerland), 12(5), 5986-95. doi: $10.3390 / \mathrm{s} 120505986$

Roy, J., Vantol, B., Cowley, E. A, Blay, J., and Linsdell, P. (2008). Pharmacological separation of $\mathrm{hEAG}$ and $\mathrm{hERG} \mathrm{K}+$ channel function in the human mammary carcinoma cell line MCF-7. Oncology Reports, 19(6), 1511-6.

Roy, S. W., and Irimia, M. (2008). When good transcripts go bad: artifactual RT-PCR "splicing" and genome analysis. BioEssays: News and Reviews in Molecular, Cellular and Developmental Biology, 30(6), 601-605. doi:10.1002/bies.20749

Sazani, P., and Kole, R. (2003). Therapeutic potential of antisense oligonucleotides as modulators of alternative splicing. The Journal of Clinical Investigation, 112(4), 481486. doi:10.1172/JCI200319547.The

Schägger, H., and von Jagow, G. (1991). Blue native electrophoresis for isolation of membrane protein complexes in enzymatically active form. Analytical Biochemistry, 199(2), 223-31.

Schindelin, J., Arganda-Carreras, I., Frise, E., Kaynig, V., Longair, M., Pietzsch, T., ... Cardona, A. (2012). Fiji: an open-source platform for biological-image analysis. Nature Methods, 9(7), 676-82. doi:10.1038/nmeth.2019

Schönherr, R., and Heinemann, S. H. (1996). Molecular determinants for activation and inactivation of HERG, a human inward rectifier potassium channel. The Journal of Physiology, 493 ( Pt 3, 635-42.

Schonherr, R., Lober, K., and Heinemann, S. H. (2000). Inhibition of human ether a gogo potassium channels by Ca2+/calmodulin. EMBO, 19(13), 3263-3271.

Schroeter, A., Walzik, S., Blechschmidt, S., Haufe, V., Benndorf, K., \& Zimmer, T. (2010). Structure and function of splice variants of the cardiac voltage-gated sodium channel Nav1.5. Journal of Molecular and Cellular Cardiology, 49(1), 16-24. doi:10.1016/j.yjmcc.2010.04.004

Sekine-Aizawa, Y., and Huganir, R. L. (2004). Imaging of receptor trafficking by using alpha-bungarotoxin-binding-site-tagged receptors. PNAS, 101.(49), 17114-9.

Smith, P. L., Baukrowitz, T., and Yellen, G. (1996). The inward rectification mechanism of the HERG cardiac potassium channel. Nature, 379(6568), 833-6. doi: $10.1038 / 379833 \mathrm{a} 0$

Spector, P. S., Curran, M. E., Keating, M. T., and Sanguinetti, M. C. (1996). Class III Antiarrhythmic Drugs Block HERG, a Human Cardiac Delayed Rectifier K+ Channel: 
Open-Channel Block by Methanesulfonanilides. Circulation Research, 78(3), 499-503. doi:10.1161/01.RES.78.3.499

Staudacher, I., Schweizer, P. A., Katus, H. A., and Thomas, D. (2010). hERG: protein trafficking and potential for therapy and drug side effects. Current Opinion in Drug Discovery \& Development, 13(1), 23-30.

Steele, D. F., Eldstrom, J., and Fedida, D. (2007). Mechanisms of cardiac potassium channel trafficking. The Journal of Physiology, 582( $\mathrm{Pt} 1)$, 17-26. doi:10.1113/jphysiol.2007.130245

Stevens, L., Ju, M., and Wray, D. (2009). Roles of surface residues of intracellular domains of heag potassium channels. European Biophysics Journal: EBJ, 38(4), 52332. doi:10.1007/s00249-009-0402-8

Stühmer, W. (1998). Electrophysiologic recordings from Xenopus oocytes. Methods in Enzymology, 293, 280-300.

Stühmer, W., Conti, F., Suzuki, H., Wang, X., Noda, M., Yahagi, N., ... Numa, S. (1989). Structural parts involved in activation and inactivation of a sodium channel. Nature, 339(6226), 597-603.

Sun, X. X., Bostrom, S. L., and Griffith, L. C. (2009). Alternative splicing of the eag potassium channel gene in Drosophila generates a novel signal transduction scaffolding protein. Molecular and Cellular Neurosciences, 40(3), 338-343. doi:10.1016/j.mcn.2008.11.005

Takenokuchi, M., Yasuda, C., Takeuchi, K., Nakamachi, Y., Mukai, M., Kondo, S., ... Tatsumi, E. (2004). Quantitative nested reverse transcriptase PCR vs. real-time PCR for measuring AML1/ETO (MTG8) transcripts. Clinical and Laboratory Haematology, 26(2), 107-14. doi:10.1111/j.1365-2257.2004.00587.x

Tan, B. Z., Jiang, F., Tan, M. Y., Yu, D., Huang, H., Shen, Y., and Soong, T. W. (2011). Functional characterization of alternative splicing in the $C$ terminus of L-type CaV1.3 channels. The Journal of Biological Chemistry, 286(49), 42725-35. doi:10.1074/jbc.M111.265207

Tan, G. M. Y., Yu, D., Wang, J., and Soong, T. W. (2012). Alternative Splicing at C Terminus of CaV1.4 Calcium Channel Modulates Calcium-dependent Inactivation, Activation Potential, and Current Density. Journal of Biological Chemistry, 287(2), 832-847. doi:10.1074/jbc.M111.268722

Tang, Z. Z., Sharma, S., Zheng, S., Chawla, G., Nikolic, J., and Black, D. L. (2011). Regulation of the mutually exclusive exons $8 \mathrm{a}$ and 8 in the CaV1.2 calcium channel transcript by polypyrimidine tract-binding protein. The Journal of Biological Chemistry, 286(12), 10007-10016. doi:10.1074/jbc.M110.208116 
Terlau, H., Ludwig, J., Steffan, R., Pongs, O., Stühmer, W., and Heinemann, S. H. (1996). Extracellular Mg2+ regulates activation of rat eag potassium channel. Pflügers Archive: European Journal of Physiology, 432(2), 301-12.

Tian, L., Duncan, R. R., Hammond, M. S., Coghill, L. S., Wen, H., Rusinova, R., ... Shipston, M. J. (2001). Alternative splicing switches potassium channel sensitivity to protein phosphorylation. The Journal of Biological Chemistry, 276(11), 7717-20. doi:10.1074/jbc.C000741200

Tombola, F., Pathak, M. M., and Isacoff, E. Y. (2006). How does voltage open an ion channel? Annual Review of Cell and Developmental Biology, 22, 23-52. doi:10.1146/annurev.cellbio.21.020404.145837

Ufartes, R., Schneider, T., Mortensen, L. S., de Juan Romero, C., Hentrich, K., Knoetgen, H., ... Stühmer, W. (2013). Behavioural and functional characterization of Kv10.1 (Eag1) knockout mice. Human Molecular Genetics, 22(11), 2247-62. doi:10.1093/hmg/ddt076

Urrego, D., Tomczak, A. P., Zahed, F., Stühmer, W., Pardo, L. A.and Stühmer, W. (2014). Potassium channels in cell cycle and cell proliferation Potassium channels in cell cycle and cell proliferation. Philos Trans $R$ Soc Lond B Biol Sci doi: 10.1098/rstb.2013.0094.

Varani, L., Spillantini, M. G., Goedert, M., and Varani, G. (2000). Structural basis for recognition of the RNA major groove in the tau exon 10 splicing regulatory element by aminoglycoside antibiotics. Nucleic Acids Research, 28(3), 710-9.

Veale, E. L., Rees, K. A, Mathie, A., and Trapp, S. (2010). Dominant negative effects of a non-conducting TREK1 splice variant expressed in brain. The Journal of Biological Chemistry, 285(38), 29295-29304. doi:10.1074/jbc.M110.108423

Wagner, V., Stadelmeyer, E., Riederer, M., Regitnig, P., Gorischek, A., Devaney, T., ... Schreibmayer, W. (2010). Cloning and characterisation of GIRK1 variants resulting from alternative RNA editing of the KCNJ3 gene transcript in a human breast cancer cell line. Journal of Cellular Biochemistry, 110(3), 598-608. doi:10.1002/jcb.22564

Warf, M. B., and Berglund, J. A. (2010). Role of RNA structure in regulating premRNA splicing. Trends in Biochemical Sciences, 35(3), 169-78. doi:10.1016/j.tibs.2009.10.004

Warmke, J. W., \& Ganetzky, B. (1994). A family of potassium channel genes related to eag in Drosophila and mammals. Proceedings of the National Academy of Sciences of the United States of America, 91(8), 3438-42.

Watson, J. V, Chambers, S. H., and Smith, P. J. (1987). A pragmatic approach to the analysis of DNA histograms with a definable G1 peak. Cytometry, 8(1), 1-8. doi:10.1002/cyto.990080101 
Weber, C., Mello de Queiroz, F., Downie, B. R., Suckow, A., Stühmer, W., and Pardo, L. A. (2006). Silencing the activity and proliferative properties of the human EagI Potassium Channel by RNA Interference. The Journal of Biological Chemistry, 281(19), 13030-7. doi:10.1074/jbc.M600883200

Wonderlin, W. F., and Strobl, J. S. (1996). Potassium Channels, Proliferation and G1 Progression. J. Membrane Biol., 154, 91-107.

Wonderlin, W. F., Woodfork, K. A, and Strobl, J. S. (1995). Changes in membrane potential during the progression of MCF-7 human mammary tumor cells through the cell cycle. Journal of Cellular Physiology, 165(1), 177-85. doi:10.1002/jcp.1041650121

Woo, S. K., Kwon, M. S., Ivanov, A., Geng, Z., Gerzanich, V., and Simard, J. M. (2013). Complex N-glycosylation stabilizes surface expression of transient receptor potential melastatin 4b protein. The Journal of Biological Chemistry, 288(51), 3640917. doi:10.1074/jbc.M113.530584

Zarei, M. M., Eghbali, M., Alioua, A, Song, M., Knaus, H.-G., Stefani, E., and Toro, L. (2004). An endoplasmic reticulum trafficking signal prevents surface expression of a voltage- and $\mathrm{Ca} 2+-$ activated $\mathrm{K}+$ channel splice variant. Proceedings of the National Academy of Sciences of the United States of America, 101(27), 10072-7. doi:10.1073/pnas.0302919101

Zerangue, N., Schwappach, B., Jan, Y. N., and Jan, L. Y. (1999). A new ER trafficking signal Regulates the Subunit Stoichiometry of Plasma Membrane K ATP Channels. Cell, 22, 537-548.

Zhang, H. Y., Liao, P., Wang, J. J., Yu, D. J., and Soong, T. W. (2010). Alternative splicing modulates diltiazem sensitivity of cardiac and vascular smooth muscle $\mathrm{Ca}(\mathrm{v}) 1.2$ calcium channels. British Journal of Pharmacology, 160(7), 1631-1640. doi:10.1111/j.1476-5381.2010.00798.x

Ziechner, U., Schönherr, R., Born, A.-K., Gavrilova-Ruch, O., Glaser, R. W., Malesevic, M., ... Heinemann, S. H. (2006). Inhibition of human ether à go-go potassium channels by $\mathrm{Ca} 2+/$ calmodulin binding to the cytosolic $\mathrm{N}$ - and $\mathrm{C}$-termini. The FEBS Journal, 273(5), 1074-86. doi:10.1111/j.1742-4658.2006.05134.x 


\section{Acknowledgments}

I am very grateful to Prof. Dr. Walter Stühmer for hosting me in his department, for all the interesting scientific as well as non-scientific discussions. I am definitely proud of having been part of the staff of this outstanding and open-minded scientist. I would like to thank him also for the organization of exciting departmental lab outings. I enjoyed them a lot.

I express my deepest gratitude to Prof. Dr. Luis Pardo, who represented for me not only an excellent supervisor, but also a wonderful person and a mentor. Whenever I asked, no matter how busy he was, or what time of the day it was, he was always willing to discuss with me any type of issue.

Further, thanks to Prof. Dr. Tobias Moser and to Prof. Dr. Michael Hörner, for their punctual participation to my thesis committee meetings, for the fruitful scientific discussion and suggestions guiding me through the project development. Additional credits to Prof. Dr. Michael Hörner for his great work with the management of the CMPB, the program I am affiliated to, as well as for his commitment to the organization of interesting seminars and retreats.

Many thanks also to Dr. Miso Mitkovski for introducing me to the world of confocal microscopy; I express gratitude also to Kerstin, Uschi and Michael for their excellent technical assistance, and to Ute for her kindness in helping me solving any sort of issue I had along my doctorate path.

Moreover I would like to thank Diana, Camilo, Fernandinha, Ara, Alonso, Aura, Lisa and all the other present and former MBNS colleagues. Thanks to the pleasant atmosphere you created it was much easier for me to work hard and enjoy the everyday's life in the lab.

I also owe a lot to my dearest friends I had the fortune to meet in Göttingen during the last three and half years. They shared with me the joys and helped me to nurse the 
sorrows during the nevertheless magnificent adventure of my $\mathrm{PhD}$. Thanks wherever you are now, I hold you in my heart.

And, last but not least....cari mamma e papà se sono arrivato fino a questo punto il merito è anche vostro. Mille grazie per il vostro sostegno incondizionato, vi voglio e vi vorrò sempre bene! 


\section{Curriculum vitae}

PERSONAL DATA

NAME, SURNAME Vincenzo, Romaniello

DATE AND PLACE OF BIRTH June $1^{\text {st }}, 1985$ in Aversa, Italy

CITIZENSHIP Italian

E-MAIL_ $\quad$ romaniello@em.mpg.de; siemprevince@hotmail.it

STUDIES AND ACADEMIC CAREER

October 2010 - April $2014 \quad \mathrm{PhD}$ thesis at Oncophysiology group, dept. Molecular Biology of Neuronal Signal, MaxPlanck-Institute of Experimental Medicine, Göttingen, Germany.

October 2007-September 2010 Internship at Dept. of Neuroscience with prof. Maurizio Taglialatela, Faculty of Medicine at Università "Federico II", Naples, Italy.

March 2008 - March 2010

Master's degree in Medical Biotechnology at Università Federico II, Naples, Italy (Mark 110/110).

October 2003-March 2008

Bachelor's degree in Medical Biotechnology at Università Federico II, Naples, Italy (Mark 98/110).

\section{LABORATORY SKILLS}

\section{CELL CULTURES}

- Propagation of primary (rNSC) and secondary cell cultures (HEK293, CHO, COS, C2C12, HeLa, SH-SY5Y, IGR39, etc.).

- Transfection of mammalian cell lines using liposomal and electroporation approaches. 


\section{MOLECULAR BIOLOGY}

- Total RNA and mRNA isolation from mammalian cells and tissues.

- DNA isolation from bacterial and mammalian cells and tissues.

- PCR: reverse transcriptase PCR (RT-PCR), nested PCR, real-time PCR.

- Molecular cloning: DNA pufication from PCR products, ligation, trasformation of Escherichia coli cells.

- Northern Blot.

- Ribonuclease Protection Assays (RPA) using custom-designed ${ }^{32}$ P labeled RNA antisense probes.

- Gene silencing stategies (siRNA, shRNA) in mammalian cells.

- Proliferation assays (MTT, ${ }^{3} \mathrm{H}$-thymidine, Alamar Blue).

- $\quad$ Site directed mutagenesis.

- RNA injection in Xenopus laevis oocytes.

\section{BIOCHEMISTRY}

- Protein electrophoresis: SDS-PAGE, blue native PAGE (BN-PAGE), twodimensional gel electrophoresis (2D SDS-PAGE).

- Protein immunoprecipitation and Western blot.

- Immunocitochemistry (ICC) using mammalian cell lines (HEK293 and C2C12).

- Expertise in inverted and confocal microscopy (Zeiss and Leica devices).

\section{ELECTROPHYSIOLOGY}

- Two-electrode voltage clamp in Xenopus laevis oocytes.

- Patch clamp recordings in outside out configuration with Xenopus laevis oocytes.

- Patch clamp recordings in whole cell configuration with HEK293, CHO, SHSY5Y and IGR39 mammalian cell lines. 


\section{CONFERENCE PARTICIPATIONS}

October 2013: $18^{\text {th }}$ World Congress on Advances in Oncology and $16^{\text {th }}$ International Symposium on Molecular Medicine; Hersonissos, Crete, Greece.

http://tessera.spandidos-publications.com/home

Giving a talk titled "Identification of the role of $K_{V} 10.1$ (Eag1) splice variants in tumors."

September 2012: $3^{\text {rd }}$ International Conference on Ion Channels and Transporters in Cancer; Würzburg, Germany. http://campus.uni-muenster.de/itc2012-wuerzburg.html Presenting a poster titled "Role of alternative splicing on the biological properties of $K_{V} 10.1$ channels."

\section{PUBLICATIONS}

Romaniello $V^{*}$, Ramos Gomes $F^{*}$, Sánchez A, Weber C., Stühmer W. and Pardo LA. E65 and E70 represent two novel splicing isoforms modulating $K_{V} 10.1$ channel function through different biological mechanisms (in preparation).

*equal contribution 